\author{
UNIVERSIDADE DE SÃO PAULO \\ FACULDADE DE FILOSOFIA, LETRAS E CIÊNCIAS HUMANAS \\ DEPARTAMENTO DE LETRAS MODERNAS \\ PROGRAMA DE PÓS-GRADUAÇÃO EM LÍNGUA E LITERATURA ITALIANA
}

SONIA MARIA GALUCHI

SÃO BERNARDO DO CAMPO: OS IMIGRADOS ITALIANOS ENTRE A LÍNGUA MATERNA E A LÍNGUA ADQUIRIDA

São Paulo

2008 


\author{
UNIVERSIDADE DE SÃO PAULO \\ FACULDADE DE FILOSOFIA, LETRAS E CIÊNCIAS HUMANAS \\ DEPARTAMENTO DE LETRAS MODERNAS \\ PROGRAMA DE PÓS-GRADUAÇÃO EM LÍNGUA E LITERATURA ITALIANA
}

\title{
SÃO BERNARDO DO CAMPO: OS IMIGRADOS ITALIANOS ENTRE A LÍNGUA MATERNA E A LÍNGUA ADQUIRIDA
}

Sonia Maria Galuchi

Dissertação de mestrado apresentada ao Programa de Pós-Graduação em Língua e Literatura Italiana, do Departamento de Letras Modernas da Faculdade de Filosofia, Letras e Ciências Humanas da Universidade de São Paulo, para a obtenção do título de Mestre em Letras.

Orientadora: Profa. Dra. Loredana de Stauber Caprara

São Paulo

2008 


\title{
Dedicatória:
}

Ao meu pai, Antonio, não mais entre nós, mas que, espiritualmente, tem me acompanhado. É nele que busco inspiração nos meus momentos difíceis e é a ele que ofereço as minhas vitórias.

\begin{abstract}
À minha mãe, Lutfie, que embora não compreenda o porquê de tanto estudo, tanta leitura e tantas horas de trabalho, apoiou-me em todos os momentos com uma frase muito singela, mas muito sincera: se você está feliz eu também estou.
\end{abstract}

Aos meus filhos, Marcelo e Michelle, meus companheiros de graduação, cada qual na sua área, que em nenhum momento deixaram de me apoiar, sem entender muito bem por que compreender e memorizar exigiam tanto sacrifício de minha parte se para eles era tudo tão fácil. 


\section{Agradecimentos:}

À Prof. ${ }^{a}$ Dr. ${ }^{a}$ Paola Baccin, minha primeira professora de língua italiana que, em 1988, em uma escola de idiomas de São Bernardo do Campo, fez com que eu me apaixonasse, como ela, pela língua dos nossos antepassados;

À Prof. ${ }^{\text {a }}$ Dr. ${ }^{\text {a }}$ Clarice Assalim, minha professora de Filologia Românica, no Centro Universitário da Fundação Santo André, que acreditou que eu poderia desenvolver meus conhecimentos de Língua Italiana na Universidade e São Paulo, e mostroume o caminho a ser percorrido, ensinando-me a dominar as minhas incertezas;

À Prof. ${ }^{\text {a }}$ Dr. a Giliola Maggio, que, durante o seu curso de pós-graduação, motivoume e apoiou-me a fazer este trabalho;

À minha amiga Benilde, que, em momentos de maior dificuldade, esteve presente com atos e palavras, infundindo-me força para continuar acreditando em minhas possibilidades e confiando em minha capacidade;

A Berardino Capotosto, amigo virtual a princípio, que muito me ajudou com o vocabulário de língua italiana, tentando perceber dificuldades e significâncias, orientando-me sutilmente com exemplos e nuances;

À minha orientadora Prof. ${ }^{\text {a }}$ Dr. ${ }^{\text {a }}$ Loredana de Stauber Caprara, meu agradecimento eterno e especial. Sabedora da minha limitada vivência italiana orientou-me com muita paciência, ou melhor, guiou-me pelos caminhos não só da pesquisa, mas também da Política, Geografia, História, Gramática, Lingüística e tudo o que se refere à Itália e à Língua Italiana. Abriu-me as portas de sua casa com muito carinho, transformando nossos encontros em interessantes e proveitosas aulas de Língua e Cultura Italiana. 


\section{RESUMO}

Este trabalho tem como objetivo reunir uma série de entrevistas em italiano e analisar as influências locais sofridas no léxico por um grupo de imigrados italianos residentes em São Bernardo do Campo - SP, que vieram para o Brasil durante o segundo fluxo emigratório italiano, entre 1948 e 1960.

São indivíduos que possuem formação escolar limitada ao primário ou ao curso fundamental, pela classe social à que pertenciam e pela falta de condições econômicas na época, mas que hoje pertencem à classe média e, além de já terem retornado à Itália pelo menos uma vez, puderam oferecer cursos de nível superior aos filhos.

Através da amostragem analisada, pudemos constatar que, apesar do longo período fora da Itália, esses indivíduos falam um italiano compreensível, o que os torna bilíngües, ainda que o vocabulário italiano de que dispõem seja pobre, muitas vezes inadequado e tenha sofrido interferências do portuguêsbrasileiro.

As principais interferências foram classificadas em: 1- empréstimos totais, 2- empréstimos parciais, 3- comutações, 4- mudanças de significado e 5decalques. Também foram assinaladas as principais impropriedades e, em parte, o uso mais ou menos correto das preposições, dos artigos, dos pronomes, dos advérbios e das conjunções.

Palavras-chave: São Bernardo do Campo, imigrados italianos, léxico, portuguêsbrasileiro, língua materna italiana. 


\begin{abstract}
Questo lavoro ha l'obiettivo di riunire una serie di interviste in italiano e analizzare le influenze lessicali locali nel lessico di un gruppo di immigrati italiani che risiedono a São Bernardo do Campo - SP, venuti in Brasile durante il secondo flusso emigratorio italiano, tra il 1948 e il 1960.

Sono persone che possiedono una formazione scolastica limitata alle elementari o alla scuola media per la classe sociale alla quale appartenevano e alla mancanza di condizioni economiche in quel periodo, oggi però appartengono alla classe media, sono ritornati in Italia per lo meno una volta e hanno potuto offrire un'educazione scolastica superiore ai loro figli.

Attraverso gli esempi analizzati, abbiamo constatato che nonostante il lungo periodo fuori dall'Italia, essi parlano un italiano comprensibile, e possono essere considerati bilingui anche se il vocabolario a loro disposizione é povero, molte volte inadeguato e ha subito interferenze del portoghese-brasiliano.

Le principali interferenze sono state classificate in: 1- prestiti totali, 2- prestiti parziali, 3- commutazione, 4- cambiamenti di significato, 5- calchi. Inoltre sono state segnalate le principali improprietà e, in parte, l'uso più o meno corretto delle preposizioni, degli articoli, dei pronomi, degli avverbi e delle congiunzioni.
\end{abstract}

Parole-chiave: São Bernardo do Campo, immigrati italiani, lessico, portoghesebrasiliano, lingua materna italiana. 


\section{SUMMARY}

This work aims at putting together a series of interviews conducted in Italian and to analyze the local influencies suffered in the lexicon in a group of Italian who emigrated to Brazil and currently reside in São Bernardo do Campo - São Paulo. They came to Brazil during the second Italian migrating flux between $1948-1960$.

These are individuals whose school formation is limited to the primary or the secondary school, affected by the social class to what they belonged to and by the lack of economic conditions of that period. Today, however, they belong to the

middle class and have traveled to Italy at least once and were able to provide a college education for their children.

Analysing some of the interviews we could verify that despite the long period away from Italy, these people still speak a comprehensible Italian which makes them bilingual even though using a poor amount of Italian vocabulary at their disposal, quite often inadequate and which had been affected by Brazilian Portuguese.

The main interferences were classified as follow; 1- complete loan words, 2partial loan words, 3- commuting, 4- changes in the meaning and 5-calque. Some other main inaccuracies were also detected and, by chance, the use of partially correct prepositions, pronouns, adverbs and conjuctions.

Key-words: São Bernado do Campo, Italian immigrants, lexicon, BrazilianPortuguese, Italian mother tongue. 


\section{SUMÁRIO}

\section{INTRODUÇÃO}

1. Objetivo do trabalho ................................................................ 1

2. Justificativa .............................................................................. 2

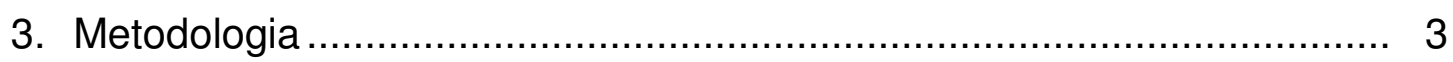

3.1. Roteiro para as entrevistas ................................................ 4

3.2. Transcrição das entrevistas .................................................. 5

3.3. Análise das influências do português no léxico italiano dos entrevistados ............................................................ 5

\section{CAPITULO I}

1. Breve história de São Bernardo do Campo …................................... 6

2. São Bernardo acolhe os imigrantes ................................................. 7

3. Data oficial da fundação da cidade ............................................. 10

4. São Bernardo após a Segunda Grande Guerra . ............................... 11

5. Segunda imigração italiana ........................................................ 12

6. Mantendo as tradições italianas na cidade de São Bernardo

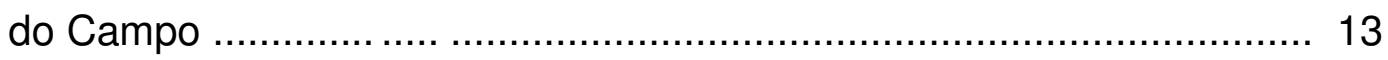

7. A língua que os imigrantes trouxeram da Itália ................................ 19

\section{CAPITULO II}

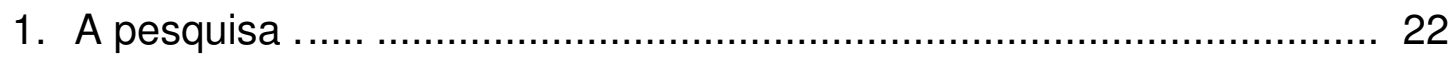

1.1. Registro e transcrição do corpus .......................................... 22

1.2. Dificuldades encontradas durante as entrevistas e as transcrições

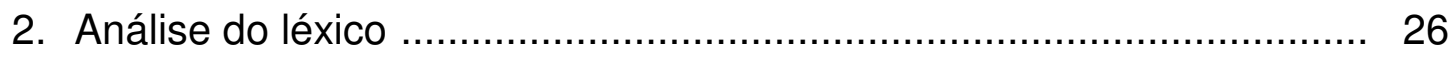

2.1. Empréstimos totais …................................................. 29

2.2. Empréstimos parciais ...................................................... 29 
2.3. Comutações ...................................................................... 29

2.4. Mudanças de significado .................................................... 29

2.5. Decalques ............................................................. 30

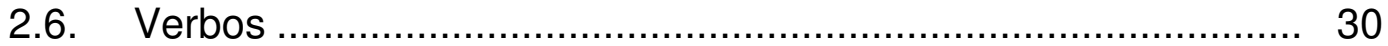

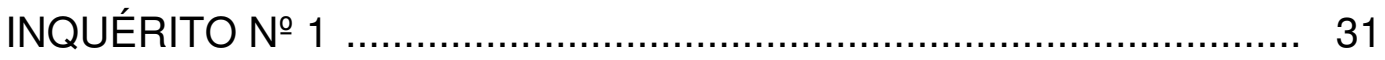

Análise …................................................................. 36

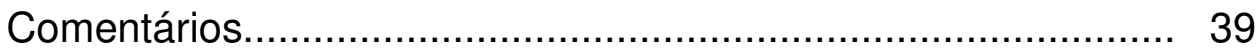

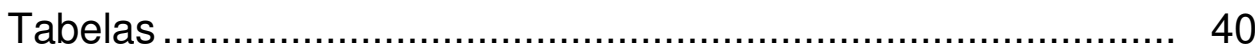

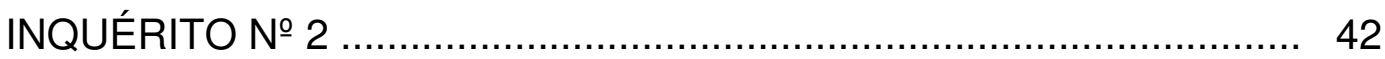

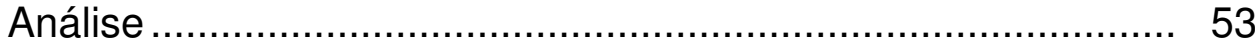

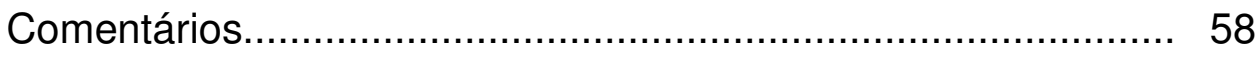

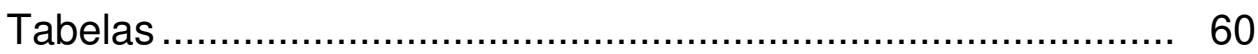

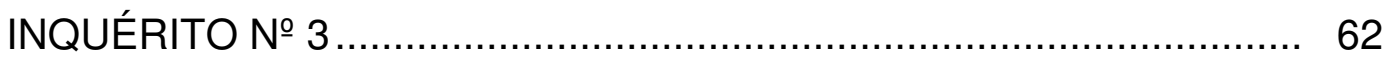

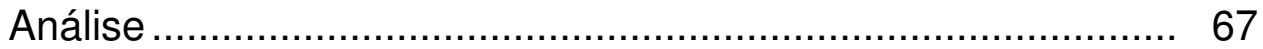

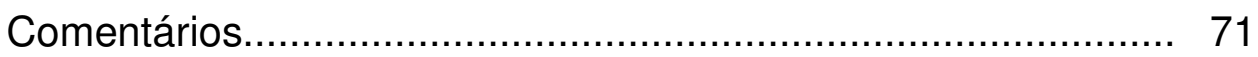

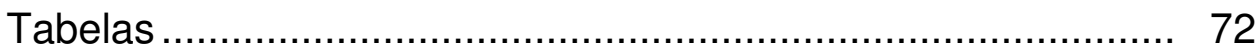

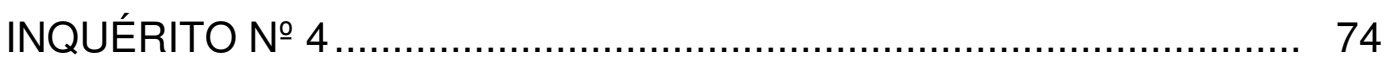

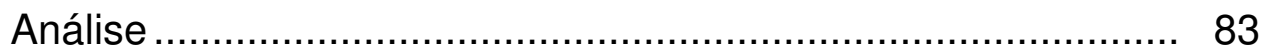

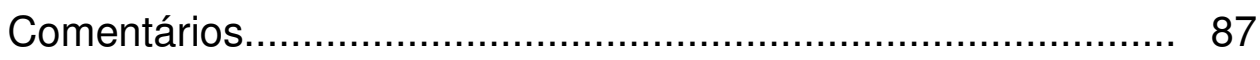

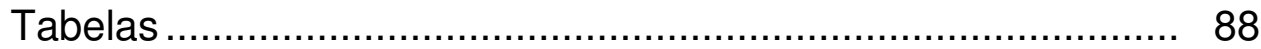

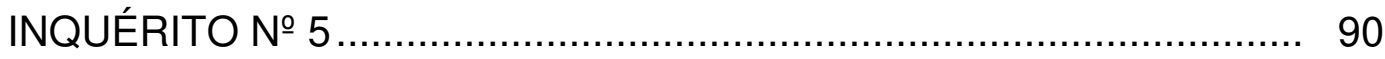

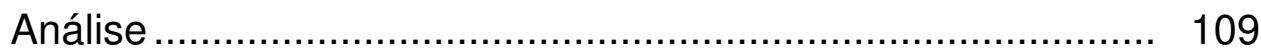

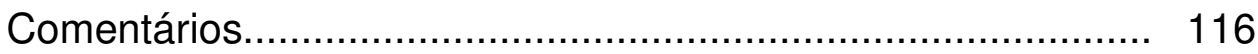

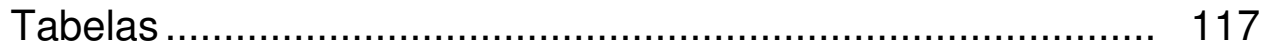

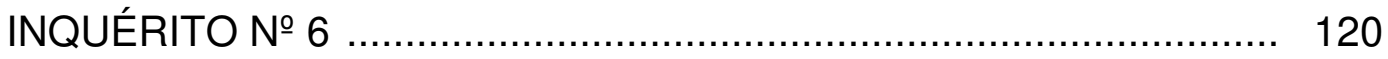

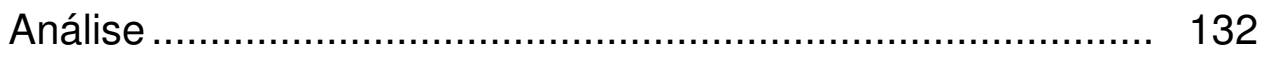

Comentários............................................................. 139

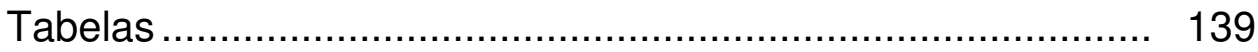

2.7. Tabelas e Gráficos gerais das principais interferências .......... 142

CONSIDERAÇÕES FINAIS ........................................................... 152

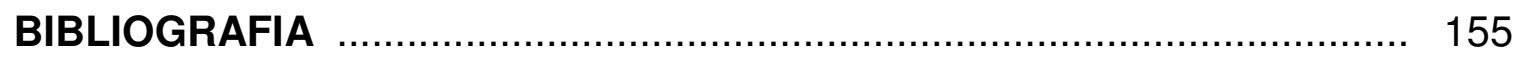




\section{INTRODUÇÃO}

\section{Objetivo do trabalho}

O presente trabalho tem como objetivo reunir testemunhas da fala em italiano e analisar as características do léxico de um grupo de italianos que emigrou para o Brasil, especificamente para a Cidade de São Bernardo do Campo, na Grande São Paulo, após o término da Segunda Guerra Mundial, entre os anos de 1948 e 1960. Esse grupo de pessoas participa de uma comunidade mais ampla que, pelo menos parcialmente, pode ser considerada bilíngüe e bicultural. Além dos entrevistados, muitos outros, não obstante o longo período distante da Itália, conseguem comunicar-se em língua italiana quando solicitados ou quando freqüentam atividades com a sua comunidade de origem, ainda que não tenham freqüentado curso superior, ou mesmo o secundário, nem na Itália nem no Brasil, principalmente por não possuírem condições econômicas para tal.

Alguns deles ainda se comunicam em dialeto quando reunidos com a família, mas, em geral, com outros italianos, procuram comunicar-se em língua italiana, sendo esta uma das poucas oportunidades que têm de usá-la. É um modo de resgatar a memória e de fortalecer sua dupla identidade, ítalo-brasileira. A maioria dos emigrados freqüentou apenas a "escola média" no país de origem, o que equivale aos últimos três anos do nosso atual primeiro grau e, no Brasil, dedicou-se ao trabalho.

Apesar de ter passado tanto tempo e de terem deixado a Itália em uma época em que os dialetos, ainda, eram muito falados, especialmente nas classes

menos favorecidas, esses imigrantes conseguem se comunicar em italiano de um modo compreensível e bastante satisfatório.

As entrevistas foram feitas com pessoas provenientes de diferentes regiões da Itália, cujas falas não são totalmente iguais, pois apresentam algumas diferenças na pronúncia e, principalmente para a nossa análise, no léxico. 
A seguir, procuraremos analisar o léxico usado por eles, considerando que sofreu a interferência do português-brasileiro, e fazer a classificação dessas interferências.

\section{Justificativa}

Vivendo em São Bernardo do Campo desde 1977, comecei a lecionar a Língua Italiana em 1993 e, a partir de então, teve início a minha convivência com a comunidade italiana local.

Os interessados que procuravam o curso não eram, apenas, descendentes e simpatizantes da Língua e da Cultura Italiana, muitos deles eram italianos imigrados na infância sem terem estudado ou completado seus estudos na Itália. Dentre estes, alguns não falavam mais a língua materna, outros falavam uma mistura de dialeto, língua italiana e língua portuguesa e, outros ainda, não haviam sequer tido contato com a língua, por terem imigrado em idade muito tenra.

De uma maneira geral, o nosso objetivo principal no curso era o de reconduzi-los ao falar italiano, uma vez que a Língua Italiana deveria ser parte de sua identidade e, no Brasil, é sinônimo de status, pois os imigrantes italianos são portadores de uma cultura diferenciada, ainda que apenas material, o que independe da cultura escolar.

Em 2003, quando ingressei na Universidade de São Paulo, tomei conhecimento da pesquisa que estava sendo desenvolvida no curso de italiano: "O italiano dos italianos de São Paulo", mas o meu interesse pela pesquisa aflorou, definitivamente, quando comecei a participar do COMITES - Comitato degli Italiani all'Estero, como conselheira, e o contato com os membros da comunidade italiana local passou a ser muito mais intenso.

Em seguida, comecei a freqüentar o curso ministrado pela Prof. ${ }^{a}$ Dr. ${ }^{a}$ Giliola Maggio, sobre a fala dos imigrados italianos. Com ela, conversamos sobre a possibilidade de estudar o mesmo assunto nos imigrantes italianos de São 
Bernardo do Campo, pois aqui temos um grupo grande, dentre os quais, muitos não falam mais a língua materna, enquanto outros mantiveram ou readquiriram o contato, e integrar esta pesquisa àquela que estava sendo desenvolvida pela Universidade de São Paulo, tendo como coordenadoras as Professoras Doutoras Loredana de Stauber Caprara, Olga Alejandra Mordente e a própria Giliola Maggio.

\section{Metodologia}

Para o desenvolvimento da pesquisa em São Bernardo, ficou estabelecido que, inicialmente, seriam selecionados de cinco a dez imigrantes que:

- chegaram à cidade após a Segunda Guerra Mundial, entre 1948 e 1960;

- não tinham freqüentado um curso superior;

- não fossem indicados por associações, mas por outros imigrantes;

- a entrevista seria feita estritamente em italiano.

O objetivo da análise da língua não foi especificado aos entrevistados, uma vez que a intenção era sim lingüística, mas não se exauria com isso, e o material poderia ser estudado sob outros aspectos. Era importante deixar o entrevistado à vontade para falar, sem ter a preocupação de que sua fala e eventuais incorreções fossem o objeto de atenção especial. Foi dito apenas que era para uma pesquisa da USP, que estava registrando a existência dos imigrantes que ainda falam a língua italiana, apesar de estarem há tantos anos longe do país de origem, em um país onde usam outra língua oficial.

Os selecionados foram contatados e foi solicitada a autorização para ser feito o registro, através de gravação, para a futura transcrição, na qual seus nomes seriam omitidos. 
Com a finalidade de se manter a fluência do diálogo, o entrevistador usou um questionário-guia para poder retomar o discurso, quando o entrevistado fizesse interrupções. Assim, o entrevistador poderia dar seqüência à conversa, não importando qual fosse o assunto, mas sim fazendo com que o imigrante continuasse a comunicar-se na sua língua de origem com bastante espontaneidade.

Foram registradas sete entrevistas, das quais seis foram transcritas e uma continua apenas registrada, por se tratar de uma pessoa que, na maior parte da entrevista, usa a língua portuguesa e o dialeto siciliano, estando assim, fora do nosso objetivo principal.

Apesar da tentativa de deixar o entrevistado à vontade, a simples presença de um gravador fez com que o mesmo se policiasse durante a entrevista, como poderá ser observado nas transcrições, quando, muitas vezes, o entrevistado se corrige após ter percebido a sua falha na comunicação, ou a incorreção lexical ou gramatical.

Os registros têm duração média de 30 minutos. Constatou-se que as mulheres ficam mais à vontade que os homens e são menos preocupadas com o uso correto das unidades lexicais na fala. Os homens, freqüentemente, limitam-se a responder as perguntas sem dar continuidade à conversa, com exceção do entrevistado $n^{\circ} 6$, que se comunica numa variedade de língua italiana bastante correta, como se poderá constatar, e se sente muito à vontade durante a gravação.

\subsection{Roteiro para as entrevistas}

O roteiro para as entrevistas, que é em língua italiana e permanece de posse do entrevistador, aqui é traduzido.

1 - Nome e sobrenome.

2 - Idade.

3 - Profissão.

4 - Região e cidade de proveniência. 
5 - Em que ano deixou a Itália e com quem?

6 - Qual o motivo que o levou a deixar o país?

7 - Como foi a viagem e o nome do navio?

8 - Qual foi a primeira impressão na chegada ao Brasil?

9 - Ao chegar, veio direto para São Bernardo do Campo?

10 - Já voltou à Italia? Qual foi a sua impressão ao chegar ao país?

11 - Tem filhos? Falam a lingua italiana?

\subsection{Transcrição das entrevistas}

As transcrições seguirão o método NURC, da Universidade de São Paulo, para o português culto falado, com as adaptações necessárias, no quadro que será apresentado à página 23 deste trabalho.

3.3. Análise das influências do português no léxico italiano dos entrevistados

Pelo contato interlingüístico num longo período de tempo, pelo fato de que os entrevistados deixaram a Itália em um momento em que o dialeto ainda era muito usado, pela limitação cultural e lingüística e pela idade avançada, não faltam incorreções na fala desses antigos imigrados. $\mathrm{Na}$ análise serão apresentadas as incorreções, impropriedades e influências mais marcantes encontradas no léxico dos italianos entrevistados, com base na pesquisa feita nos dicionários de língua italiana, citados na bibliografia. 


\section{CAPITULO I}

\section{Breve história de São Bernardo do Campo}

Quando Martin Afonso de Souza ancorou em São Vicente, em 12 de agosto de 1531, já encontrou João Ramalho vivendo entre os índios Guaianases. Fundou a Capitania de São Vicente, formada por índios, mamelucos e portugueses, que se estendia até o interior, onde se originou uma vila que, em 08 de abril de 1553, quando foi levantado o 'pelourinho', recebeu o nome de Vila de Santo André da Borda do Campo, sendo nomeado como Alcaide, João Ramalho.

$\mathrm{Na}$ Vila de São Vicente, os jesuítas já possuíam um colégio e solicitaram autorização para fundar um outro nas terras de João Ramalho, sendo o mesmo denominado Colégio de São Paulo, porque a primeira missa foi celebrada em sua capela em 25 de janeiro de 1554. Como a Vila de Santo André sofria constantes ataques dos índios Carijós, o Governador Geral do Brasil, Men de Sá, ordenou a mudança do pelourinho para o Pátio do Colégio, naquela que depois seria a Vila de São Paulo.

Transformada em uma grande sesmaria, a ex-vila de Santo André passou por um longo período de estagnação. Em 1572, Amador de Medeiros, o então ouvidor da capitania, recebe uma sesmaria que, em 1638, foi doada por seu genro Miguel Aires Maldonado, aos monges Beneditinos do Mosteiro de São Bento e estes a transformaram em duas grandes fazendas: a de São Caetano e a de São Bernardo que, em 1813, entraram em decadência devido às perseguições sofridas pelos monges no período Pombalino e às restrições ao ingresso de noviços nas ordens monásticas.

Em 1812, fruto da vontade da população residente no núcleo da Fazenda São Bernardo, que desejava uma nova igreja, mas não poderia fazê-la dentro das terras do mosteiro, o padre José Basílio Rodrigues inicia a sua construção. Edificada por Antonio Pires Santiago, a Capela Nossa Senhora da Conceição, 
construída no Caminho do Mar, passou a chamar-se Nossa Senhora da Boa Viagem, pois os viajantes que se dirigiam ao litoral ou de lá vinham, ali faziam suas orações antes de seguir viagem. Nesta capela, D. Pedro I parava para orar, quando vinha de Santos. Ao redor da capela, começou a surgir o núcleo urbano do município de São Bernardo.

Em 1812, São Bernardo foi elevada à categoria de Freguesia, pelo Marquês de Alegrete e, em 1817, com a afluência de muitos estrangeiros, principalmente de imigrantes italianos, o governo da província criou dois núcleos agrícolas nas localidades de São Bernardo e São Caetano.

Em 1867, com a abertura da São Paulo Railway, ligando São Paulo a Santos, ocorreu uma nova estagnação no Município (atual São Bernardo). A estação de São Bernardo, distante $8 \mathrm{~km}$ da sede do Município, localizada no Bairro da Estação, passou a constituir um novo núcleo urbano que, em 1910, passou a ser denominado de Santo André.

Pelo Decreto Estadual 9775 de 30/11/1938, do Interventor Federal do Estado de São Paulo, Adhemar de Barros, Santo André tornou-se a sede do município de São Bernardo, que foi rebaixado a distrito. Foi então fundada a Associação Amigos de São Bernardo, com objetivo de alcançar a emancipação político-administrativa do município. Tal objetivo foi alcançado em 1944 e oficializado em 01 de janeiro de 1945, tendo como prefeito Wallace Cockrane Simonsen, com o nome de São Bernardo do Campo. Borda do Campo foi uma homenagem a João Ramalho, por ter fundado a vila que foi o primeiro passo para a fundação da cidade e por já existir uma outra cidade no Maranhão com o nome de São Bernardo.

\section{São Bernardo acolhe os imigrantes}

Em 1876, o governo da província de São Paulo desapropriou as fazendas dos monges Beneditinos, com o objetivo de ampliar a ocupação das terras do 
atual Grande ABC. Dois foram os núcleos instalados: o de São Caetano, no mesmo ano, e o de São Bernardo, no ano seguinte.

Em São Bernardo, para a abertura da Colônia, o Governo do Estado mandou medir e fazer plantas dos lotes destinados aos imigrantes. Estes lotes receberam o nome de "Linha" e a Fazenda São Bernardo foi dividida em 15 "linhas", cada qual com o nome de um rio ou de uma pessoa; cada linha era dividida em lotes.

A presença de italianos em São Bernardo do Campo não é um fenômeno que interessa apenas no segundo pós-guerra. Os italianos estiveram presentes desde o início do fenômeno migratório, a partir de 1877, os primeiros vindos de Treviso, cidade italiana do Vêneto. Gradativamente, a região da atual São Bernardo do Campo passou a ser uma comunidade bilíngüe, tanto que alguns documentos oficiais eram emitidos nas duas línguas: português e italiano.

Os primeiros lotes do Núcleo Colonial de São Bernardo começaram a ser distribuídos aos imigrantes, a grande maioria composta por italianos e, após saldadas as dívidas com o governo, os lotes passariam a lhes pertencer.

Segundo o historiador Newton Ataliba Madsen Barbosa, a partir de 1878 instalaram-se no Núcleo Colonial de São Bernardo imigrantes italianos das seguintes regiões ${ }^{1}$ :

Lombardia:

Veneto:

Emilia Romagna:

Friuli-Venezia Giulia: Udine.

Piemonte:

Toscana:

Lazio:

Campania:

Napoli
Bergamo, Cremona, Mantova, Brescia.

Venezia, Treviso, Padova, Belluno, Verona, Rovigo, Vicenza.

Piacenza, Modena, Bologna, Reggio Emilia.

Novara.

Lucca e Massa (Carrara).

Roma.

\footnotetext{
${ }^{1}$ Optamos por manter os nomes das províncias e das regiões em italiano.
} 
Como as reservas florestais de São Bernardo do Campo eram extensas, de início os imigrantes extraíam madeira e produziam lenha e carvão.

Pesquisa feita por Ademir Médici (2000), mostra que no Núcleo Colonial São Bernardo, no ano de 1893, de um total de seus 1942 habitantes, 811 eram italianos, 688 eram brasileiros e o restante era composto por imigrantes poloneses, alemães, austríacos, franceses, espanhóis, suíços, belgas e portugueses. Em 1888 eram 993 os colonos italianos e, em 1920, dos 25.215 habitantes 6.833 eram estrangeiros, a maioria composta por italianos.

Com a diversidade das regiões de proveniência dos italianos e o alto índice de analfabetos (segundo De Mauro, eram 78\% durante o primeiro fluxo migratório), cada família se expressava em seu dialeto regional. Sobre o binômio língua-dialeto, Bettoni (1993: 428) nos diz que "sulla dibattuta questione di uma italianizzazione o dialettalizzazione dell'emigrazione italiana nel mondo ci sono purtroppo ancora, su larga scala, più ipotesi che dati precisi". Ainda no mesmo estudo, "la mobilità sociale verso l'alto reprime il dialetto in casa per il bene dei figli", o que nos leva a crer que seria o motivo principal para o abandono gradativo do uso do dialeto.

Nos arquivos de Santo André, onde se encontram todos os documentos do antigo Município (até a separação em 1945), existem impressos oficiais de lançamentos de tributos municipais com o texto frontal em língua portuguesa e, no verso, em língua italiana. A transcrição de um destes documentos é citada na página 55 do livro de Octaviano Gaiarsa.

Em 18 de abril de 1938, o Decreto-Lei 383 baixado pela Presidência da República, muda toda a liberdade de expressão, pelo menos no que diz respeito aos imigrantes, não importando qual fosse a sua origem. É o momento da nacionalização: "As sociedades compostas pela maioria de sócios brasileiros ou naturalizados, para poder funcionar, é necessário nacionalizar e adotar o idioma do País" (Médici: 163). 
A partir de então, todas as Sociedades compostas por imigrantes e seus descendentes tiveram de se adaptar às exigências do decreto, pois em suas reuniões estavam presentes observadores da polícia, como citam alguns historiadores.

Tal proibição, no entanto, não conseguiu apagar da memória dos imigrantes as suas origens e, ao término da Segunda Guerra, lentamente, foram sendo retomadas as atividades que thes remetiam às suas origens, fortalecidas pela chegada de novos imigrantes italianos, que partiam em busca de uma nova vida, já que a Itália encontrava-se semi destruída, sem condições de oferecer empregos a todos os seus habitantes e, além disso, muitos carregavam o medo de que eclodisse um outro confronto entre os países europeus.

As condições que encontraram aqui, uma vez que a cidade de São Bernardo estava em um momento de plena expansão, principalmente pela instalação de diversas indústrias de grande porte na região, fizeram com que alguns viessem diretamente para a cidade. Outros, que em um primeiro momento dirigiram-se para as fazendas de café no interior no Estado, em seguida, transferiram seu domicílio para cá e aqui se estabeleceram definitivamente.

Recém-chegados, estes imigrantes deram uma nova vida àqueles que haviam começado a semear a italianidade e, a partir deste momento, foram retomadas as antigas atividades italianas, assim como outras foram sendo criadas, passando, definitivamente, a fazer parte do calendário de eventos da cidade.

\section{Data oficial da fundação da cidade}

O dia que se comemora em São Bernardo não é o dia da fundação: 20 de agosto é o dia de São Bernardo, o Santo Doutor da Igreja nascido em Dijon, França, em 1091 e canonizado em 1173, abade cisterciense de Claraval, empenhado em restabelecer o rigor e a pureza da Ordem de São Bento. 
As datas que se relacionam com a fundação e a autonomia de São Bernardo do Campo são:

08/04/1553 - Oficialização da Vila de João Ramalho;

23/09/1812 - Elevação a Freguesia de Vila de São Bernardo;

21/10/1812 - Criação da Paróquia de São Bernardo;

02/05/1890 - Instalação do Município sob regime republicano;

19/12/1906 - Elevação de São Bernardo a cidade;

20/12/1926 - Adoção do Brasão de Armas de São Bernardo;

30/11/1944 - Decreto separando São Bernardo de Santo André;

01/01/1945 - Instalação do município de São Bernardo do Campo.

\section{São Bernardo após a Segunda Grande Guerra}

Após a Segunda Guerra, com a Lei Municipal de o 85 de 1949, que concedia isenção de impostos municipais às novas indústrias que se instalassem na cidade, principalmente na segunda metade da década de 50, foram inauguradas as principais montadoras, como: Volkswagen, Karmann-Ghia, Mercedes-Benz e Willys Overland, já que, além das vantagens fiscais, tinham a facilidade de acesso ao Porto de Santos, distante $45 \mathrm{~km}$, e à Capital do Estado, a $18 \mathrm{~km}$.

Assim, na segunda metade do século XX, São Bernardo do Campo era uma cidade atraente para quem quisesse trabalho e, melhor ainda, para os italianos, já que os seus antecessores aqui estavam bem organizados. Ainda que o destino de muitos dos imigrantes não fosse o $A B C$, muitos deles, após as decepções com os trabalhos em fazendas de café, vieram para a região em busca de empregos e aqui se estabeleceram. 
Desde a década de 50, a cidade tem sua economia baseada nas grandes indústrias automobilísticas e nas indústrias de autopeças, algumas das quais são italianas.

\section{Segunda imigração italiana}

Não vamos discorrer detalhadamente sobre os métodos e os tratados desta segunda emigração, por já terem sido abordados amplamente na tese de doutorado de Giliola Maggio e nas dissertações de Marilisa Bertechini Bilia e Marisa Castellano Tsai, que apresentam um panorama geral sobre a imigração italiana em São Paulo.

Não temos dados precisos sobre quantos foram os imigrantes da segunda leva que se dirigiram a São Bernardo do Campo, uma vez que muitos deles, em um primeiro momento, foram encaminhados às fazendas de café e outros para a cidade de São Paulo, vindo para a nossa cidade posteriormente. Também não temos nenhum estudo sobre a língua falada destes imigrantes, sendo os nossos registros os primeiros a serem feitos na região.

O que pudemos notar em nosso trabalho de pesquisa, é que, após a Segunda Guerra, os imigrantes que vieram para São Bernardo do Campo eram de classe média baixa, a maioria proveniente do campo. Procedentes de todas as regiões da Itália, como pudemos constatar nos contatos efetuados, aqui obtiveram sucesso pessoal e profissional, pois hoje muitos deles pertencem à classe média e classe média alta, puderam fornecer estudos de nível superior aos filhos e pelo menos todos os entrevistados já haviam viajado para a Itália uma ou mais vezes.

Como, a partir da segunda metade do século XX, a cidade de São Bernardo do Campo encontrava-se em pleno desenvolvimento industrial, este era um fator de atração para os que queriam escapar dos trabalhos no campo, tanto na Itália quanto no Brasil, no caso daqueles que haviam imigrado para trabalhar nas fazendas de café. 
A seguir, alguns depoimentos:

\section{Inquérito no 3:}

[...] ho cominciato a lavorare alla Chrysler ... ho lavorato due anni alla Chrysler neh ... dopo della Chrysler a: sono andato a lavorare in São Paulo ... e nu/officina meccanica ... e dopo questo in settantadue ... settanta/settantadue abbiamo aperto ... un'officina nostra io e mio fratello.

\section{Inquérito no 4}

[...] ho lavorato sulla fabbrica di/di mo/móveis [...] dopo sono passata a Matarazzo [...] lavorava su a fiação sul sul filo.

\section{Inquérito $\mathrm{n}$ - 6:}

[...] quando la Mercedes Benz si è installata sono stato uno dei primi ... a arrivare là ... e loro prestamente hanno avuto ... non ho avuto nemmeno fare il test loro han detto no abbiamo bisogno di ... mano d'opera specializzata [...]

\section{Mantendo as tradições italianas na cidade de São Bernardo do Campo}

Uma das grandes preocupações, senão a maior, da comunidade italiana e de seus oriundos, foi e é manter as tradições de seus antecessores.

Dentro da própria Prefeitura de São Bernardo do Campo, existem algumas Leis que, desde 1985, visam a homenagear os italianos e seus descendentes que para cá se dirigiram e adotaram a cidade como sua:

- Projeto de Lei o 90/85 de 06/11/1985, autoriza o Executivo a declarar Marostica como cidade-irmã de São Bernardo do Campo, de autoria do Vereador Gilberto Frigo.

- Lei no 2794 de 09/09/1986, através da qual o então Prefeito de São Bernardo do Campo, Dr. Aron Galante, após receber ofício encaminhado em 24/02/1986 ao Ministério das Relações Exteriores para a aprovação do convênio e autorizado pelo Presidente da República em 31/07/1986, autoriza o gemellaggio com a cidade de Marostica. 
- Lei no 4766 de 27 de junho de 1999, Projeto de Lei no 044/99 apresentado pelo Vereador Hiroyuki Minami, com a realização da Sessão Solene em Homenagem aos Imigrantes Italianos e seus Descendentes, toda última quinta-feira do mês de junho homenageia 12 italianos e/ou seus descendentes indicados por um grupo composto por representantes da comunidade italiana local.

- Lei no 4972 de 30 de maio de 2001, Projeto de Lei no 026/2001 dos Vereadores Gilberto Lourenço Marson e Amedeo Giusti, institui o "Dia da Colonização Italiana", com uma Sessão Solene na Câmara Municipal, realizada, anualmente, no mês de agosto, homenageando os imigrantes italianos e seus descendentes.

- DL 791 de 27 de maio de 2004, Projeto de Decreto-Legislativo no 25/2004, de autoria do Vereador Dr. Amedeo Giusti, que institui na Câmara Municipal de São Bernardo do Campo a "Comenda de San Bartolomeo", que homenageia os italianos e/ou seus descendentes que chegaram à cidade a partir de 1877.

- Lei no 5302 de 04 de junho de 2004, Projeto de Lei no 95/2004, de autoria do Vereador Dr. Amedeo Giusti, altera o artigo $2^{\circ}$ da lei municipal 4972, que transfere a Sessão Solene para outro local adequado ao evento, devido à presença crescente da comunidade.

Através de uma pesquisa documental realizada pelo jornalista e historiador Ademir Medici, a cada ano, 10 pessoas recebem a "Comenda de San Bartolomeo" em uma Sessão Solene realizada na Associação dos Funcionários Públicos de São Bernardo do Campo.

Além da preocupação da Prefeitura, alguns outros eventos foram criados pelos próprios imigrantes e seus oriundos, com a finalidade de manter unida a comunidade italiana local e preservar a cultura e as tradições trazidas, principalmente, pela primeira leva dos imigrantes que aqui chegaram no final do século XIX e início do século XX. São elas:

\section{- União dos Vinicultores Artesanais - U.V.A}

A idéia da criação de uma associação de produtores de vinho surgiu, em 1999, entre os produtores artesanais de vinho da região. 
Falava-se das dificuldades que estes haviam em comprar a uva, rolhas, vasilhames e equipamentos para a produção de vinho.

No dia 17 de julho do mesmo ano, 26 produtores reunidos criaram uma Associação com o nome de U.V.A., União dos Vinicultores Amadores. Em 12 de julho de 2001, o termo "Amadores" foi substituído por "Artesanais".

Hoje, a U.V.A. conta com 91 produtores associados cadastrados, sendo 59 da cidade de São Bernardo do Campo. A grande maioria é formada por descendentes de italianos.

Anualmente, na última sexta-feira do mês de julho, realiza-se um encontro entre os produtores em que cada um leva os diversos tipos de vinho que produziu no ano, para apresentá-los aos outros fabricantes.

Entre os meses de setembro, outubro ou novembro, é realizada uma festa, aberta a amigos dos produtores, com a finalidade de apresentar os vinhos produzidos.

Mais antigas são as festas religiosas que desde o início mantêm unida a comunidade italiana.

\section{- Festa di San Bartolomeo}

A Festa di San Bartolomeo é realizada no último domingo do mês de agosto, no Parque Municipal de São Bernardo - Estoril.

Uma missa campal é celebrada em italiano às 10h30min, acompanhada por um Coral que canta as músicas sacras em língua italiana. Após a missa, a comunidade italiana, seus descendentes, convidados e simpatizantes, reúnem-se nos quiosques ali localizados e reservados especialmente para o encontro. Cada família leva um prato de doce e/ou salgado, bebidas e, todos reunidos, passam o domingo em uma grande festa de confraternização regada a muito vinho e muita música italiana.

A construção da Capela de San Bartolomeo deu-se graças à iniciativa do Pe. Fiorente Elena. Não foi encontrada a data nos documentos dos arquivos do 
Serviço de Memória e Acervo da Prefeitura Municipal de São Bernardo do Campo, mas sabe-se que é de 1958, pois, em 2007, comemoraram-se os 50 anos da Festa.

Abaixo transcrevemos os dois documentos encontrados: como surgiu a idéia da festa e a convocação para participar da primeira.

\section{P. Fiorente scrive}

Come è sorta la festa di San Bartolomeo al Parque Municipal de São Bernardo do Campo

Quando Pe. Fiorente nel lontano 1958 visitava Chiozza per la prima volta, sentì un fremito di nostalgia e allegria immense tutte le volte che incontrava parenti e amici di persone che lui conosceva in Brasile e gli son care oltremodo per legami di amicizia. In quei giorni egli si sentiva come uno di loro per i ricevimenti che tutti gli facevano sempre con maggior entusiasmo: dal Campaccio, alla Loggia, alla Crocetta, al Giro. Una vera e propria apoteosi fu l'arrivo alla Pieve per la Messa Cantata tra lo squillare delle campane, il saluto caro di Don Parini, priore della Chiesa di Chiozza. La predica di P. Fiorente commosse fino alle lacrime ... ai singhiozzi quando ricordò un po' tutto e tutti qui in Brasile. L'unico ricordo che trovò potesse essere caro ai suoi, quando tornasse, pensò che potevano essere quei fiori delle tombe che egli con delicato pensiero raccolse al cimitero di Chiozza. Delle noccioline, delle noci, delle foglie di fico raccolte nei piccoli poderi di ciascuno. La farina di neccio e la bobina col suono delle campane della loro Pieve, tramite l'amico e compagno di viaggio Sig. Eduardo Santucci.

All'arrivo in Brasile si volle da tutti fare una Messa Campale davanti all'immagine di San Bartolomeo e perché P. Fiorente contasse a tutti quello che i loro cari avevano detto di dire, e quello che aveva visto in Garfagnana. Credetelo che in quel giorno più che pregare si pianse. Poi venne l'idea di erigere là, dove tanti anni prima i Garfagnini avevano abbatuto la foresta vergine, una chiesetta dedicata al loro Patrono San Bartolomeo, e tutti gli anni fare la festa del Santo. Tramite P. Parini abbiamo fatto venire la terra delle tombe dei loro morti in Italia, contenuta in una urna fatta col legno del castagno più vecchio di Chiozza, che li aveva visto nascere, alimentati e cresciuti con le sue castagne. Le feste si susseguono così di anno in anno sempre con maggior numero di frequentatori e le Autorità civili ed Ecclesiastiche di San Bernardo non mancano di accompagnare la nostra simpatica festa. Abbiamo anche l'idea di portare in pellegrinaggio fino a Chiozza un'urna 
contenente la terra delle tombe dei nostri morti di qui ... proprio come in Italia si portava l'urna del soldato che combattè per la Patria. Sì perché anche gli emigrati sono dei veri eroi e l'onore che le nostre autorità che giungono dall'talia ricevono, lo si deve atribuire allo sforzo dei nostri emigrati, che hanno per anni e anni tenuto alto il morale della Patria.

Carta de convocação para a primeira missa em homenagem a San Bartolomeo:

A tutti coloro che provengono da Chiozza, dall'Alpe di San Pellegrino, da Val Bona e Dall'Isola abbiamo il piacere di comunicare che: una comissione di Chiozzini si è reunita a $S$. Bernardo do Campo per organizzare una festa di confraternizazione coi nostri compaesani. $E$ precisamente si sarebbe stabilito di festeggiare il santo patrono nostro $S$. BARTOLOMEO il giorno 24 agosto prossimo mentre lassù sui nostri bei monti i compaesani nostri di tutta la Garfagnana si riuniranno intorno al Santo Apostolo Martire. A Rio Grande nel bel parque Municipal de S. Bernardo do Campo avremo una $S$. Messa durante la quale ci sarà trasmesso il suono delle nostre campane, il discorso di Don Parini Priore di Chiozza, i canti della Befana ecc.

Nessuno manchi. Sarà un avvenimento davvero commovente. Ci rivedremo tutti. Potremo fare imprimire su disco i nostri saluti da mandare ai nostri cari in Italia. Si farà la colazione al sacco e quindi non dimenticare le frittelle di neccio, la farinata, la torta e tutto quel che è proprio dei nostri usi e costumi. festa.

Una banda di musica concorrerà per rendere più completa la

Per chi non avesse mezzi di trasporto proprii avvisiamo che ci saranno onibus a tutte le ore che faranno servizio da S. Bernardo a Rio Grande Parque Municipal.

Tutti a Rio Grande il giorno 24 di Agosto.

Tutti ci sentiremo a casa nostra. Già abbiamo avuto l'adesione di centinaia de Chiozzini entusiasti, e perfino della Garfagnana ci giungono le congratulazioni al suon del TERZETTO.

Arrivederci presto

Pe. Fiorente Elena, Eduardo Santucci, Setimo Guazzelli, Primo, Saulle e Ernesto Bechelli 


\section{- Missa Italiana}

Com a vinda do Padre Giuseppe Bortolato, em janeiro de 2006, transferido da Igreja Nossa Senhora da Paz, em São Paulo, para a Matriz de São Bernardo do Campo, Nossa Senhora da Boa Viagem, membros da comunidade italiana local e dirigentes de Associações italianas reuniram-se com o Padre e the expuseram a idéia de se celebrar, mensalmente, uma missa em língua italiana, com o objetivo de aproximar os italianos, descendentes e simpatizantes da língua e cultura italiana. Acertados os detalhes, em maio do mesmo ano foi realizada a primeira missa. A partir de então, cada vez mais a participação da comunidade tem aumentado. Desde outubro de 2006, após a celebração da missa, no Salão Paroquial é servido um almoço tipicamente italiano, preparado por membros da comunidade, uma vez que a missa é celebrada às $12 \mathrm{~h}$, causando transtornos no preparo do almoço familiar, típico do domingo.

Desde as primeiras missas celebradas pelo Pe. Giuseppe Bortolato, notase o papel importantissimo do envolvimento da Igreja com a comunidade italiana, pois além de ser um encontro religioso, o evento está unindo os italianos e seus descendentes, que estavam dispersos pela Região do Grande ABC, como acontece na Igreja Nossa Senhora da Paz, em São Paulo, todo o primeiro domingo do mês.

\section{- Coral Bicchieri d'Oro}

O Coral Bicchieri d'Oro foi criado em 1983 com o objetivo de manter a tradição musical trazida pelos imigrantes italianos do Norte da Itália, principalmente das regiões do Vêneto e da Toscana.

Faz parte do Círculo Italiano de Toscana de Riacho Grande, criado pelos descendentes de italianos que chegaram no início do século passado ao Riacho Grande, sub-distrito de São Bernardo do Campo, onde vieram para trabalhar com lenha, carvão e comércio e, posteriormente, alguns, com a indústria moveleira. 


\section{- Associações}

- Brasilitália Associação Ítalo Brasileira de Cultura, Lazer e Integração fundada em 21 de abril de 1974, tendo a sua razão social alterada para Sociedade Cultural Brasilitalia em 25 de maio de 1979, com o objetivo de unir os imigrantes italianos, seus descendentes e simpatizantes, independentemente da região de proveniência.

- Círculo Italiano de Toscana de Riacho Grande, fundado em 15 de dezembro de 1991, com a finalidade de proporcionar aos seus membros uma maior participação na perpetuação das tradições italianas, principalmente no tocante à música.

Esta associação participa de vários eventos ligados à comunidade italiana de nossa cidade, como a Sessão Solene da imigração italiana realizada pela Câmara dos Vereadores, e é responsável pelo retorno da missa rezada e cantada em italiano na Igreja Matriz de São Bernardo do Campo, realizada no primeiro sábado do mês de agosto, e da missa na festa de San Bartolomeo, no último domingo do mesmo mês, no parque municipal de São Bernardo.

No ano de 2006, o Círculo Italiano de Toscana de Riacho Grande foi reconhecido pela região Toscana da Itália como uma associação toscana, participando assim de programas mantidos pelo governo daquela região.

\section{A língua que os imigrantes trouxeram da Itália}

Na Itália, após a Segunda Guerra, com a obrigatoriedade de freqüentar pelo menos oito anos de escola, aliada aos meios de comunicação de massa como os jornais, a radiodifusão e, finalmente, a televisão, gradualmente ocorreu uma sempre maior italianização dos dialetos. Portanto, esta segunda leva de imigrantes 
chegou nos anos 48/60, com certa compreensão e uso do italiano comum falado naquele período e com certo grau de alfabetização.

Segundo Beccaria (1989), o caminho percorrido até que o italiano se tornasse "uma língua falada comum a todos os habitantes da península foi longo e árduo". Isto significa que os imigrantes do segundo pós-guerra, ainda que tivessem um dialeto regional, podiam entender uma língua italiana comum a todos os italianos. Além disso, com a obrigatoriedade de freqüentar a escola, praticamente todos os que emigraram, naturalmente em idade escolar ou acima desta, eram alfabetizados, diferentemente daqueles que deixaram a Itália no final do século XIX e no início do século XX.

Dos nossos entrevistados, apenas um chegou ao Brasil antes da idade escolar. Com toda a sua formação escolar em língua portuguesa, aprendeu o dialeto em casa com os pais e, depois de adulto, freqüentou um curso de língua italiana. $\mathrm{Na}$ época em que foi registrada a entrevista, preparava-se para ir à Itália.

Os demais entrevistados vieram com o conhecimento da língua materna, adquirido na escola elementar e, ou não continuaram os seus estudos no Brasil, ou freqüentaram a escola brasileira por um período de tempo muito curto.

Adultos retornaram à Itália uma ou mais vezes, ou seja, voltaram a vivenciar a língua italiana dentro da Itália.

Sobre os estudos podemos observar alguns trechos dos depoimentos:

\section{Inquérito no 2:}

[...] perché il corso che ho fatto io ... bisogna avere prima ginasio poi si poteva andare a fare il corso ... taglio e confezione era una ... professoressa parigina [...]

\section{Inquérito no 3:}

[...] no io ho studiato un anno ho andato alla scuola dopo ... un mio padre non c'aveva tanta: a possibilità e io ... è: dovuto a lavorare [...]

\section{Inquérito $\mathrm{n}^{\circ}$ 4:}

[...] fino al/al quinta alla quinta 


\section{Inquérito no 5:}

[...] ho fatto l'elementare: e poi ho preparato/ho fatto il ginnasio perché volevo ... in casa l'ho fatto particolare neh [...] mi mandavano dal collegio [...] librettini ... perché studiavo per conto mio ...

\section{Inquérito $\mathrm{n}^{\mathbf{0}}$ 6:}

[...] ho fatto la ter/la quarta la quinta elementare in Italia ... in tre o quattro scuole diverse...

Observação: o entrevistado № 1 não freqüentou a escola italiana. Sua formação escolar é brasileira. 


\section{CAPITULO II}

\section{A pesquisa}

Este capítulo é dedicado à análise e transcrição das entrevistas, a partir das quais selecionamos as interferências, algumas impropriedades e incorreções do léxico. Especificamente serão examinados os substantivos, os adjetivos e os verbos e, eventualmente, as preposições, os artigos, os pronomes, os advérbios e as conjunções.

\subsection{Registro e transcrição do corpus}

Para o corpus deste trabalho, foram realizadas seis transcrições das sete entrevistas registradas.

Para as entrevistas, foi preparado um questionário para uso do entrevistador, a fim de este não esquecer pontos chaves das entrevistas que, num certo grau, deveriam ser uniformizadas.

Cada entrevistado é proveniente de uma região diferente, ou seja: Campania, Toscana, Lazio, Veneto, Piemonte, Liguria e Sicilia (não transcrita).

Para o propósito da pesquisa, o processo de transcrição deve ser o mais correto possível e o mais próximo de expressar a fala do entrevistado, a fim de poder estudar as interferências lingüísticas, mas não abordará as facetas relativas à pronúncia, de forma que nas transcrições as palavras são grafadas, por exemplo, para o que se refere às consoantes duplas.

Seguindo o método de pesquisa, desenvolvido em trabalhos anteriores, todos coordenados pelos respectivos Orientadores de Italiano, as transcrições foram feitas usando o método NURC (Norma Urbana Culta) (Castilho, A,T. \& 
Preti,D. 1985) com algumas alterações, devidas ao diverso tipo de língua, no caso de uma língua estrangeira, conforme o quadro apresentado abaixo.

\begin{tabular}{|c|c|c|}
\hline Ocorrências & Sinal & Exemplificação \\
\hline $\begin{array}{l}\text { Incompreensão de palavras ou } \\
\text { segmentos }\end{array}$ & ( ) & si predica ( ) ogni giorno \\
\hline Truncamento & 1 & io avevo/otto anni/nove anni \\
\hline Entonação enfática & maiúscula & in corpo in/NATURALE \\
\hline Silabação & - & se riesci/ri/RI-U-SCI-RÒ \\
\hline Interrogação & ? & mamma hai pianto? \\
\hline Qualquer pausa & $\ldots$ & ... in febbraio .... venti di febbraio \\
\hline $\begin{array}{l}\text { Comentários descritivos do } \\
\text { transcritor }\end{array}$ & ((minúscula)) & $(($ risos $))$ \\
\hline Superposição de vozes & $\begin{array}{l}\text { [ ligando as } \\
\text { linhas }\end{array}$ & $\begin{array}{l}\text { [ma capisce } \\
\text { [capisce tutto sì }\end{array}$ \\
\hline $\begin{array}{l}\text { Prolongamento de vogais e } \\
\text { consoantes }\end{array}$ & : & dodici::: cruzeiro \\
\hline
\end{tabular}

\section{OBSERVAÇÕES:}

1. Iniciais maiúsculas: só para nomes próprios e siglas;

2. Números por extenso;

3. Não se indica o ponto de exclamação (frase exclamativa);

4. Não se anota o cadenciamento da frase;

5. Podem-se combinar sinais. Por exemplo: e:.... (prolongamento e pausa);

6. Não se utilizam sinais de pausa, típicos da língua escrita, como ponto e vírgula, ponto final, dois pontos, vírgula. As reticências marcam qualquer tipo de pausa, conforme referido. 
As entrevistas são chamadas de Inquéritos (I) e são numeradas de 1 a 6 , para facilitar as exemplificações e a menção nas análises e comentários. Esclarecemos, ainda, que:

- Doc.: é o documentador;

- L1 .: é o entrevistado expressando-se em sua Língua de origem;

- Os nomes dos entrevistados foram substituídos pela letra "X", cada uma correspondendo a uma sílaba dos nomes e sobrenomes;

- Os nomes de localidades e expressões, como: baixada fluminense, Estado do Rio de Janeiro, são mantidos em português e não são assinalados, excetuando-se os casos em que haja alguma incorreção ou mistura com o italiano.

- As palavras, o conjunto de palavras ou expressões que são analisadas ou comentadas, são grafadas em negrito para facilitar as suas localizações durante a leitura;

- As preposições, os artigos, os pronomes, os advérbios e as conjunções analisados ou presentes nos comentários são grafados em negrito e sublinhados;

- As análises aparecem após cada transcrição, para facilitar as consultas, usando apenas o número da(s) linha(s). O conjunto Inquérito (I), ํo do inquérito (1 a 6) e $\mathrm{n}^{\circ}$ da linha, é mencionado quando tiverem sido feitas as citações fora das análises individuais;

- Nas análises, quando um tipo de interferência não for encontrado naquela transcrição, será representado pelo símbolo Ø;

- São mencionadas as citações em língua portuguesa;

- Seguem, ainda, algumas observações e comentários que cremos sejam necessários para uma melhor compreensão das análises.

A título de esclarecimento, informamos que, freqüentemente, os entrevistados se preocupam com a compreensão do entrevistador brasileiro e procuram, eventualmente, adaptar o seu léxico ao léxico português, como por exemplo, no Inquérito 1 quando o entrevistado usa paese no sentido de pequena 
localidade que, em italiano nunca seria cidade. O entrevistador percebe uma hesitação no uso desta palavra: de/ del mio paese, isto se nota pela seqüência do seu discurso $(\mathrm{I}-1,22-25)$.

\subsection{Dificuldades encontradas durante as entrevistas e as transcrições}

Parte das dificuldades e algumas incorreções na gravação das entrevistas e nas transcrições do corpus foram decorrentes dos limites de meu conhecimento de língua italiana, no início do trabalho.

Os meus estudos de Língua Italiana foram iniciados em uma escola de línguas estrangeiras em São Bernardo do Campo, em 1988. Após o término do curso, fui convidada pela mesma escola para lecionar. O meu aprofundamento em língua italiana ocorreu como autodidata, pelo desejo de resgatar a memória de minhas origens. Já naquele período, comecei a observar a dificuldade de manter unida a comunidade italiana local, o que afastava cada vez mais os italianos de sua língua, de sua cultura, enfim, de suas origens.

Em 2002 graduei-me em Letras: Português-Inglês, pelo Centro Universitário da Fundação Santo André e, imediatamente, procurei um curso na Pós do Programa de Italiano da Universidade de São Paulo, onde fui aceita como aluna especial.

A minha intenção era encontrar um meio de resgatar as raízes de uma comunidade dispersa em uma cidade que, basicamente, teve o seu desenvolvimento apoiada nos imigrantes italianos. Ao mesmo tempo, seria um resgate das minhas origens.

Quando comentei com as Profs. Doutoras Loredana e Giliola o meu desejo de entrar no mestrado a fim de pesquisar os italianos de São Bernardo do Campo e sua fala italiana, ambas me apoiaram. Sob a orientação das duas, durante seis meses, freqüentei um curso de adaptação de Língua Italiana na USP, ao mesmo tempo em que freqüentei diversos cursos de atualização, ministrados pelos 
professores da Universidade de Perugia. Estes cursos eram patrocinados e apoiados pela FECIBESP - Federação das Entidades Culturais Ítalo-Brasileiras do Estado de São Paulo, onde sou reconhecida como professora de língua italiana através da Sociedade Cultural Brasilitalia. Neste período, preparei-me para o exame CELI 5 - Certificato di Conoscenza della Lingua Italiana, Livello 5, no qual fui aprovada em novembro de 2007.

Como Conselheira do COMITES - Comitato degli Italiani all'Estero desde o ano de 2004, em 2007, através do Consulado, pedi uma bolsa de estudos para um estágio na Itália, porém, até o momento, não foi possível obtê-la.

No decorrer do meu trabalho, estudei e aprendi muito, porém as gravações já haviam sido feitas e, na impossibilidade de refazê-las, nas transcrições serão apresentados diversos erros cometidos pela documentadora, pois não podem ser corrigidos, uma vez que assim estavam registrados.

\section{Análise do léxico}

Poderiam ser feitos diversos tipos de análise, no entanto, optamos por analisar o léxico, para dar continuidade aos estudos feitos na Tese de Doutorado de Giliola Maggio (2002): Pedrinhas Paulista: memória e invenção e nas Dissertações de Mestrado de: Marilisa B. Bilia (1998): Análise lexical das interferências da língua portuguesa na língua falada por italianos de nível universitário residentes na cidade de São Paulo e de Marisa Castellano Tsai (2006): Palavras da Memória: uma análise das interferências da língua portuguesa na língua italiana falada por italianos na cidade de São Paulo e, também, por tratar-se de um trabalho mais objetivo e adequado às características de um mestrado, em que o tempo é limitado, e para o qual foi necessário organizar, reunir, gravar e transcrever todo o corpus.

O léxico dos entrevistados, em geral, é bastante limitado por vários motivos e diversos foram os tipos de interferências encontradas. 
A nossa proposta concentra-se em assinalar as impropriedades e analisar as interferências lexicais, especificamente os substantivos, os adjetivos, os verbos e só em parte o uso mais ou menos correto das preposições, dos artigos, dos pronomes, dos advérbios e das conjunções.

Seguindo os moldes das pesquisas mencionadas na página 26, sobre 0 mesmo assunto, analisaremos:

\subsection{Empréstimos Totais}

2.2. Empréstimos Parciais

\subsection{Comutações}

2.4. Mudanças de significado

2.5. Decalques

2.6. Verbos

Observa-se que, pelo longo período em que os entrevistados se encontram distantes do contato lingüístico com a sua comunidade de origem, pelo esquecimento devido à idade e o desuso da língua materna, pela necessidade de comunicar-se na língua do país onde passaram a viver, o sistema lingüístico original foi enfraquecido, facilitando as interferências do léxico português-brasileiro na fala.

Muitas vezes, como pode ser observado, durante as entrevistas, o entrevistado assim que percebe a interferência, tenta fazer a correção, conforme observamos:

[...] corso di/di/di/ di:/ta/ cor/ di... taglio... e/e confezione. (I-2, 32)

[...] i/il ginásio neh a quel tempo ... perché sarebbe stato ... prim/il la quinta ... la sesta (1-2,50-51)

[...] lavorava su a fiação sul sul filo $(I-4,99)$ 
Porém, nem sempre consegue perceber e faz a transferência lexical, conforme os exemplos:

[...] che è quel prédio bianco $(1-2,277)$

[...] ma ci sono bastante cugini $(\mathrm{I}-3,135)$

[...] ci davano da mangiare con la caderneta $(1-4,192)$

[...] ho dimenticato il papel che avevo pagato $(\mathrm{I}-5,570)$

Em um estudo sobre o italiano falado no México, por Anna De Fina e Franca Bizzoni, a primeira diz que "I cambiamenti che la L1 (Língua 1) subisce sotto la pressione della L2 (Língua 2) sono generalmente studiati come fenomeno di attrito (o erosione)" (2002: 15).

Através do contato direto e do uso freqüente da $L 2$, a $L 1$ do imigrante tende a empobrecer-se, principalmente por causa do pouco contato mantido com a sua comunidade de origem e a necessidade de comunicar-se na língua do país que o acolhe.

"Tale indebolimento può portare con sé una varietà di conseguenze sulla L1: dall'adozione sempre più frequente di prestiti lessicali, morfologici e sintattici dalla L2, alla semplificazione sinttatica o semantica, alla perdita totale o alla morte della L1 [...]" (2002: 16).

Franca Bizzoni cita que a erosão "normalmente é involuntária e, na maior parte dos casos, não é percebida pelo falante [...]" (2002: 82).

Mario Vilela, 1994, em seu livro Estudos de Lexicologia do Português, nos diz que:

"O léxico é a parte da língua que primeiramente configura a realidade extralingüística e arquiva o saber lingüístico de uma comunidade. [...] e que tem três possibilidades para se adaptar a situações novas: câmbios semânticos, empréstimos e formação de palavras (a partir de palavras ou elementos existentes na língua). A urgência em serem satisfeitas a necessidade de comunicação e expressão dos falantes, a exigência em configurar o que de novo surge na comunidade e a necessidade em manter a sistematicidade da língua, são as maiores forças que se manifestam no léxico" (1994: 14). 
A partir do momento em que o falante de uma língua sente a necessidade de se comunicar em uma outra que não é a sua língua de origem, aciona a sua criatividade, adaptando ao seu sistema lingüístico um elemento de um outro sistema.

Nelly Carvalho (1989: 42), nomeia como "adaptações fonéticas", sem que entre em ação a criatividade do falante, pois "os empréstimos pressupõem uma interpretação e uma adaptação à estrutura da língua importadora [...] e têm sua origem no momento em que objetos, conceitos e situações nomeados em língua estrangeira transferem-se para outra cultura [...]".

Serão passíveis de análise os:

2.1. Empréstimos totais: quando a transferência de um elemento de uma língua para a outra é feita integralmente, muitas vezes por não existir um correspondente na língua do imigrante, por esquecimento ou simplesmente pelo hábito de se usar tal palavra em língua portuguesa. Notou-se também, que o entrevistado, muitas vezes, usa o léxico em língua portuguesa pela preocupação que tem de que o entrevistador não o compreenda, por ser um brasileiro. Ex.: prédio, grão-de-bico.

2.2. Empréstimos parciais: quando alguns elementos são transferidos do português e outros são mantidos em língua italiana, encontrados em unidades lexicais múltiplas. Ex.: antepassati ao invés de antenati.

2.3. Comutações ${ }^{2}$ : quando radicais da língua portuguesa são mantidos e os morfemas de gênero e número do português são substituídos pelos italianos com a mesma função designativa. Ex.: reali ao invés de reais.

2.4. Mudanças de significado: quando um vocábulo existente na língua italiana é usado indevidamente por ser homógrafo e/ou homófono de outro português, grafado com seu radical original, porém com morfema de gênero e número correspondentes àqueles de língua italiana. Ex.: carte ao invés de lettere, carro ao invés de auto/macchina, etc.

${ }^{2}$ Com referência às comutações, quando o trabalho já estava terminado dei-me conta de que, às vezes, apesar de diferenças de uso, os radicais são os mesmos nas duas línguas - italiano e português - e que, talvez, deveria analisar diferentemente algumas palavras. 
2.5. Decalques: quando algumas palavras são elaboradas a partir do modelo português. Ex.: vinteun, quattro milla e ottocente, fatto questione.

2.6. Verbos: serão analisados com o mesmo padrão de substantivos e adjetivos. 


\section{INQUÉRITO № 1 (I-1)}

Sexo: Masculino

Data de nascimento: 19/07/1947

Idade: 57 anos

Cidade: Noepoli

Província: Potenza

Região de Proveniência: Campania

Profissão: Professor aposentado

Entrevista realizada em: agosto/2004

1 Doc il suo nome e cognome

L1 XXXXXX XXX

Doc ahn età?

L1 devo dire la mia età?

5 Doc sì/ la sua età

L1 Sí ma:... sono già diventato un vecchio cinquantasette anni

Doc qual è la: sua data di nascita?

L1 di/diciannove luglio quarantasette

Doc quarantasette ... la ... sua professione?

10 L1 sono pensionato :io:io ho lavorato: circa trentatré anni/trentatré anni... come insegnante di ciências físicas e: biológicas...io io ero: ero: di ruolo: è ... effettivo:... concursado... nella la scuola pubblica do/do Estado di São Paulo

Doc e da quanto tempo è in pensione?

15 L1 da: aprile: duemiletré

Doc aprile duemilatré ... a: regione: di Italia e città di provenienza?

L1 regione si chiama Basilicata ... la città è un paese... piccolo paese là di circa mille/trecento abitanti si chama Noepoli ... in: provincia: di Potenza

20 Doc e:... come si ricorda del suo: paese: o: lei è venuto troppo piccolo:

L1 no/sì son venuto nel quarantanove con due anni non/non mi ricordavo del/del mio paese poi sono andato lì a ... nel/nell'anno: se/ 
millenovecentosettanta ... la prima volta ... poi sono ritornato ... circa quattro cinque vo/cinque volta/volte ... e come mi ricordo: è un: è: un 25 po' strano perché lì non c'è:/è un paese:... piccolo ... è vuo/ praticamente vuot/vuoto durante: maggior parte de/dell'anno

Doc [è una città

L1 [è un po' str/

Doc di campagna?

30 L1 è in campagna sì è ne/negli Appennini ... de/... nel Sud ... Basilicata è in sud d'Italia

L1 [vicino a

Doc [e lei già è ritornato: quattro cinque volte

L1 cinque volte/quattro volte/quattro/quattro volte ... sì

35 Doc e quanto tempo è stato ogni volta che è andato?

L1 prima volta un mese: poi/dopo ... du/due settimane e la terza volta ... quattro cinque giorni

Doc lei ha dei parenti ancora?

L1 sì ho dei parenti ... ho un cugino ... e una zia ... e ci sta:... ci sono $\mathrm{i}$

40 miei ... i miei compadri/padrini/padrini di battesimo ... pure:.: allora

Doc bene ... ah: sulla guerra ... che cosa: lei ha sentito parlare perché voi siete venuti dopo la guerra

L1 sì

Doc e: lei sa dirmi cosa pensavano: era scappare della guerra qual è stato

$45 \quad$ il motivo ... che voi siete venuti:?

L1 è il motivo e: credo che era perché: ... è Italia era distrutta non c'era ... lavoro ... e qua/qua in Brasile c'era un ... un fratello di mio padre e lui: è venuto nel quarantotto ... da solo ... cioè con ... un fratello/fra/fra/fratello ... per rimanere quattro cinque anni fare

50 l'America qui e poi ri/rientrare... poi dopo: noi/loro ci/lui mi ha ci ha/cha/chiama/chiamò mia madre e a me ... siamo venuti e siamo: rimasti ... fino adesso

Doc in quale mese: è venuto?

L1 ottobre ... ottobre quarantanove

55 Doc in nave?

L1 nave si chamava ... Marco Polo

Doc Marco Polo ... quanto tempo di viaggio ... lei sa?

L1 circa ... due settimane:... credo ... più o meno 
Doc bene e com'è:

$60 \mathrm{~L} 1$ e: io non $\mathrm{mi}$ ricordo delle/del/del viaggio

Doc [ era piccolo non sai bene

L1 [ con due anni

L1 bisogno fare un: come si dice? ritornare lì fare l'ipnosi ((risos))

Doc va bene

65 L1 va bene

Doc e: questo: suo zio già era qui a São Bernardo o a São Paulo?

L1 no lui è:... lui era/ quando è venuto è venuto qua/a Santo André poi/so/poi è andato a São Paulo ... e poi dopo aveva una/una/ una ditta di/faceva mobili/di: mobili

70 Doc certo

L1 ahn Nova Iguaçu ... baixada Fluminense ... e allora noi siamo andati in questo luogo

Doc ah la prima volta siete andati: a Rio?

L1 è a Rio ... Estado do Rio

75 Doc e: quando siete [venuti?

L1 [e poi/

L1 poi/come/come le cose lì no non era/non/non andavano bene tra... il mio padre e fratello... siamo poi/ circa tredici/ tredici anni siamo:...

80 venuti a Santo André che c'era la/una sorella di/di mio padre che... ha dato una mano là...per incominciare qui ... Santo André ... e lui faceva:: è lavorato du/due o tre ditte e poi è andato a lavorare/de/ autonomo

Doc e quando siete venuti a São Bernardo o soltanto tu/lei è venuto qui?

85 L1 São Bernardo no a Santo André ... siam venuti nel :sessantatré

Doc ma lei abita a São Bernardo da quanto tempo?

L1 no/io abito/a São Bernardo dal/novanta:cinque

Doc dal novantacinque

L1 dal novantacinque

90 Doc va bene ha lavorato anche a São Bernardo?

L1 io? sì... ho: $\mathrm{mi} / \mathrm{mi}$ sono:... mi sono ritirato ero: in quella scuola lì: come si chiama là? Maria ... Iracema ... 
Doc Munhoz

L1 Munhoz ... che sta lì: in Piazza Lauro Gomes...in centro... centro città

95 Doc ho capito ... ah:: lei parla bene la:: lingua italiana ma:... da quando lei parla questa lingua mi racconti un po' la storia... già/già parlava: a casa con i genitori: mi/mi parla un po' ... della tua conoscenza della lingua materna perché lei è venuto troppo piccolo

L1 no/mio padre no/no non ... mia madre non hanno/non hanno come si

100 dice ... fatto questione che si parlasse solo italiano a casa allora come io andavo sempre in giro alla scuola ... eccetera ... parla/ pure in/eh in: portoghese ...a casa ...mi padre e mia madre parlavano in dialetto lucano là ... ma io ho sempre: ... eh non/non dimentich/ non/non/non ... è/son un pochino emozionato scusa ... non ho mai

105 è: ... non ho mai:... lasciato di:... pensare a/alle mie radici sai? e allora da picco/da circa ca/quattordici anni circa ... volevo rientrare in Italia e poi come non/non/non è stato possibile... ho: imparato un pochino: leggendo da solo/ ho fatto un corso là ... ho fatto un corso ... in una/una scuola che era del/ con/consolato na rua sete de: a/abril ...

110 negli anni ... sessanta credo ... fine de/degli anni sessanta ... e è così e poi ... adesso: da parecchi anni vedo ... ho la televisione la tevê $A$ ... a tevê $A$... e: metto/vedo la televisione la RAl e così vo/vado ... vado ... allenando un pochino

Doc e giornali e riviste

115 L1 giornale e riviste e ecc/libri ... eccetera così che io ... e poi sono/sono andato in Italia quattro cinque volte sempre si ... si impara un pochino ... con que/con queste/queste gite

Doc a: casa lei parla qualcosa in italiano con i suoi figli?

L1 eh parlo/posso parlare/cosa parlo/non posso parlare?

120 Doc parolacce no

L1 no è meglio no ((risos)) solo:... predico... ahn predicare ahn [ sai cos'è predicare

Doc [sì lo so

125

L1 si predica ... ( ) ogni giorno ((risos)) quando le cose non vanno bene si predica

Doc ma loro parlano un: po': perché hanno ascoltato a casa o si interessano:... di imparare l'italiano come funziona?

L1 è: mai si hanno:/ mai hanno avuto: certo interesse di/di imparare l'italian... di/quest'anno hanno imparato un pochino che ho: spinto un 130 po'... ma loro:... non so cosa succede:... e questi/questi/che sono figli/nipoti ogni/in ogni genere sono:... so/loro si diment/vanno dimenticando la/le sue radici e credo che ... perché: no/non ci sta così una: ... come si dice un rapporto tra ... tra italiani qui a s::specialmente qui a San San Bernardo io/no/no 
135 Doc [lei non partecipa a niente?

L1 [non non partecipo di ni/

L1 esatto no... ogni tant/ due o tre volte sono andato alì a/ dal Circolo Italiano dove c'era: c'è un ...come si/si cha/chiamo ... un ... patronato Ena/Ena/Enasco ... che è della mia regione ... ma se no ... loro non 140 hanno: ... sono diciamo veri brasiliani

Doc uhn ... va bene

L1 e questo mi: ha:: come si dice...mi lascia un po' ... un rammarico $(($ risos $))$

Doc ha: dei parenti:... qui ancora a Santo André: São Paulo?

145 L1 sì c'è/ho una/San San Bernardo qua c'è una in questo palazzo c'è una parente

Doc ma parla l'italiano?

L1 no lui è/lei è:... è fa tradu/traduce: :idioma inglese

Doc uhn

150 L1 Santo Andre ... so: ci sta là un cugino di mio padre

Doc ma non parla anche italiano

L1 parla

Doc parla con lui lei ...

L1 con me no ... no .. più portoghese si parla non ... ho parenti a Rio de Janeiro [loro

Doc [ma è un po' difficile

Doc [di mantenere la lingua senza

L1 [loro

160 Doc avere con chi scambiare

L1 [loro parlano per più portoghese è difficile scambiare perché ... scambiare con le mure

Doc è un po' complicato

L1 è un po' complicato

165 Doc [e quale

L1 [bisogna aveva

eu avevo bisogno di: fare ... un corso di italiano ... per tutti gli anni ((risos)) per potere/per potere migliorare la la pronuncia perché in verità non non parlo ... così bene ... parlo ... pochino mi faccio capire 
170 Doc tá una:: ultima domanda ... i piani per il futuro quali sono?

L1 i piani ... beh io avev/io avevo intenzione di/di rientrare in Italia... quest/i ... mi/miei piani

Doc mi parli un po'/

L1 rientrare con ... pure un figlio con la nuora e la nipote ... però:...

175 adesso abbiamo un cambio che qua in Brasile sempre è così fanno un piano ... e poi dopo ... dieci anni circa adesso già noi:... questi soldi qua non hanno ... non servono a niente diciamo ... non è così? normale no?... vediamo se ... se riesci/ri/RI-U-SCI-RÒ ((risos)) a fare questo ... questo come si dice:... impegno non so s'è così che 180 si dice

Doc questo sogno diventare realtà?

L1 è così ... questo scopo ... questi sono i piani adesso sono pensionato:... :sto a casa

$185 \quad$ [pensi di fare?

L1 [no noi non abbiamo proprietà in Italia no ... bisogna/bisogna/bisognava ritornar lì per veder se ho: delle/dei ... qualche diritto lì non so/non so una legge della regione che ... ci sono dei diritti ... per: i lucani che/chi ...

190 lavoratori lucani che stanno a/all'estero ... poi bisogna veder se ci sono i fondi no ... bisogna andare lì per/per provare se si ... si/si va o non va

Doc e questo lei:... pensa di far quando?

L1 bene vediamo se: faremo...eh: diciamo marzo... così febbraio marzo

$195 \quad \ldots$ fine di febbraio inizio marzo ... circa ... qu/quanti/cinq/quattro cinque mesi

Doc va bene ... allora ... grazie

L1 prego

Análise das interferências:

\subsection{Empréstimos totais:}

12 - efetivo concursado: o entrevistado usa di ruolo e em seguida efetivo ... concursado para explicar ao entrevistador o seu significado. 
79 - de autônomo: neste sentido em italiano diríamos lavoratore autonomo.

106-107 - tevê A a tevê A, em italiano, la Ti Vu A.

\subsection{Empréstimos Parciais}

13 - Estado di São Paulo: mistura português com italiano, tratando-se de uma citação: Estado de São Paulo.

\subsection{Comutações: $-\varnothing$}

\subsection{Mudanças de significado: $-\varnothing$}

\subsection{Decalques:}

15 - duemiletré: para este decalque encontramos duas possibilidades:

- do português dois mil e três

- ou do italiano duemila e tre

95-96 - non hanno fatto questione: partindo do modelo em português: não fizeram questão: non hanno preteso, non hanno fatto pressione.

160 - scambiare con le mura: em italiano o correto é col muro, provavelmente o entrevistado baseou-se no português com as paredes.

\subsection{Verbos:}

Freqüentemente o entrevistado faz uma mistura da pronúncia do verbo chamar-se com o verbo chiamarsi, misturando o pronome si com o verbo em português, ou fica indeciso quanto ao uso do italiano, conforme a linha 51:

18 - si chama Noepoli

51 - ha/cha/chiama/chiamò

56 - nave si chamava

138 - come si/si cha/chiamo ...

Faz uso do verbo ir em português ao invés de andare, mas percebe a tempo e faz a autocorreção:

112 - e così vo/vado ... vado, provavelmente vou, mas existe em italiano, principalmente em Toscano, a forma vo. 
Impropriedades:

$91-\mathrm{mi}$ sono ritirato: Ainda que o verbo ritirarsi ${ }^{3}$ seja dicionarizado, aqui o seu uso é impróprio, pois o que quis dizer é que era pensionato aposentado.

160 - avere con chi scambiare

162 - è difficile scambiare perché ... scambiare con le mure, parlare col muro, dialogare.

\section{Preposições:}

12 - do/do Estado di São Paulo. Com uma mistura de italiano e português, usa, primeiramente, a preposição do em português, onde seria necessário usar di, no caso, dello Stato. Já em Estado di São Paulo, atrapalha-se e usa a preposição italiana di em vez da portuguesa de.

109 - na rua Sete de: a/abril. Usa a preposição na, quando deveria ser usada nella e, caso tivesse usado via, a preposição seria in.

\section{Pronomes:}

Observamos em duas oportunidades o uso indevido dos mesmos: 102 - mi padre: acreditamos seja um uso dialetal, correto mio.

167 - eu avevo: empréstimo total do português, em italiano: io avevo.

\section{Obvservações:}

11 - ciências físicas e: biológicas: citação em português antecedida pela preposição em italiano $\underline{\text { di. }}$.

22 - del/del mio paese: hesitação no uso de "paese", por são saber se o entrevistador entenderia o sentido de pequena localidade.

36 - poi dopo: ênfase esclarecedora.

40 - compadri/padrini/padrini di battesimo: repetição esclarecedora, passa de uma expressão com facetas dialetais - compadri - a outra correta em italiano - padrini - e uma terceira explicativa - padrini di battesimo.

${ }^{3}$ Segundo lo Zingarelli, ritirarsi significa lasciare, abbandonare un ufficio, un'atività pubblica 0 privata spec. Definitivamente: ritirarsi dopo 25 anni di attività. 
A palavra mais usada em dialeto é compare já dicionarizada também em italiano e, normalmente, a título de esclarecimento, usa-se: compare di battesimo, compare di cresima. Encontramos, também, compadre, italianização de compare.

60 - e: io non mi ricordo delle/del/del viaggio: hesitação no uso do léxico. $\mathrm{O}$ uso da preposição delle nos induz a pensar que talvez ele quisesse dizer algo como della traversata, mas depois corrige e diz del viaggio.

Podemos ainda classificar as frases em que aparece come si dice, como tentativa de se aproximar ao significado pretendido. O entrevistado não está seguro de que a expressão usada por ele seja compreensível, correta ou entendida em seu significado correto:

63 - bisogno fare un: come si dice? ritornare lì fare l'ipnosi

99-100 - non hanno come si dice ... fatto questione che si parlasse solo italiano a casa

133 - una: ... come si dice un rapporto tra ... tra italiani qui

142 - e questo mi: ha:: come si dice ... mi lascia un po' ... un rammarico

179 - a fare questo ... questo come si dice: ... impegno non so se è così che si dice

\section{Comentários:}

1 - o entrevistado parece muito controlado, numa posição desconfortável, por ter consciência dos seus limites expressivos em italiano. As principais observações a respeito do léxico indicam certa insegurança no domínio da língua e um desejo de se fazer entender pelo entrevistador.

2 - freqüentemente o entrevistado se preocupa com a compreensão do entrevistador brasileiro e procura, eventualmente, adaptar o léxico italiano ao léxico português. Vê-se isso, por exemplo, quando usa paese no sentido de pequena localidade (em português, cidade), mas que em italiano nunca seria città. $O$ entrevistador percebe que há uma hesitação em usar esta palavra: del/del mio paese. Isto se nota pela seqüência do discurso (27-31). 
Tabela no 1 - Empréstimos Totais

\begin{tabular}{|l|l|}
\hline \multicolumn{1}{|c|}{ Português } & \multicolumn{1}{c|}{ Italiano } \\
\hline efetivo concursado & di ruolo \\
\hline de autônomo & lavoratore autonomo \\
\hline tevê A (duas vezes) & Ti Vu A \\
\hline
\end{tabular}

Tabela no 2 - Empréstimos Parciais

\begin{tabular}{|l|l|}
\hline \multicolumn{1}{|c|}{ Português e Italiano } & \multicolumn{1}{c|}{ Português correto } \\
\hline Estado di São Paulo & Estado de São Paulo \\
\hline
\end{tabular}

Tabela no 3 - Decalques

\begin{tabular}{|l|l|l|}
\hline \multicolumn{1}{|c|}{ Decalque } & \multicolumn{1}{c|}{ Português correto } & \multicolumn{1}{c|}{ Italiano correto } \\
\hline duemile e tre & dois mil e três & duemilatré \\
\hline hanno fatto questione & fizeram questão & hanno preteso \\
\hline col muro & com as paredes & con le mura \\
\hline
\end{tabular}

Tabela no 4 - Verbos

\begin{tabular}{|l|l|l|}
\hline \multicolumn{1}{|c|}{$\begin{array}{c}\text { Forma apresentada } \\
\text { (pronúncia? dialeto?) }\end{array}$} & \multicolumn{1}{c|}{ Português correto } & \multicolumn{1}{c|}{ Italiano correto } \\
\hline si chama & chama-se & si chiama \\
\hline ha/cha/chiama/chiamò & chamou & ha chiamato \\
\hline si chamava & se chamava & si chiamava \\
\hline vo/ & vou & vado \\
\hline si cha/chiamo & se chama & si chiama \\
\hline
\end{tabular}


Gráfico das Principais Interferências (I-1)

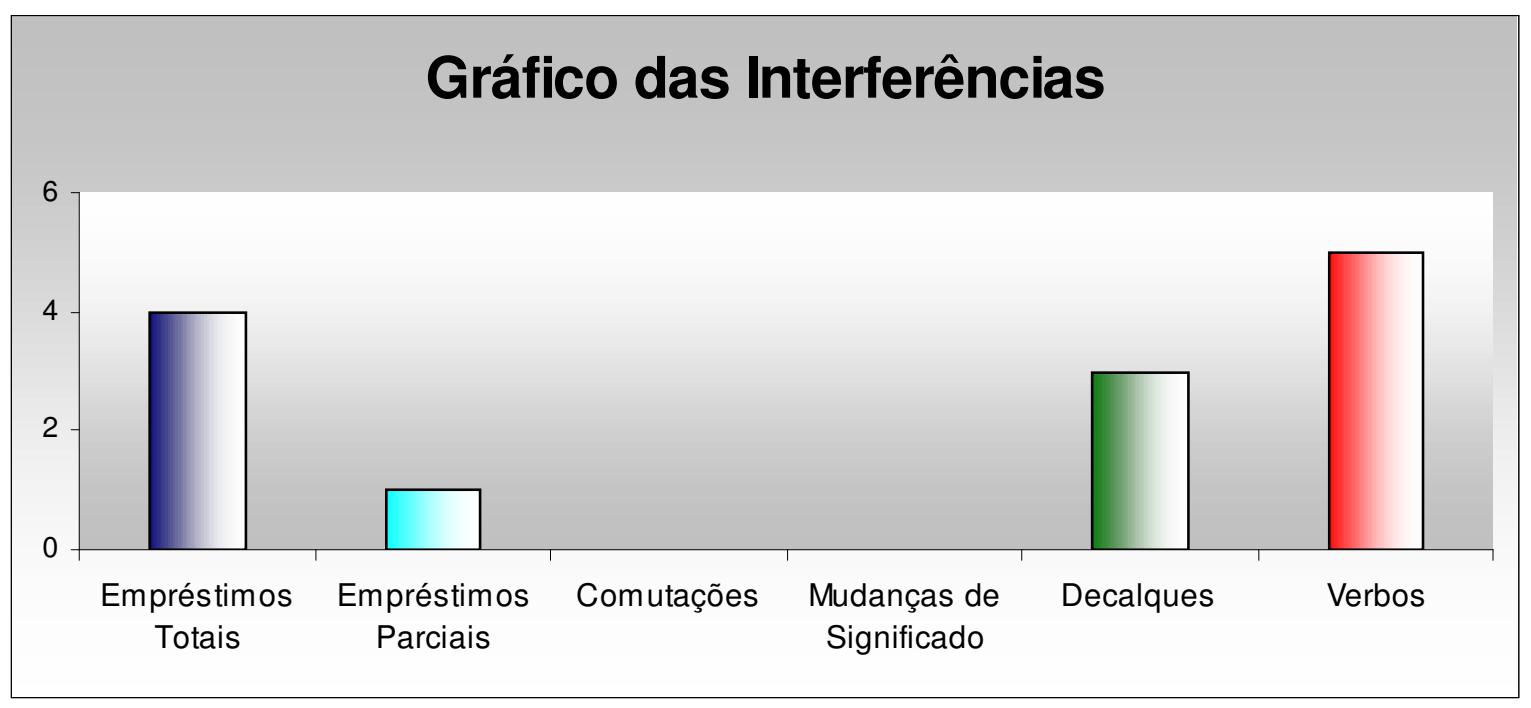




\section{INQUÉRITO № 2 (1-2)}

Sexo: Feminino

Data de nascimento: 01/01/1917

Idade: 87 anos

Cidade: Bagni di Lucca

Província: Lucca

Região: Toscana

Profissão: Pensionista, ex-costureira

Entrevista realizada em: outubro/2004

1 Doc il suo nome e cognome

L1 il mio nome è XX ... ma in sui/sui documenti ... italiani $c^{\prime}$ '̀ prima il supranome neh... prima XX XX XXX sarebbe il mio nome completo

5 Doc va bene la sua età?

L1 è: ottantasette

Doc data di nascita?

L1 il primo del primo del diciassette

Doc diciassette? la sua professione possiamo adesso parlare un po' di

10 quello che lei faceva ... perché oggi lei è in pensione?

L1 eh no pensione non ce n'ho

Doc no?

L1 no ... c'ho solo la: pensione ... di mio marito quella:/che:/lui prendeva

15 anche quella italiana

Doc va bene va bene ... tá la regione e la città di provenienza

L1 la regione: è: la regione è Lucca neh/... la provincia è Lucca neh ... e: la:: :nostro paese è Bagni di Lucca neh

Doc Bagni di Lucca ... molto bene ... uhn ... come lei si ricorda del suo 20 paese: la sua città ... che cosa le viene in mente?

L1 ma la nostra città non è città ... perché io abit/è Bagni di Lucca ma noi si abitava in montagna neh ... e io mi ricordo tutto perché vero ... ci ho vissuto ((risos)) trenta/trent'anni neh 
Doc mi racconta un po' come era la vita ... che cosa lei faceva

25 L1 facevo lo stesso la sarta

Doc uhn

L1 facevo la sarta ... e là pure avevo clienti buoni ... la/la moglie del/la moglie del dottore ... la moglie del farmacista ... la moglie del/del tabaccaio ... e lavoravo bene c'avevo tante/tante ragazze ... che mi

30 aiutavano ... perché volevano imparare ... perché io ci ho il diploma ... un/proprio ... diploma italiano della/della/della regione ... che ho fatto il corso di/di/di di:/ta/ cor/ di ... taglio ... e/e confezione

Doc uhn

L1 e: tem questo/diploma mio ... dove si è messo Melissa per farle

35 vedere

L2 ta lá em casa eu acho

L1 sta na tua casa? ah sì perché

Doc dopo lei me lo mostri

L1 e questo: diploma ... proprio è del governo neh

40 Doc certo

L1 perché il corso che ho fatto io ... bisogna avere prima ginásio poi si poteva andare a fare il corso ... taglio e confezione era una ... professoressa ... parigina

Doc ahn

45 L1 che faceva ... a Firenze e Lucca non c'era a Bagni di Lucca si stava/si andava laggiù a Lucca proprio

Doc tá lei ha studiato a Lucca?

L1 a Lucca sì

Doc va bene

50 L1 Bagni di Lucca ho fatto solo: i/il ginásio neh a quel tempo ... perché sarebbe stato ... pri/il la quinta ... la sesta...poi si faceva la sesta la settima e l'ottava... che sarebbe equival/equivale al ginásio

Doc certo ... va bene ... lei è venuta dopo la guerra

L1 dopo la guerra sì

55 Doc cosa lei si ricorda della guerra?

L1 AH mi ricordo tutto perché noi abbiamo passato ... tutta la guerra neh? ... e a nostra casa che ... c'è il quadro ali che l'ha fatto la mamma di Melissa ... la nostra casa era molto grande ... quattordici stanze neh ... perché era una casa ... uhn di: mio nonno sarebbe 
stato ... un uomo molto ... facoltoso perché ... aveva la/la luce elettrica ... aveva fondato la luce elettrica a Bagni di Lucca lui era il direttore ... e pe/pena che è morto presto e ... i figli sono stati educati tutti a: ... ahn ... come si chiama quel ... come è pure mia mamma ... co/no cottolengo eh:....come si chiama quel/quel/quell'educazione che danno $\mathrm{i} / \mathrm{i} / \mathrm{i} / \mathrm{i}:$ i preti?

Doc non mi ricordo nonna dopo lei mi racconta

L1 è: insomma sono stati tutti educati là ... e mia mamma ... era: maestra di: infanzia neh ... ed aveva ragazzi sempre perché/ma in casa no perché ... aveva una sorella ... che quando è morta i genitori aveva sette anni ... e così ... lei ha dovuto prendere redini di tutto neh perché aveva due contadini neh ... molta terra neh ... e doveva vedere e stare a/a faccia di tutto neh ( ) lei ... perché i: fratelli erano tutti ... in co/in collegio

\section{Doc sì e la guerra?}

75 L1 e la guerra è stata così ... a::/loro/venivano i soldati ... prima abbiamo tenuto in casa ... i soldati tedeschi neh ... perché i tedeschi avevano invaso tutto lì a Bagni di Lucca neh ... e era la linea gotica ... si chiamava la linea gotica ... era proprio: sta/stabilito ... dagli americani e tutto ... e ali ... era un: posto un dove si trovavano molto i soldati ... 80 perché ((risos)) c'era paura perché in montagna ... loro stavano su i tedeschi ... e gli americani stavan giù neh ... è questo il fatto ... e dopo son venuti su ... i/gli americani neh ... e: bella notte ... bella notte di Natale ... che: i soldati ... fanno festa neh ... sono venu/e son/erano gl'inglesi prima ... sono venuti gl'inglesi ... e lì in casa

85 nostra ci stava il comando ufficiali neh ... degli ufficiali ... prima t'ho/t'ho/t'ho detto gli inglesi ... ma erano ... facoltosi si stava bene perché ... loro ... davano tante cose per mangiare perché ... alfine noi si aveva il grano tante/tanto ... granturco pure ... ma non si poteva macinare perché ... erano tutti chiusi i mulini ... ha capito?

90 Doc uhn uhn

L1 erano tutti chiusi e non è/e c'era anche il guaio ... che se aprivano se facevano macinare qualche cosa ... potevano anche dar fuoco ... a/ al stabelecimento

Doc uhn uhn

95 L1 e così... loro davan tante cose si sta/si stava relativamente bene ... sempre con paura perché i tedeschi stavano in cima neh ... e la notte di Natale sono scesi a Barga ... Barga Castelnuovo ... giustamente lì dove c'è: $\mathrm{i} / \mathrm{i} / \mathrm{i} / \mathrm{il}$ il libro che Giovanni Pascoli neh ... era da quelle parti là di/di Castelnuovo di/di Castelnuovo Barga ... sono scesi giù ... e gli 100 inglesi erano tutti là al tavolino a:: na mia sala è grande più/più grande di qui ... laggiù in fondo alla casa ... e c'è un tavolo grande c'è sempre quello neh ... perché le cose non cambiano lá ... in Italia lo sa 
lei neh ... difficile cambiare ... e loro erano tutti a tavola e ci hanno invitato pure noi ... la mia fa/tutti la mia famiglia a/mamma i miei 105 fratelli erano tutti i due alla guerra ... e mio fratello era in Germania ... era stato preso prigionero in Germania ... e l'altro mio fratello era in Australia ... in Australia ... e là mio fratello s'era trovato bene perché lui ha fatto l'interprete ... ai/ai/al campo di concentramento ... ha fatto l'interprete questo ... e ... lui aveva cinque lingue che 110 parlava ... è stato bene là ... ma non poteva comunicarsi con noi no ... non c'era comunicazione ... una volta la croce rossa sono andati là ... e hanno mandato: un/un un foglietto ... che lui stava bene che non ci pensasse ... così così ... che l'avevan trovato in campo di concentramento

115 Doc certo

L1 perché ... lui si era fatto/si era fatto ... australiano inglese neh si era fatto inglese ... era sergente staff dal/dell'inglese

Doc certo

L1 e ... è dopo la/la guerra è stata così ... questi inglesi stavano bene 120 avevano tutto ... preso la casa dei contadini ... sa neh la casa? nostra casa poi dietro ... c'era la casa dei contadini ... poi là c'erano le stalle ... e c'era ... poi il terreno là è grande neh

Doc era una casa di campagna

L1 di campagna sì

125 Doc ah voi avevate la piantagione:

L1 tutto di tutto le piantazioni ... gli orti neh ... ma sempre coi/coi coloni neh

Doc certo

L1 colla/la/le persone neh ... e dopo questi inglesi sono andati via a notte 130 son partiti quando han sentito ... bombardamenti si sentiva ... mamma mia ... che paura che noi si ha avuto quella notte ... e loro hanno preso le jeep i camion ... e sono partiti là per campi nea/neanche per la strada ... tutti per i campi ... via via ... per andare in città neh ... per raggiungere la tru/truppa americana neh

135 Doc lei già era sposata in questo periodo?

L1 no no ... non ero neanche fidanzata

Doc uhn uhn

L1 ero fidanzata al primo tempo ... con un ragazzo che era ... nella marina ... era capoposto della marina ... e lui era in/la categoria sua

140 era infermiere neh ... e: quando è stato ... quando è stato là ... lui era ingaggiato sulla nave Littorio ... la più grande nave italiana di guerra 
Doc come si chiamava?

L1 Littorio

\section{Doc Littorio}

145 L1 è nave Littorio ... e dopo ... è: hanno silurato la nave gli inglesi neh ... son venuti proprio a silurar la nave in porto neh ... e là c'è stato un guaio ... la nave è stata ... decimata ... e lui ha avuto due proiettili nelle spalle ... e così che ... non c'è stato verso ... era un'etisia fulminante neh ... è venuto a casa da Taranto neh ... che la nave è

150 stata silurata a Taranto ... e quando: è venuto su ... si è curato tanto ma ... lui mi ha detto non ti posso sposare ... la facciamo finita con questo ... namoro perché non/non non c'è verso ... con la mia salute ... lui non lo sapeva meglio degli altri che aveva studiato l'infermiere neh

155 Doc certo e lei si è sposato/quando si è sposata quando?

L1 millenovecentoquaratassette

Doc ah dopo la guerra

L1 dopo la guerra sì

Doc e quando siete venuti in Brasile?

160 L1 io son venuta nel millenovecentocinquanta

Doc già aveva: un bambino?

L1 e avevo il bambino ... il bambino è nato nel quarantotto

Doc ah ho capito lei si ricorda il nome della nave?

L1 mi ricordo Nortin

165 Doc Nortin

L1 era una nave di bandiera portoghese

Doc portoghese ... quanto tempo è durato il viaggio?

L1 venti: un giorno

Doc che cosa lei si ricorda del viaggio?

170 L1 ah del viaggio :era un viaggio ... disastroso ... perché questa nave ... si fermava pure ... e la gente aveva tanta paura e mi mi trat/io son venuta con mio fratello ... e il mio bimbo neh ... e il mio bimbo si sentiva male ... lui gli fa male il mare ... aveva il mal di mare ... e poverino vomitava ... è:/è era un disastro ... era un disastro ... ma

175 veramente siamo arrivati finalmente neh ... e là ... facevano baccalà ... e ... ceci ... come si chiama qui cece Melissa?

\section{Doc grão-de-bico}


L1 grão-de-bico eh ... e l'odore in tutta la s/in tutta la nave era tremendo ... a noi poi l'ufficiale che il bimbo si sentiva male ... ci hanno dato una gabina sul/sul/sulla ... sul ... come si chiama su/su por/sul porto della nave neh ... e lì si stava benino assai neh ... si stava giù in basso così ... lui vicino all'oblò non poteva stare perché ... si sentiva male di più ... allora c'ha preso una poltrona ... e si teneva sul ponte ... della nave

185 Doc certo

L1 perché lì si sentiva un pochino meglio

Doc certo

L1 ma è stato/stato male poverino ... ha perduto un due chili ... sulla nave

190 Doc voi siete arrivati: a Santos?

L1 a Santos

Doc ahn e come è stato l'arrivo::

L1 ah l'arrivo è stato bello perché mio marito era già qui neh ... mio marito era ... sette mesi che era qui già ... aveva già trovato la casetta ... beh la casetta ... a gente non ha piaciuto neh non è piaciuto neanche al bimbo ... perché non c'aveva ... comodità neh

Doc dov'era?

L1 era in via Don João quinto alla Lapa

Doc certo

200 L1 via Don João quinto quarantassete

Doc che testa buona ... e voi avete abitato in questo posto per quanto tempo?

L1 eh per quanto tempo siamo arriv/siamo ... stati lì quasi un anno ... erano tre case sa? una accanto all'altra ... e davanti c'era ... una 205 botteg/una fruttivendola ... che lui mangiava tante banane ... perché questa fruttivendola dava tante banane a lui ... per mangiare ((risos)) ma lui era simpatico perché ... piaceva a tutti poi cantava italiano già ... già cantava

Doc e suo marito lavorava con che cosa?

210 L1 co/coi stucchini si chiamano ... e: di gesso ... le statue di gesso

Doc certo e lei in questo periodo cosa faceva?

L1 io facevo la sarta neh

Doc [già

L1 [subito 
subito ho cominciato a lavorare la settimana dopo che ero arrivata ... la mia vicina ha detto ah io c'ho due vestiti da fare se lei ha ... la macchina era chiusa ... ma io l'aprii subito ... e ho messo subito a lavorare ... perché c'era una saletta ... meno male ... e c'era una saletta e una camera ... e la cucina neh ... e non c'era: aveva 220 comprato il mio marito ... un:: letto neh ... un armadio e un lettino per il bimbo neh ... e poi ci abbiamo/ci avevo la/la ... la tavola meno male in/in in sala ... per poter tagliare neh ... insomma io stavo con/stavo contenta ... ma però ... avevo sempre l'idea di tornare neh ... di ritornar via ... e non/ci avevo un .baule che è là ... un baule che è 225 venuto dall'America del Nord che mio papà ... mio papà ... ha abitato più nell' America del Nord che in Italia perché lui ci aveva una maturazione di banane ... e faceva questo lavoro neh ... maturava le banane e poi ci avevano il camion che le portavan via quando erano mature per i fruttivendoli neh ... ma ... questo baule ... 230 non lo volevo aprir non lo volevo aprir ... che c'era tutto il mio corredo ... e perché volevo tornar via neh

Doc ah ho capito ... quanto tempo voi avete abitato a São Paulo?

L1 dieci anni

Doc e dopo a São Bernardo?

235 L1 è a São Bernardo venti ... prima si abitava in Santo André neh

Doc ahn

L1 era provincia di Santo André ma qui nella/nella Perera Barreto ... una entrata ... che si chiama Jardim Paraiso ... c'era una rivendita di ma/di carro ... ci sarà ancora mi pare ... davanti alla mia casa c'è 240 un::/:una palma ... grande ... che il nostro amico che lavorava nella Brastemp ce l'aveva data la/la pianta ... e quella ce l'hanno lasciata ... perché la casa ... ali era comoda ... perché era grande c'aveva un::/:un orto grande mio marito seminava tutto ... non si comprava niente di verdura ... ma l'hanno vo/voluta prendere per fare la

245 passarella ... lo sa che c'è una passarella qui per andare a Santo André

L1 $\quad[$ non so se ...

Doc [sì lo so

L1 e la nostra casa era lì ... hanno preso la casa e il terreno ... tutto neh

250 Doc e voi siete venuti dopo a São Bernardo

L1 a São Bernardo

Doc ahn e che cosa suo marito faceva a São Bernardo?

L1 lui faceva sempre ne/nella Ford anche quando si stava in Santo André ... ha lavorato venticinque anni nella Ford

255 Doc e lei ha continuato a fare la sarta 
L1 è ma: no/non c'era ... non c'era clienti buoni qui in Santo André no

Doc uhn

L1 lavoravo poco

Doc uhn

260 L1 non lavoravo tanto no

Doc uhn

L1 lavoravo da sola non c'avevo neanche le ragazze per fare: le/le rifiniture neh ... perché a: quel tempo che dico IO ... si faceva tutto a mano le rifiniture neh ... non c'era quelle macchine per fare suliati

265 Doc certo

L1 non c'era

Doc le è piaciuto São Bernardo?

L1 è piaciuto più São Bernardo che là dove abitavo ... stava/si stava nella Frei Gaspar ... e là ci hanno rubato due volte ... son venuti i ladri 270 ma meno male che non c'era nessuno ... hanno preso quel che hanno voluto ... e poi ... hanno spaccato tutto il vitrô della cucina ... e la porta della cucina che era ... la porta:/mio marito ha sempre detto di non chiuderla ... io invece l'avevo chiusa ... e per entrare hanno spaccato la porta neh ... per entrar su in camera ... era un bel 275 sobradino lì ... ma dopo siam venuti via perché c'(avevamo) tanta paura ... e siam venuti in un appartamento qui ne/nella avenida Redenzione ... che c'è quel prédio bianco

Doc sì lo so dov'è

L1 e noi siam/abbiam un appartamento lì si è comprato un apparta/ 280 abbiamo venduto là e siam venuti lì

Doc e dimmi una cosa ... lei ... parla italiano con chi?

L1 con nessuno qui

Doc ahn e come lei mantiene viva la lingua?

L1 è perché: ma ... ci siamo nati ... ci siamo studiato tutto perché non 285 devo parlare la mia lingua?

Doc non lo so lei non pratica con nessuno ... com'è lei guarda la TV la RAI come funziona perché

Doc [adesso

L1 [la RAl

290 Doc Melissa parla un po'

L1 la RAI la RAI l'ho fatta tirare perché ... m'era venuto ottantotto re/reali di/di/di di prezzo 
Doc ahn

L1 e l'ho fatta tirare quella là ... ma insomma io anche quando vado in Italia dicono tutti ... non ti non ti non ti sbagli mai ... perché c'è tanta gente che va là ... e non sa parlare ... lo sa lei

Doc [sì è vero

L1 [che succedon

questi fatti

300 Doc eh sì

L1 c'è tanti di questi fatti

Doc uhn lei già è tornata in Italia quante volte?

L1 ... cinque volte

Doc cinque volte ... per tempi lunghi o corti:

305 L1 la prima volta son tornata quasi subito ... perché la mi mamma ... voleva vedere il bimbo ... e la mi mamma era un poco malacciata e mi aveva detto di venire neh ... e allora sono andata là con Giuseppe ... aveva cinque anni ... ci siamo stati cinque anni senza andare neh ... senza andare là

310 Doc certo

L1 e siamo andati là ci sono stata tutta l'estate ... ci sono stata sei mesi

Doc e per ritornare

L1 per ritornare si era comprato già ... io sono andata con una bella nave ... colla Conte Grande ... e s'ha preso il biglietto di andata e ritorno neh ... siamo ritornati:: a fine di ottobre

Doc lei non è diventata triste di lasciare l'Italia?

L1 è sono diventata triste ma ... che si vuole? mio marito stava qua ... e io non potevo star ... lontana da lui

Doc certo è vero

320 L1 è ... a:: quel tempo si stava bene qui ... noi ... io lavoravo lui lavorava là alla Ford ... e era molto ri/richiesto ... perché lui sapeva l'inglese ... e ha lavorato a/a: montare la fabbrica di motori ... la fabbrica di motori là/qui in Ipiranga neh ... la Ford qui in Ipiranga ... e guadagnava bene perché ... dopo era chefe ... da/dalla manutenzione ... mio 325 marito è questo qui quando aveva vent' anni ... quando andò militare ... lui ha fatto tutte le guerre ... guerra d'Africa ... e quest'altra guerra ... tutte ... prigioniero sei anni

Doc dio ... allora il Brasile è stato un paradiso

L1 ah lui ci teneva e stava molto volentieri ... benché vero ... siamo 
Doc ah è?

L1 sì perché i suoi son tutti in America ... i suoi ora c'è un fratello solo l'ultimo neh ... che sarebbe stato ... il più grande di lui aveva un anno di differenza ... ma non si sa se è vivo o morto e si telefona ... e non 335 risponde nessuno ... ora devo telefonare a: mi/quell'altro mio nipote ... per vedere quel che dice neh ... se è morto 0 se è vivo ... ora avre/avrebbe novantadue anni neh

Doc novantadue?

L1 è novantadue... ma mio marito è morto con vent/novant'anni neh

340 Doc novanta ... quando lui è morto?

L1 è morto quindici di agosto

Doc che anno?

L1 novecentodue ... due mila e du/no millenovecento ((risos)) è: mio/mia cara ... la morte di mio marito è stato un colpo per me ... è stato quattro anni a lottare con il câncer ... quattro anni

Doc e lei abita da solo adesso/da sola

L1 da sola sì

Doc sì

L1 c'è una donna qui che viene tutti i giorni neh ... ma di notte sto sola ... 350 e lei il sabato e la domenica non viene ... mah che vuole fare? ma io non mi lamento per star sola Dio è con me ... e: prego tanto il Signore che ... mi lasci in salute neh ... perché non posso ... perché mio figlio ... fa di tutto per me ... di tutto

Doc è? e lei ha degli amici: italiani che incontra: alle volte o no?

355 L1 è sarebbe tutti alla Lapa neh i propri amici veri ... di quel tempo ... e nella Lapa si va poco perché è lontano e Giuseppe mio figlio ... è sempre ... in moto per poter trovare da lavorare ... qualche cosa e non trova da far niente ... e sta preoccupato

Doc qui a São Bernardo lei no/no/non ha conosciuto:::

360 L1 sì ho conosciuto: gente ma ... non/non ci stiamo in comune perché io non ... c'è una mia amica Esidora ... che lei è stata in Italia ora a poco ... quella è molto amica mia e un'altra mia amica ... una italiana spagnola ma ... abita in São Paulo ... là na/Pacaembu/no Perdizes ... in un appartamento ... se avessi la macchina potrei fare 365 qualche cosa ... potrei andare se avessi preso la/la patente ... ma ... questo è stato mio figlio che non ha voluto ... perché mio marito me la faceva prendere quando abitavo là in Santo André ... aveva 
comprato un Jeep neh ... prima macchina che si comprò ... aveva comprato un Jeep e: diceva che potevo imparare neh ... sul Jeep 370 era ... più facile anche neh ... ma mio figlio non voleva diceva che andavo a finire in qualche poste ... in qualche poste della luce ... e non voleva che mi imparassi a guidare no ... ma lui ha fatto tanto per suo padre ... nossa ha fatto ... una vita ... portava da tutte le parti e: esami e qui e là ... tutto si è fatto di tutto ... ma lui per tutt/faceva lui perché lo portava da tutte le parti neh ... è stato in diversi ospedali pure ma ... non c'è stato verso ... il male suo era ... liposarcoma

Doc questo è grave

L1 si repro/si reproduceva neh ... ha fatto quattro cirurgie ... è stato una cosa molto grave ... avevamo fatto una bella casina ... qua in/in Sant/ 380 in Itanhaem ... e poi abbiamo dovuto venderla perché lui ha perso anche la vista neh ... io pure ci vedo poco ... ma ... fece l'operazione pure/pure lui da cataratta ma non era cataratta ... no/non riuscì a: non riuscì bene no ... guarda un po' se c'è a moça là Melissa

Doc va bene signora $\mathrm{XX}$ la ringrazio molto ... grazie

385 L1 di che?

Doc da/dall'attenzione ... grazie

L1 la pensione di mio marito dà per vivere ... mais o meno bene ... perché c'ho anche quella italiana ... quell'italiana è venuta perché lui ha fatto dodici anni di/di ... guerra neh ... guerra e prigionia neh ... guerra e prigionia ... ma non ... a me m'è venuta sessanta per cento ... non viene intera quell'italiana no

Doc ma per lei basta no?

L1 no ... ma questa del Brasile è mais o meno buona dà per aiutare un pochino loro ... ora pra Melissa ho fatto tutto io

395 Doc uhn uhn va bene

L1 sono stata poi in:... in Recife ora ultimamente neh

Doc per quanto tempo?

L1 sono stata là dicessette giorni

Doc ah

400 L1 l'acqua non vuol caffè? 


\section{Análise das interferências:}

\subsection{Empréstimos totais:}

32 - fatto il corso di/di/di di:/ta/cor/di ... taglio e/e confezione: onde a entrevistada estava para dizer corte, mas fez a autocorreção imediatamente, quanto a taglio e confezione. Os esclarecimentos encontram-se nas observações após as análises.

41 - bisognava avere prima ginásio

50 - ho fatto solo: i/il ginásio neh a quel tempo

52 - che sarebbe equival/equivale al ginásio

$\mathrm{Na}$ realidade parece que ela freqüentou a "scuola di avviamento". Não foi utilizado o vocábulo ginnasio em italiano devido à sua pronúncia e por considerar que a entrevistada referia-se ao significado que o vocábulo tem em português, ou seja, ginásio corresponderia às $5^{\underline{a}}, 6^{\underline{a}}, 7^{\underline{a}}$ e $8^{\underline{a}}$ séries do primeiro grau conforme linhas:

50-51 - sarebbe stato ... pri/il la quinta ... la sesta ... poi si faceva la sesta la settima e l'ottava ...

151-152 - la facciamo finita con questo ... namoro perché non/non non c'è verso ... : ela poderia dizer: con questo amore, con questa relazione, con questo legame ou con questo fidanzamento.

A entrevistada entende que a palavra é mais carinhosa que o fidanzamento, mencionado na linha:

138 - ero fidanzata al primo tempo ...

195 - la casetta a gente non ha piaciuto: enquanto em português esta expressão refere-se "a nós", em italiano indica os outros. Frase muito incorreta: a noi non è piaciuta.

238-239 - c'era una rivendita di ma/di carro: indecisa, queria dizer macchine. Como em italiano se usa o plural, isto talvez tenha gerado a dúvida, mas acabou optando pelo empréstimo total da palavra portuguesa carro.

277 - che c'è quel prédio bianco: em italiano, edificio.

324 - chefe da/dalla manutenzione: em italiano capo. A hesitação da/dalla talvez signifique a sua percepção de que tenha errado a preposição: correta, della.

345 - a lottare con il câncer ... quattro anni: cancro em italiano. 
371 - andavo a finire in qualche poste ... in qualche poste della luce: em vez de palo per l'elettricità ou palo della luce.

383 - guarda un po' se c'è a moça là: em italiano, la ragazza.

\subsection{Empréstimos Parciais:}

368-369 - aveva comprato un Jeep neh ... aveva comprato un Jeep e: diceva che potevo imparare neh ... sul Jeep.

Jeep, um modelo de carro, masculino em português, no entanto feminino invariável em italiano, logo, tanto o artigo indeterminado como a preposição deveriam ser usados no feminino: una Jeep e sulla Jeep.

\subsection{Comutações:}

290 - re/reali - do português real/reais, unidade monetária brasileira, com o morfema -i da língua italiana designando plural.

378 - ha fatto quattro cirurgie - do português cirurgias, com a desinência italiana que indica o plural feminino -e. O uso correto é operazioni chirurgiche. Caso a entrevistada tenha-se baseado na palavra italiana chirurgia, a mesma está dicionarizada como: Branca della medicina che utilizza atti operatori e si avvale di tecniche manuali o strumentali di intervento cruento per la terapia de malattie altrimenti non curabili (lo Zingarelli).

\subsection{Mudanças de Significado: - $\varnothing$}

\subsection{Decalques:}

72 - vedere e stare a/a faccia di tutto neh. Em português seria a frente de tudo e, em italiano, a capo di tutto, attenta a tutto.

93 - stabelecimento do português estabelecimento. Em italiano, stabilimento, porém não caberia o uso na frase em que foi usada a palavra stabelecimento, pois seria qui all'edificio ou alla costruzione (al mulino).

168 - venti: un do português vinte e um em vez do correto em italiano, ventuno.

245 - passarella ... lo sa che c'è una passarella qui per andare a Santo André: do português passarela, em italiano, passerella. 
275 - un bel sobradino - sobrado, em português, acrescido da desinência de diminutivo -ino. Em geral, casa com dois pavimentos: térreo e superior. Em italiano poderia ser chamado de una casetta, una villetta. Podemos considerar como um empréstimo adaptado.

398 - sono stata là dicessete giorni: do português dezessete, em italiano, diciassette.

\subsection{Verbos:}

34 - e: tem questo/diploma mio - usa o verbo ter em vez do verbo em italiano esserci: c'è questo diploma.

61 - aveva fondato la luce: aveva portato la luce.

195 - ... a gente non ha piaciuto neh non è piaciuto: primeiramente faz uso indevido do auxiliar avere, mas faz a correção logo em seguida, usando 0 auxiliar essere.

291 - la RAI l'ho fatta tirare. L'ho fatta togliere

294 - e l'ho fatta tirare quella là: poderia ter sido dito em outras palavras: ho fatto cancellare l'abbonamento alla RAI ou l'ho fatta togliere.

387 - la pensione di mio marito dà per vivere ... : è sufficiente. Poderia ter dito: è sufficiente per vivere ou mi basta per vivere.

393 - dá per aiutare - do português dar, ser suficiente: è sufficiente per aiutare.

Impropriedades:

62 - e pe/pena ${ }^{4}$ che è morto presto e ...: em italiano pode ter o significado de peccato, que seria a palavra a ser usada No contexto, porém, é impróprio.

64 - co/no cottolengo ${ }^{5}$ eh:... come si chiama quel/que/quell'educazione che danno $\mathrm{i} / \mathrm{i} / \mathrm{i} / \mathrm{i}:$ : i preti? A entrevistada parece ter esquecido a palavra collegio mas procura uma outra em língua italiana. Em seguida encontra a palavra e usa corretamente na linha:

73 - i: fratelli erano tutti ... in co/in collegio.

${ }^{4}$ No Zingarelli aparece como uso possível, mas não nesta frase: é una pena vederlo soffrire così.

${ }^{5} \mathrm{O}$ uso é indevido, uma vez que cottolengo significa: Istituto per minorati fisici e psichici. Ambiente con persone non molto vivaci intellettualmente. 
139-140 - e lui era in/la categoria sua era infermiere neh. Usa um empréstimo adaptado com um deslizamento de significado. Correto: funzione, qualificazione.

147 - la nave è stata decimata, frase imprópria, decimare não cabe aqui. Poder-se-ia dizer: la nave è stata silurata, morirono in molti; provavelmente do português dizimada ${ }^{6}$.

227-228 - ci aveva uma maturazione di banane ... maturava le banane: un posto dove faceva maturare le banane: tanto o substantivo maturazione quanto o verbo maturare, são vocábulos dicionarizados, porém o seu uso é impróprio no discurso, uma vez que acreditamos que a entrevistada se referia a um depósito onde a fruta amadurecia. Porém não foi identificado o correspondente em italiano.

238 - una entrata che si chiama Jardim Paraíso: do português uma entrada: lugar por onde se entra. Em italiano entrata é o ingresso ou o particípio passado do verbo entrare. Não se aplica ao que a entrevistada quis dizer. O mais correto seria un passaggio, un'apertura, una stradina.

\section{Preposições:}

37 - sta na tua casa: nella tua casa.

100 - na mia sala è grande: artigo definido la mia sala è grande.

363 - là na/Pacaembu/no Perdizes: provavelmente quis dizer no bairro Pacaembu no bairro Perdizes. Em italiano, com bairro: rione ou quartiere, normalmente é usada a preposição a. Assim, provavelmente o que queria dizer é al Pacaembu/a Perdizes.

383 - da cataratta na non era cataratta: o correto seria a preposição di com o artigo definido la: della cataratta.

394 - ora pra Melissa ho fatto tutto io: per Melissa ho fatto tutto io.

\section{Advérbios:}

57 - c'è il quadro ali:

79 - e ali era un: posto

\footnotetext{
${ }^{6} \mathrm{O}$ verbo dizimar está dicionarizado como: p.ext. provocar a morte em massa (de grande número de pessoas) - Dicionario Houaiss da Língua Portuguesa.

Em italiano, decimare era uma palavra tristemente conhecida em tempos de guerra, significava eliminar uma em cada dez pessoas que se encontravam em um determinado lugar. Como aqui, não é o caso, optamos pela impropriedade.
} 
242 - perché la casa ... ali era cômoda: o correto é lì ou là.

87 - alfine noi si aveva il grano: aqui podemos dizer que poderia ser um decalque, caso a entrevistada tenha pensado no português ao final. Porém, se pensou em usá-lo no sentido de alla fine ou infine, ambos seriam com o significado de finalmente, insomma, in conclusione.

\section{Artigos:}

57 - a nostra casa: decalque do português, quando no italiano se usa 0 artigo definido precedendo os pronomes possessivos: la nostra casa.

104 - fa/tutti la mia famiglia a mamma i fratelli: la mamma.

129 - sono andati via a notte: sono andati via la notte

\section{Pronomes:}

Mencionamos um caso, que cremos seja interessante evidenciá-lo: 305-306 - perché la mi mamma ... voleva vedere il bimbo ... e la mi mamma era un poco malacciata: em vez de usar o pronome italiano correto mia, usa o toscano $\underline{\mathrm{mi}}$.

\section{Observações:}

3 - c'è prima il supranome: em italiano cognome. Em italiano existe a palavra soprannome, porém há um outro significado: apelido.

32 - ho fatto il corso di/di/di di:taglio e confezione 42 - si poteva andare a fare il corso ... taglio e confezione: em português, o correto seria corte e costura, já em italiano é taglio e cucito.

125 - tutto di tutto le piantazioni: este caso poder-se-ia chamar de uma toscanização fonética de uma palavra que ela não conhecia no ambiente em que viveu. Ela, de fato, logo em seguida corrige: gli orti neh ... O termo usado pelo entrevistador - piantagione $^{7}$ - também não caberia na pergunta.

\footnotetext{
${ }^{7}$ No Vocabolario della Língua Italiana di Nicola Zingarelli significa: 1 - (raro) Lavoro del piantare, del mettere a dimora piante arboree.

2 - Área de terreno occupata da piante della stessa specie: $p$. di caffè, di tabacco. Azienda agricola caratterizzata di grande estensione e monocultura, tipica delle regioni tropicali.
} 
139 - in/la categoria sua era infermiere: poderia ter apenas dito que lui era infermiere, mas como quis mencionar a categoria, isto é, a função - la funzione - teria sido melhor dizer simplesmente era infermiere. É evidente que a entrevistada não tem familiaridade com a linguagem militar (147).

180 - come si chiama sul por/sul porto: indecisa quanto à palavra que deveria usar, manteve a mesma, talvez por esquecimento. $O$ correto seria sul ponte, que é usado logo em seguida na linha:

183-184: e si teneva sul ponte della nave.

264 - non c'era quelle macchine per fare suliati: do português chuleados, um empréstimo italianizado, quando em italiano dever-se-ia dizer rifiniture ou sopraffili.

271 - hanno spaccato tutto il vitrô: forma homofona do francês vitraux. Largamente e popularmente usada em português, não dicionarizada em nenhuma das duas línguas. Em italiano, conforme as dimensões, poder-seia usar: vetrata, invetriata.

290 - la mamma era un poco malacciata: em italiano não existe este lema. Se não é um regionalismo toscano, acreditamos que tenha querido dizer ammalazzata, em português, adoentada.

Citações (nomes de ruas):

198-200 - via Don João quinto alla Lapa via Don João quinto - usa via em italiano, mas mantém o nome da rua em português.

276-277 - nella Avenida Redenzione - mantém avenida em português, mas italianiza o nome próprio Redenção.

\section{Comentários:}

1 - Aqui a entrevistada mantém-se preocupada com o entendimento do entrevistador. Podemos observar nas linhas:

176 - ...ceci ... come si chiama qui cece Melissa ((a neta))?

177 - Doc: grão-de-bico

178 - L1 : grão-de-bico eh

2 - O uso de expressões com um empréstimo parcial do português, também é interessante mencionar: 
387 - dá per vivere ... mais o meno bene ... : più o meno bene

393 - ma questa del Brasile è mais o meno buona: do português, mais ou menos, quando em italiano é più o meno.

360-361 - che lei è stata in Italia ora a poco ... : da expressão portuguesa agora há pouco. Se a entrevistada queria dizer que a amiga esteve na Itália há pouco tempo deveria ter dito è stata in Italia poco tempo fa ou simplesmente poco fa. Se queria dizer que retornou da Itália há pouco tempo, deveria dizer: è stata in Italia ed è da poco ritornata, o ed è ora ritornata, o ed è ritornata poco fa.

373 - ... nossa ha fatto ... una vita ...: interjeição portuguesa cuja forma completa é Minha Nossa Senhora! ou Minha Nossa! ou ainda Nossa Senhora! que finalmente no discurso popular se reduz a uma só palavra Nossa! É a correspondente em italiano de Madonna mia! ou Madonna santa! ou simplesmente Madonna!

3 - Perguntada pelo entrevistador (16) la regione e la città di provenienza, a entrevistada usa a palavra regione não no sentido de Geografia Política, mas no sentido mais geral:

17-18 - la regione: è: la regione è Lucca neh? ... la provincia è Lucca neh ... e: la:: :nostro paese è Bagni di Lucca neh.

Quando se refere à cidade na qual morou no Brasil, ela aplica seus conhecimentos administrativos indevidamente:

237 - era provincia di Santo André.

4 - Justamente por ser a entrevistada com a idade mais avançada, nota-se que se sentiu não só à vontade em usar a língua italiana, mas demonstrou alegria em fazê-lo e não se preocupou com o modo de expressar-se, pois o mais importante, para ela, no momento da entrevista, era ter com quem se comunicar em língua italiana e poder não só recordar como dividir essas lembranças e pouquissimas vezes teve lapso de memória. 
Tabela no 1 - Empréstimos Totais

\begin{tabular}{|l|l|}
\hline \multicolumn{1}{|c|}{ Português } & \multicolumn{1}{c|}{ Italiano } \\
\hline ginásio (três vezes) & corso di avviamento \\
\hline namoro & legame/fidanzamento \\
\hline a gente & a noi \\
\hline carro & macchine \\
\hline prédio & edificio \\
\hline chefe & capo \\
\hline câncer & cancro \\
\hline poste (duas vezes) & palo per l'elettricità/palo della luce \\
\hline a moça & la ragazza \\
\hline
\end{tabular}

Tabela no 2 - Empréstimos Parciais

\begin{tabular}{|l|l|l|}
\hline \multicolumn{1}{|c|}{ Forma apresentada } & \multicolumn{1}{c|}{ Português correto } & \multicolumn{1}{c|}{ Italiano correto } \\
\hline un Jeep (2 vezes) & um Jeep & una Jeep \\
\hline sul Jeep & no Jeep & sulla Jeep \\
\hline
\end{tabular}

Tabela no 3 - Comutações

\begin{tabular}{|l|l|l|}
\hline \multicolumn{1}{|c|}{ Forma apresentada } & \multicolumn{1}{c|}{ Português correto } & \multicolumn{1}{c|}{ Italiano correto } \\
\hline reali & reais & reais \\
\hline cirurgie & cirurgias & operazioni chirurgiche \\
\hline
\end{tabular}

Tabela no 4 - Decalques

\begin{tabular}{|l|l|l|}
\hline \multicolumn{1}{|c|}{ Forma apresentada } & \multicolumn{1}{c|}{ Português correto } & \multicolumn{1}{c|}{ Italiano correto } \\
\hline a faccia di tutto & a frente de tudo & a capo di tutto/attenta a tutto \\
\hline stabilimento & estabelecimento & qui all'edificio \\
\hline venti: un & vinte e um & ventuno \\
\hline passarella & passarela & passerella \\
\hline sobradino & sobradinho & casetta/villetta \\
\hline dicessete & dezessette & diciassette \\
\hline
\end{tabular}


Tabela no 5 - Verbos

\begin{tabular}{|l|l|l|}
\hline \multicolumn{1}{|c|}{ Forma apresentada } & \multicolumn{1}{c|}{ Português correto } & \multicolumn{1}{c|}{ Italiano correto } \\
\hline tem & tem & c'è \\
\hline tirare & retirar/cancelar & togliere \\
\hline dá (duas vezes) & dá & è sufficiente \\
\hline fondato & instalado/implantado & portato \\
\hline ha piaciuto & agradou & è piaciuto \\
\hline
\end{tabular}

Gráfico das Principais Interferências (I-2)

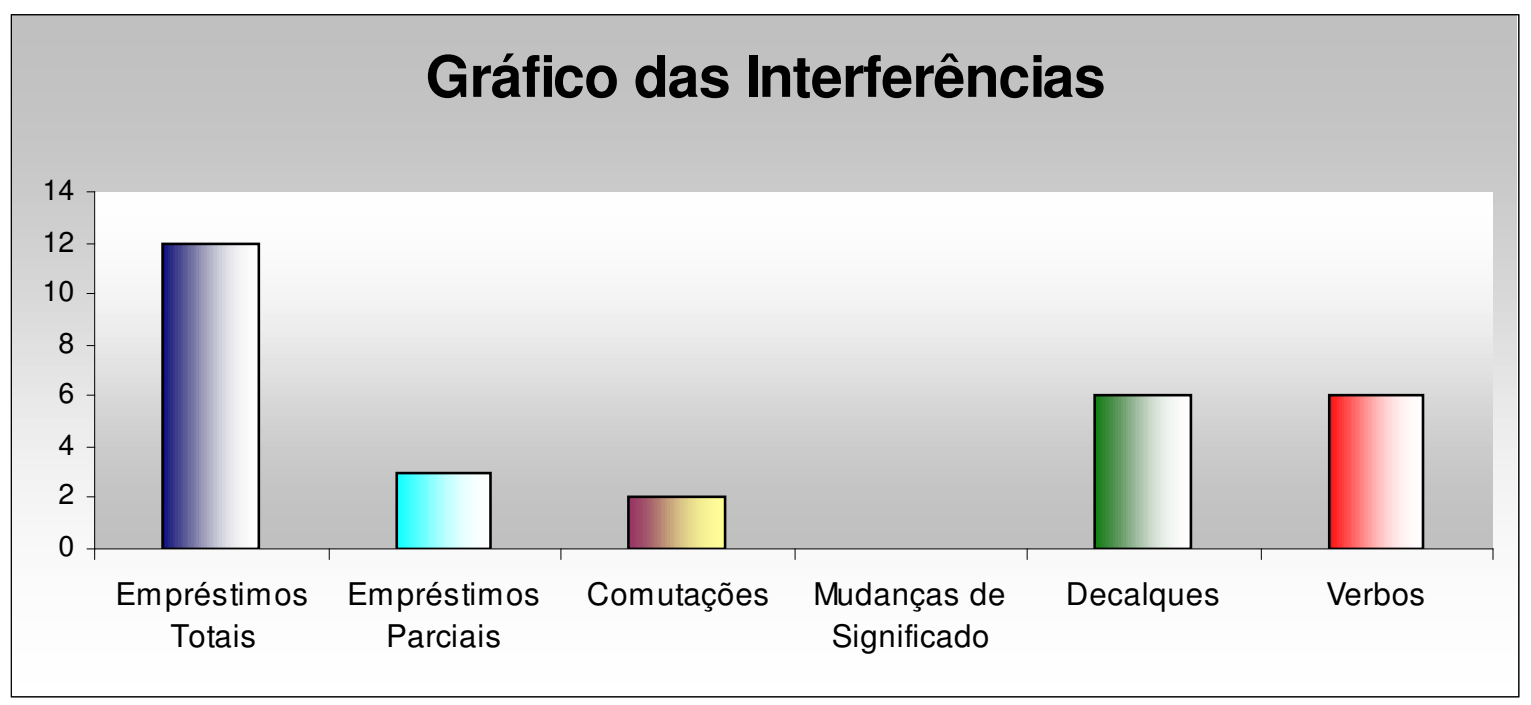




\section{INQUÉRITO № 3 (I-3)}

Sexo: Masculino

Data de Nascimento: 06/12/1947

Idade: 59 anos

Cidade: Fontechiari

Província: Frosinone

Região de Proveniência: Lazio

Profissão: empresário

Entrevista realizada em: dezembro/2006

1 Doc il suo nome e cognome

L1 XXX X XX

Doc la sua età?

L1 cinquantanove anni

5 Doc professione?

L1 commerciante

Doc regione di Provenienza

L1 è: ... Fontechiare provincia di Frosinone

Doc Frosinone ... e come si ricorda il suo paese la sua città ... era una 10 città di campagna?

L1 sì una città di campagna ... di: lavoro e: di ... e: di: ... come si può dire? di: campagna di: ... animali ... questo mio padre faceva questo lavoro di/di campagna

Doc e: quali sono i suoi ricordi della guerra?

15 L1 io non mi ricordo ... quasi niente perché ho nato in quarantassette

Doc ah dopo la guerra

L1 dopo la guerra

Doc certo ... e perché ha lasciato il suo paese?

L1 perché ci avevo un fratello che abitava qua in Brasile ... e m'ha fatto

20 una richiesta ... per venire ... ․ㅡ cinquantanove ... qua in Brasile

Doc e in quale mese è partito? 
L1 è: ... ottobre di: ... quaran/cinquantanove

Doc racconta un po' del viaggio quello che lei si ricorda nome della nave delle persone eccetera

25 L1 sì sì mi ricordo che la nave è Anna $C$ è una:/una na/una nave italiana neh... molto grande per/per l'epoca che abbiamo venuto ... e è stato un viaggio ... ma: buono ... è: solo ... forse ... tutti quanti i bambini che eran in/in nave ... ah nel stretto di Gibilterra ... quasi tutti si/si sentivano male neh ... e quello là che è stato solo il/il disturbio per la viagge il resto è stato un: ... maraviglioso

Doc e con chi lei è venuto?

L1 io ho venuto con mio padre ... mia madre e mio fratello Giovanni

Doc Giovanni uhn uhn quanto tempo di viaggio?

L1 se nun/se non mi ... dimentico: forse è stato undici ...o dodici... giorni

35 Doc già era troppo veloce ... e com'stato l'arrivo?

L1 bene abbiamo: arrivato al porto di:... prima al porto di Rio de Janeiro dopo ... porto di Santos

Doc all'arrivo è venuto subito a São Bernardo o ... è restato a São Paulo o ad un'altra città prima?

40 L1 no prima noi abbiamo andato a abitare in/na Penha a: ... un comune qua ... vicino: a São Paulo

Doc e quando lei è venuto a São Bernardo?

L1 abbiamo ven/dopo di cinque anni abbiamo venuto a São Bernardo

Doc e le è piaciuta la città?

45 L1 sì qua a São Bernardo era ... molto meglio che ... dove abitavamo prima

Doc e cosa le è piaciuto di più?

L1 ah che era un/un paesetto ... più in disinvolvimento dove ci sono tutte le/le industrie qua c'era la Ford ... la Mercedes ... la Volkswagen ... dove c'era più progresso ... è: di quell'altra città ... quell'altro ... comune

Doc e: ... lei ha lavorato subito/appena arrivato già ha lavorato qui a São Bernardo ha trovato lavoro?

L1 no io ho studiato un anno ho andato alla scuola dopo ... un mio padre non c'aveva tanta: a possibilità e io ... è: dovuto a lavorare non per forza di: ... ma più per la volontà di: di vincere neh $\mathrm{e}$... ho cominciato a lavorare di: ... officina meccanica e a fino adesso faccio ... questo lavoro 
Doc raccontami un po' di questo lavoro a São Bernardo quanti anni lei aveva ... dove lavorava

L1 prima quando abbiamo venuto qua ... a São Bernardo io ... eh ho: e: ho cominciato a lavorare alla Chrysler ... ho lavorato due anni alla Chrysler neh ... dopo della Chrysler a: sono andato a lavorare in São Paulo ... e nu/officina meccanica ... e dopo questo in settantadue

65 ... settanta/settantadue abbiamo aperto ... un'officina nostra io e mio fratello

Doc quale fratello?

L1 Gio/Giovanni

70

Doc Giovanni per quanto tempo lei ha lavorato in questa officina o se ancora lavora

L1 ancora fino a oggi sempre è stato quest/quest'officina

Doc è qua a São Bernardo?

L1 no adesso è stato trent'anni qua a São Bernardo e adesso fanno... quattro anni che stiamo in Santo André

75 Doc ah va bene ... ahn: cosa lei ha studiato in Italia?

L1 ho fatto fino alla quinta ... elementare

Doc e qui quando lei è arrivato che mi ha detto che ha studiato un anno

L1 quando ho cominciato qua ho cominciato in/nella quarta... nel quarto anno

80 Doc uhn

L1 dopo non ho studiato più ... io ho fatto un po' di musica ... faceva/ studiava la musica

Doc va bene ... lei ha studiato un anno prima di lavorare

L1 sì

85 Doc e ancora ... pratica la musica?

L1 ma io c'aveva una fisarmonica neh ... dopo che mio padre ha visto che io non ... non c'aveva tanta volontà l'ha/l'ha venduta ((risos))

Doc va bene eh: allora ... lei ha occasione di parlare la lingua italiana?

L1 sì alle volte c'è... sono delle amiche eh mas molto poco ... eh normalmente parliamo in brasilia/in portoghese

Doc tá in casa anche non parla in ita/

L1 no/no ... uhn non ci ho l'abitudine di parlare in italiano

Doc [ah allora par/

L1 [poche paroletta 
95 alle volte ma ... come mia moglie è/è brasiliana e i miei figli ... non ci ho quella ehn: ... voglia di:/di stare a imparare $0 \ldots$ infine ach/ ehn:... eh come si può dire: ... non c'ho l'abitudine di/di stare a forzare i figli a parlare in italiano

Doc allora lei parla soltanto con gli amici?

100 L1 è gli amici alle volte quando mi incontro con/con qualcuno di italiano così ... e con i fratelli neh

Doc uhn uhn ... i fratelli ancora parlano

L1 sì

105 la TV o soltanto quando:

L1 a me ... mi piace molto vedere la tv ... la RAl neh che passano tutti $\mathrm{i}$ giorni ... e alle volte qualche giornale ... qualche rivista

Doc e solo per praticare soltanto questo ... TV rivista e incontri con i fratelli e con gli amici ... va bene è: è già tornato in Italia

110 L1 [sì una volta

Doc [quante volte?

L1 una volta solo

Doc e per quanto tempo adesso lei mi racconta quanto tempo è stato lì

L1 è stato trenta giorni

115 Doc uhn solo nella sua regione?

L1 solo/solo son stato solo no/nella bassa Italia ... era per andare in alta Italia ma dopo ... non/non ci aveva più tempo era il tempo era poco allora... non/non ci sono andato

Doc le è piaciuto?

120 L1 sì mi è piaciuto è: un altro modo di/di vivere neh gli italiani ... ma ... sto bene/sto bene qua in Brasile ... non ci ho voglia di

Doc tá adesso raccontami un po' di questo viaggio... che cosa/lei è andato da solo?

L1 no sono stato io e/e mio fratello Giuseppe

125 Doc ah raccontami un po' di come è stato questo viaggio... cosa avete visto ... fatto ... con chi avete parlato

L1 eh: bom siamo andato di aereo neh e:... ho:... eh:... sono stato a Roma sono stato in/in Vaticano là: abbiamo andato a ... a Napoli ... è: Isola Lire ... eh abbiamo andato là in Pisa nella Torre di Pisa ... e i 130 parenti: visitati tutti i parenti ... infine ... è stato trenta giorni num/num dà per andare molto in molti: posti neh ... ma è stato un bel viaggio mi è piaciuto 
Doc lei ha ancora molti parenti in Italia?

L1 sì abbiamo ... i cugini neh ... e i zii già sono morti ... ma ci sono 135 bastante cugini c'ho le mie nipoti che mia sorella ... abitava neh adesso è morta fa tempo che ... si è morta ... e c'è mio cognato ... e i miei cugini ... con i figli e ... i parenti più... più anziani già sono ... andati tutti venuto a passeggiare

L1 sì/sì è venuto un/c'ho mio cognato è venuto ... una volta ... eh: solo $\mathrm{i}$ : miei ... cugini che no ma mio cognato è venuto una volta ... mio fratello ci va sempre in Italia neh Giuseppe va sempre ... e ma ... i parenti così che stanno anche altri parenti che stanno fuori stanno 145 negli Stati Uniti stanno ... in Venezuela ... Canada ... questi noi non ne abbiamo visto più

Doc loro non mant/voi non mantenete contatto

L1 sì alle volte si telefona neh ma ... carte così o viaggio ... non ci falt/ non ci manca volontà ma ... non ci ha avuto possibilità e allora non/non ci siamo andati

Doc e questi che sono in altri paesi voi vi comunicate ancora in italiano?

L1 sì quando si parla in italia/si parla in italiano

Doc ah va bene ... e lei pensa di andare un'altra volta ha qualche progetto L1 sì sì... quasi sempre si uno pensa di andare ma ... sempre ci mancano i soldi allora ... sta zitto neh

Doc ah va bene ... raccontami un po' della sua infanzia perché lei è venuto con quattordici anni

L1 tredici anni

Doc tredici anni ...cosa se ne la ricorda di questo periodo?

L1 bom uhn

Doc come era la vita?

L1 la vita era buona e mio padre lavorava fuori... lavorava in Francia neh in questo tempo ... e: e mia madre ... faceva la contadina neh in Italia ... e scuola è: scherzi ... e: e: ... solo non si viaggiava come si viaggia 165 oggi ... si va a spiaggia là non c'era spiaggia vicino ... montagna:... eh: ... scherzi di/da/da ragazzini ... solo... non c'è molto di raccontare di questa

Doc e suo padre e la sua madre parlavano qualcosa sulla guerra? [com'è stata?

170 L1 [sì sì 
Doc nella sua regione

L1 sì mio padre lui è: fatto la guerra del trentacinque al quarantacinque ... parlava molto di/della vita che ... in/incluso mio zio Pasquale che ... sono renovato io è ... è morto in guerra neh ... e: mio pai/mio padre 175 parlava sempre della guerra ... gli amici venivano a casa ... di/di questi amici che lui conosceva neh ... e sempre si parlava della guerra neh

Doc va bene eh: lei si è sposato qui in Brasile in che anno?

L1 mi è sposato in settantaquattro

180 Doc settantaquattro... ha quanti figli?

L1 tre figli

Doc tre figli ... e loro parlano italiano?

L1 no no ... solo Daniela che ha fatto ... un corso neh ... e: ma gli altri non ... ci hanno ... volontà ( )

185 Doc e i figli già son andati in Italia?

L1 [no ... nessuno

Doc [nessuno

L1 solo Daniela ci è andata

Doc già è stata un po' di tempo

190 L1 Daniela ... Daniela ... la più vecchia è stata là in Italia

Doc ah va bene ... allora la ringrazio

L1 grazie

\section{Análise das interferências:}

\subsection{Empréstimos totais:}

28-30 - nel stretto di Gibilterra ... quasi tutti si/si sentivano male neh ... e quello là che è stato solo il/il disturbio per la viagge il resto è stato un: maraviglioso: disturbio em português, unidade lexical muito próxima a disturbo, em italiano, e com a mesma função designativa.

48 - ah che era un/un paesetto ... più in disinvolvimento: do português desenvolvimento, em italiano sviluppo. Poderia dizer: un paesetto ... in pieno sviluppo. 
134-135 - ma ci sono bastante cugini c'ho le mie nipoti che mia sorella ...: em italiano, abbastanza, molti, numerosi, diversi.

127 - eh bom siamo andato di aereo neh

160 - bom uhn. Em ambos os casos, usa bom não como um adjetivo, mas sim como um marcador. Correspondente em italiano, bene.

174 - e: mio pai/mio padre. O entrevistado se confunde e usa o vocábulo pai em português, mas imediatamente se autocorrige: mio padre.

\subsection{Empréstimos parciais:}

78-79 - ho cominciato in/nella quarta ... nel quarto anno: provavelmente se recorda que em italiano é a quarta elementare, mas confunde-se, pois freqüentou a escola no Brasil quando o ensino básico (primário) era composto por quatro anos: do primeiro ao quarto ano. Classificado como empréstimo parcial, pois usa a preposição italiana nel e pronuncia em italiano o vocábulo anno.

\subsection{Comutações:}

28-30 - nel stretto di Gibilterra ... quasi tutti si/si sentivano male neh ... e quello là che è stato solo il/il disturbio per la viagge il resto è stato un: maraviglioso: la viagge, em português, vocábulo feminino, a viagem, com a transferência de morfemas da língua italiana. Em italiano il viaggio.

\subsection{Mudanças de Significado:}

148 - sì alle volte si telefona neh ma ... carte così o viaggio: do português cartas, na língua italiana, lettere. Poderia também ser classificado como decalque, caso o entrevistado tenha partido do modelo português e usado o morfema de número em italiano -e, ou como uma impropriedade, mas optamos por esta classificação, uma vez que a palavra é dicionarizada com diversos significados, mas nenhum corresponde ao que o entrevistado queria dizer.

\subsection{Decalques: $-\varnothing$}

\subsection{Verbos:}

Frequentemente usa o auxiliar avere em substituição ao auxiliar essere: 
15 - ... quasi niente perché ho nato in quarantassette

26 - molto grande per l'epoca che abbiamo venuto ...

32 - io ho venuto con mio padre ...

36 - bene abbiamo arrivato al porto di: ...

40 - no prima noi abbiamo andato a abitare in/na Penha a: ...

43 - abbiamo ven/dopo di cinque anni abbiamo venuto a São Bernardo

54 - no io ho studiato un anno ho andato alla scuola dopo ...

61 - prima quando abbiamo venuto qua ... a São Bernardo io ...

128 - sono stato in/in Vaticano là: abbiamo andato a ... a Napoli ...

129 - eh abbiamo andato là in Pisa nella Torre di Pisa ...

No entanto, quase no final da entrevista, começa a recordar-se e a utilizar os auxiliares de modo correto:

114 - è stato trenta giorni : sono stato trenta giorni.

118 - ... non/non ci sono andato

125 - no sono stato io e/e mio fratello Giuseppe

127 - bom siamo andato di aereo neh e: ...sono stato a Roma

128 - sono stato in/in Vaticano là:

141 - sì/sì è venuto un/c'ho mio cognato è venuto ... una volta ...

150 - non/non ci siamo andati

188 - solo Daniela ci è andata

190 - ... la più vecchia è stata là in Italia

Notamos, ainda, alguns usos indevidos dos verbos:

55 - non c'aveva tanta: a possibilità e io ... è dovuto a lavorare: correto, sono dovuto andare a lavorare.

74-75 - e adesso fanno ... quattro anni che stiamo in Santo André : o melhor seria dizer: e adesso sono quattro anni che abitiamo a Santo André.

96 - ... voglia di:/di stare a imparare $0 \ldots$ infine ach/: provavelmente queria dizer: infine credo che ou penso che, percebe a tempo o uso do verbo em português acho, faz uma interrupção abrupta, continuando imediatamente 0 seu discurso.

106-107 - la RAI neh che passano tutti i giorni ...: neste caso, diríamos: la RAI che trasmette tutti i giorni, ou ainda, la RAI che va in onda tutti i giorni

131 - num/num dá per andare molto in molti: posti neh ... : em português, 0 verbo dar com a negação possui o significado de não é possivel, não se pode, porém em italiano deve ser usado: non si può andare molto in molti : 
posti neh... ou ainda non si ha la possibilità di andare molto in molti: posti neh ...

136 - adesso è morta fa tempo che ... si è morta, uso correto: è morta.

148-149 - non ci falt/ non ci manca volontà ma ... o entrevistado estava para dizer o verbo em português falta, mas fez a correção imediatamente após: non ci manca volontà.

172 - sì mio padre lui è: fatto la guerra del trentacinque al quarantacinque .... o entrevistado se confunde e usa o auxiliar essere, quando deveria ter usado: sì mio padre lui ha fatto la guerra.

173-174 - in/incluso mio zio Pasquale che ... sono renovato io è ... : a frase está totalmente incorreta. Provavelmente queria dizer que seu nome é em homenagem ao tio: io rinnovo il suo nome.

179 - mi è sposato in settantaquattro, deveria ter dito mi sono sposato nel settantaquattro.

\section{Preposições:}

15 - quasi niente perché ho nato in quarantassette

20 - ... per venire .. in cinquantanove ... qua in Brasile.

63 - ... e dopo questo in settantadue

O modo mais usual para referir-se a um ano é com a preposição articulada nel, assim, em todos os casos deveria tê-la usado. Provavelmente se confunde por usar habitualmente a preposição em no português.

28 - ah nel stretto di Gibilterra ... O encontro consonantal st de stretto pede o artigo definido lo que unido à preposição in forma a preposição articulada nello stretto di Gibilterra ...

63-64 - sono andato a lavorare in São Paulo ... e nu/officina meccanica: provavelmente queria dizer numa, ou seja, em uma, mas imediatamente interrompe a comunicação e omite tanto a preposição quanto 0 artigo indefinido italianos: in una.

74 - quattro anni che stiamo in Santo André, correto a Santo André.

127 - eh: bom siamo andato di aereo neh: em italiano a preposição é in aereo, diferente do português de avião.

166 - non c'è molto di raccontare: para este caso a preposição a ser usada é da raccontare. 
172 - lui è: fatto la guerra del trentacinque al quarantacinque: a preposição é dal trentacinque al quarantacinque.

\section{Advérbios:}

57-58 - ... officina meccanica e a fino adesso faccio ... questo lavoro, correto finora.

\section{Artigos:}

55 - non c'aveva tanta: a possibilità e io ... è dovuto a lavorare: em italiano, la possibilità.

\section{Conjunção:}

89 - ... sono delle amiche eh mas molto poco ...: em italiano, $\underline{\text { ma }}$, però.

\section{Observações:}

1 - Perguntado pelo entrevistador (7) la regione di provenienza, "regione amministrativa", ele responde como "regione geografica":

8 - è: ... Fontechiari provincia di Frosinone

2 - 19-20 - perché ci avevo un fratello che abitava qua in Brasile ... e m'ha fatto una richiesta ... per venire. Como o seu irmão já trabalhava no Brasil, acreditamos que queria dizer mi ha chiesto per venire ou m'ha fatto una chiamata per venire.

\section{Comentários:}

1 - Podemos classificar as frases em que aparecem come si può dire uma tentativa de recordar as palavras que quer usar, como podemos observar: 11-12 - sì una città di campagna ... di: lavoro e: di ... e: di: ... come si può dire? di campagna di: animali ... 97-98 - ehn:... eh come si può dire: ... non c'ho l'abitudine di/di stare a forzare i figli a parlare in italiano 
2 - O nível de discurso deste entrevistado é inferior aos outros transcritos, seja pela propriedade lexical quanto pela gramatical.

Tabela no 1 - Empréstimos Totais

\begin{tabular}{|l|l|}
\hline \multicolumn{1}{|c|}{ Português } & \multicolumn{1}{c|}{ Italiano } \\
\hline distúrbio & disturbo \\
\hline disinvolvimento & sviluppo \\
\hline bastante & abbastanza/numerosi/diversi \\
\hline bom (duas vezes) & bene \\
\hline pai & padre \\
\hline
\end{tabular}

Tabela no 2 - Empréstimos Parciais

\begin{tabular}{|l|l|l|}
\hline \multicolumn{1}{|c|}{ Forma apresentada } & Português correto & Italiano correto \\
\hline nel quarto anno & no quarto ano & la quarta elementare \\
\hline
\end{tabular}

Tabela no 3 - Comutações

\begin{tabular}{|l|l|l|}
\hline \multicolumn{1}{|c|}{ Forma apresentada } & \multicolumn{1}{c|}{ Português correto } & Italiano correto \\
\hline la viagge & a viagem & il viaggio \\
\hline
\end{tabular}

Tabela no 4 - Mudanças de Significado

\begin{tabular}{|l|l|l|}
\hline \multicolumn{1}{|c|}{ Forma apresentada } & \multicolumn{1}{|c|}{ Português correto } & \multicolumn{1}{c|}{ Italiano correto } \\
\hline carte & cartas & lettere \\
\hline
\end{tabular}

Tabela no 6 - Verbos

\begin{tabular}{|l|l|l|}
\hline \multicolumn{1}{|c|}{ Forma apresentada } & Português correto & \multicolumn{1}{c|}{ Italiano correto } \\
\hline ho nato & nasci & sono nato \\
\hline abbiamo venuto (4 vezes) & viemos & siamo venuti \\
\hline ho venuto & vim & siamo venuti \\
\hline abbiamo arrivato & viemos & siamo arrivati \\
\hline abbiamo andato (três vezes) & fomos & siamo andati \\
\hline ho andato & fui & sono andato \\
\hline è dovuto a lavorare & tive de ir trabalhar & $\begin{array}{l}\text { sono dovuto andare a } \\
\text { lavorare }\end{array}$ \\
\hline fanno & faz & sono \\
\hline ach/ & acho & penso che/credo che \\
\hline
\end{tabular}




\begin{tabular}{|l|l|l|}
\hline \multicolumn{1}{|c|}{ Forma apresentada } & Português correto & \multicolumn{1}{c|}{ Italiano correto } \\
\hline passano & transmite & trasmette \\
\hline num dá & não dá/não é possível & non si può \\
\hline si è morta & morreu & è morta \\
\hline falt/ & falta & manca \\
\hline è fatto & fez & ha fatto \\
\hline sono renovato & eu renovo & ho rinnovato \\
\hline mi è sposato & casei & mi sono sposato \\
\hline
\end{tabular}

\section{Gráfico das Principais Interferências (I-3)}

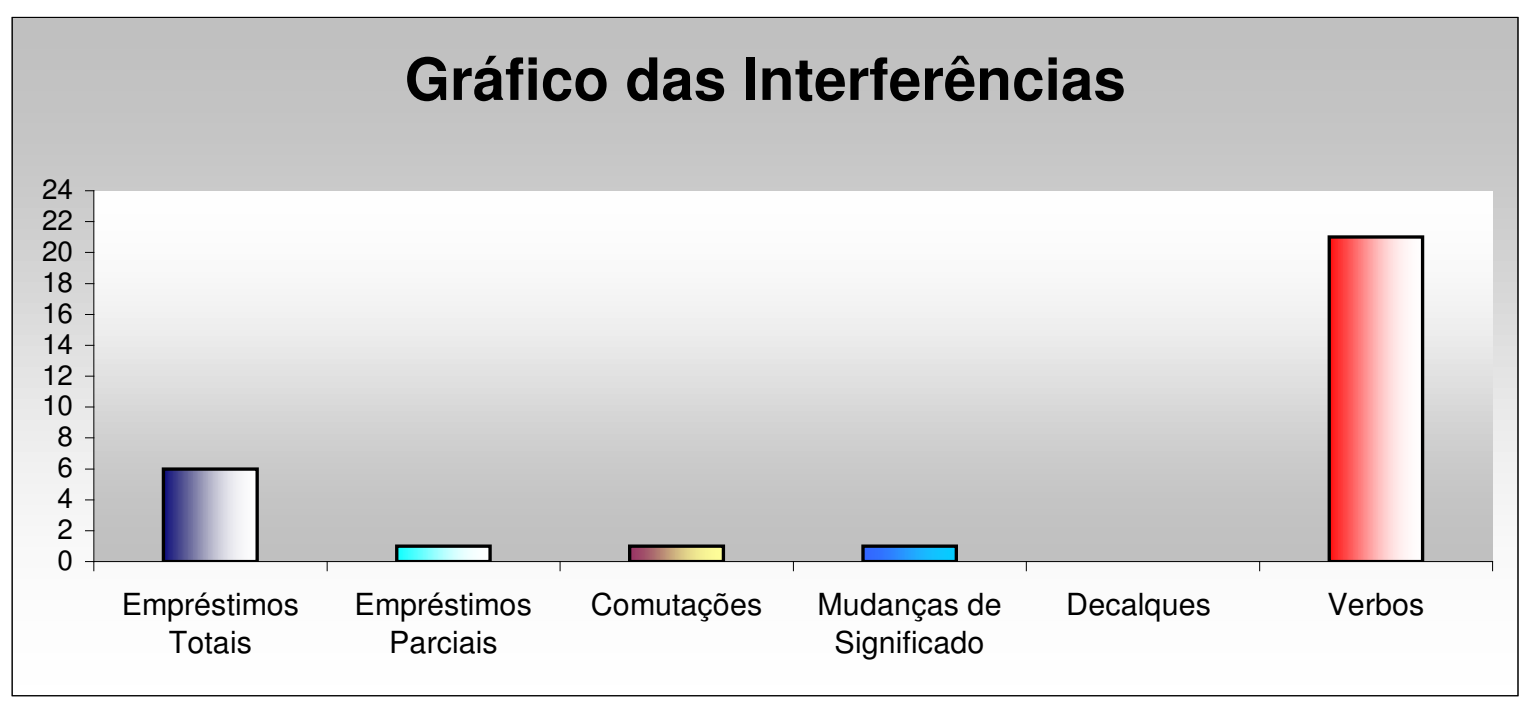




\section{INQUÉRITO № 4 (I-4)}

Sexo: Feminino

Data de nascimento: 22/08/1940

Idade: 66 anos

Cidade: Adria

Província: Rovigo

Região de proveniência: Vêneto

Profissão: do lar

Entrevista realizada em: dezembro/2006

1 Doc II suo nome e cognome

L1 XX XX XX

Doc età?

L1 sessantasei anni

5 Doc professione?

L1 casalinga

Doc ah sì ... regione e città di provenienza

L1 è:.:: nata in Adria ... provincia di Rovigo

10 campagna?

L1 era una città di campagna

Doc ahn mi parla un po' di/di quel periodo come era la città/lei è venuta con quanti anni?

L1 con tredici anni

15 Doc uhn

L1 la città era una città piccola di campagna ... eh: ...mio papà lavorava con le alleva/le mucche ... miei zii lavoravano in campagna

Doc ma già era una casa di campagna

L1 sì già era casa di campagna

20 Doc lontano dalla città?

L1 no no no no era quasi ben in centro della città 
Doc e voi avevate una proprietà ... per creare le mucche

L1 no lui/lui lavorava le mucche per il patrone per/della azienda neh

$\begin{array}{lll}\text { Doc } & \text { uhn e lei in ques } \\ 25 & \text { solo studiava }\end{array}$

Doc era lontana la scuola?

L1 no la mia non non era lontana non

Doc ahn faceva a piedi o in

L1 a piedi tutto a piedi

30 Doc uhn quanto tempo per arrivare alla scuola?

L1 ah dieci quindici minuti

Doc lei ha studiato fino:

L1 fino al/al quinta alla quinta

Doc alla quinta va bene ... quante sorelle o fratelli

35 L1 siamo in sette ... sei italiani e una brasiliana

Doc ahn e quando siete venuti in Brasile?

L1 siamo venuti con la nave che era l'ultimo viaggio che faceva che dopo si fermava in ... in Argentina

Doc uhn ... si ricorda il nome della nave?

40 L1 sì Sestriere

Doc Sestriere

L1 Sestriere

Doc quanti giorni di viaggio?

L1 ventidue giorni

45 Doc e: chi è venuto tutta la famiglia o una parte

L1 no ... la mia famiglia è venuta TUTTA la mia famiglia

Doc ma tutta in questo viaggio?

L1 la mamma il papà e noi fratelli

Doc che erano allora sei

50 L1 sei

Doc sei

L1 sei

Doc e: lei era la più vecchia la più giovane 
L1 no:: io sono la ... quarta

55 Doc la quarta quanti ragazzi e quante ragazze

L1 due fratelli ... e cinque sorelle

Doc tá e una è nata qui

L1 sì una è nata qui ... quattro/quattro sorelle italiane la brasiliana nata qui

60 Doc in che anno: siete venuti?

L1 nel cinquantadue

Doc cinquantadue ... venti giorni di viaggio

L1 ventidue giorni

Doc ventidue e siete venuti diritto a São Bernardo o ... avete abitato in 65 alcun altro posto

L1 no no siamo sbarcati in Santos ... e siamo andati: ... e siamo stati alla migrazione di Sa/di San Paolo ... e di là siamo venuti a prenderci ... quelli della fazenda ... e siamo andati tutti in fazenda a lavorare il caffè

70 Doc ma a São Paulo interior di São Paulo

L1 sempre all'interior

Doc all'interno

L1 sì ... quelle parte di Bauru da quelle parte di là

Doc quanto tempo siete stati in quella regione?

75 L1 noi siamo stati undici mesi là

Doc uhn

L1 undici mesi

Doc uhn e dopo?

80

L1 e dopo siamo venuti in São Bernardo ... porque su/sul nostro paese ... sono partiti in sei famiglie

Doc uhn

L1 e queste sei famiglie ognuna che veniva pra São Paulo che erano tutte nell' interiore ... ogni una che vinha pra São Paulo chiamava l'altra

85 Doc uhn

L1 già già trovava il lavoro ... e quando veniva su de/dell'interior/ e veniva già con lavori tutto ... abbiamo lavorato in: ... no Matarazzo 
Doc uhn ... qua a San Bernardo ?

L1 qua a San Bernardo

90 Doc vicino a via Anchieta?

L1 sì

Doc ah e facevate che cosa ... anche lei ha lavorato lì?

L1 sì ho lavorato

Doc ahn

95 L1 io la prima: fabbrica ho lavorato sulla fabbrica di/di mo/moveis ... non sapevo né parlare l'italiano ... e dopo sono passata ... a Matarazzo

Doc ahn e faceva

L1 lavorava su a fiação ... sul/sul filo

100 Doc era grande l'impresa qui no?

L1 sì

Doc peccato che non funziona più ... boh e suo padre faceva cosa ... quando siete arrivate qui? dopo di venire/

L1 mio papà faceva: faceva: ... non era proprio il guardia quelli che

105 limpava scritori ... faceva così

Doc ahn ahn ma lavorava durante la giornata

[non la sera il giorno

L1 [sì sì

no lavorava la notte

110 Doc ah la notte tá

L1 nel giorno noi avevamo un/un piccolo ... come si chiama ... una piccola/piccolo pezzo di terra ... qui in San Bernardo e papà piantava la salata tante: ... verdure come una piccola orta

Doc uhn uhn ma non era qui

115 L1 qui in San Bernardo

Doc ma non qui dove voi [abitate adesso

L1 [no no no

Doc era a:

120 L1 bom era qui na alameda Gloria qui vicino

Doc in quel periodo c'era lo spazio per fare un'orta ... molto bene ... del suo paese che cosa lei si ricorda? 
L1 ah mi ricordo quando andavo a/a/alla messa ... alla scuola ... qualche volta la mamma ci portava al cinema

125 Doc ah e non era lontano

L1 no no eu non abitavo lontano no

Doc ahn

L1 mi ricordo così ... ero piccola neh

Doc e lei ha parenti ancora in Italia

130 L1 in Italia ci ho tanti cugini ancora ... ci ho un zio ancora a Torino ... ci ho un zio ci ho parenti

Doc ma a Adria

L1 Adria c'ho un zio

Doc lei già è tornata in Italia?

135 L1 sì

Doc quante volte

L1 siamo andati tre volte

Doc uhn quando?

L1 settantacinque ... novanta otto ... e due anni indietro che è morto 140 il fratello di Livio

Doc ah tá ... ahn ahn ... e come si sente adesso quando arriva in Italia no/ la prima volta mi racconta la prima volta

L1 la prima volta è:: un spettacolo

Doc uhn

145 L1 ahn vogliamo vedere conoscere sono nata qui guarda che era così era accolà era ... bellissimo

Doc ma siete andati solo voi due o con i figli?

L1 no solo noi due ... dopo venticinque anni di Brasile

Doc suo marito era anche in viaggio

150 L1 è venuto con la nave insieme con gli altri Livio

Doc ahn

L1 Livio era amico tanto di miei fratelli là na Italia ma io non mi ricordo di Livio là na Italia ... no ... mia mamma conosceva tanto la mamma di Livio erano amiche ... Livio studiava con i miei fratelli ... ma io no/non 155 mi ricordo bene di lui là in Italia no

Doc e come vi siete incontrati qui? 
((risos))

Doc dimmi qualcosa voglio sapere la storia

L1 era tutte famiglie unite neh eravamo tante famiglie unite ... e si abbiamo conosciuti ... lui frequentava anche la mia casa por causa di miei fratelli neh ... si abbiamo conosciuti così

Doc ma qui a San Bernardo già

L1 sì sì qui a San Bernardo

Doc ah ma lei era giovanissima

165 L1 è: sì avevo: sedici anni

Doc e lui?

L1 lui/lui aveva venti .. perché ce n'ha quattro di più di me

Doc ah e vi siete sposati

L1 sì sì

170 Doc quanto tempo di namoro?

L1 quattro anni

Doc giovani ah

L1 quattro anni eh quattro anni

Doc va bene ... che bravo

175 L1 sì sì

Doc e come è stato l'arrivo a San Bernardo quando siete arrivati a San Bernardo venuti dall'interno di San Paolo come è stata l'impressione la prima impressione

L1 è: la prima impressione bom ... è stata meglio che nel/su/sulla fazenda nell'interiore neh

Doc ahn

L1 perché noi altri ci piace vedere gente vedere neh ... e: l'impressione è così che dobbiamo lavorare ... per per farsi un qualcosa neh ... per farsi un qualcosa ... miei fratelli hanno cominciato a studiare ... io/io

185 non ho studiato niente qui in Brasile non ho studiato niente ... e così si abbiamo: ... ma siamo stati contenti di San Bernardo abbiamo trovato tanta gente che ci hanno aiutato

Doc uhn

L1 figli di italiani ... neti di ital/ ci abbiamo trovato buonissima gente $190 \quad$... buonissima gente

Doc erano più uniti che no/

L1 no:ssa ... là/là tutti ci davano da mangiare con la caderneta 
Doc ah questo io mi ricordo

L1 non si/non si interessava chi eravamo chi non eravamo ... eh loro avevano tanta fiducia sopra di noi altri ... tanta fiducia

Doc è: ha cambiato tantissimo ... ta è: per parlare la lingua italiana voi parlate in italiano a casa ... o non

L1 parliamo dialetto ... il nostro dialetto veneto

Doc ah

200 L1 qui ci parliamo

Doc anche con i figli?

L1 sì ... anche con i miei neti

Doc e loro capiscono?

L1 tutto ((risos))

205 Doc e parlano o no?

L1 la/la più vecchia di Fernanda che ci ha tredici anni e mezzo quella ci risponde ma in dialetto ... perché parlo tanto il dialetto io e Livio

Doc uhn uhn

L1 noi ci parliamo tanto perché ha avuto ... io sono stata con la mia

210 suocera trentanove anni ... e lei parlava sempre il dialetto anch'io sempre:

Doc lei ha abitato con voi

L1 mia suocera sì ... trentanove anni

Doc ahn ahn ... e la più piccola parla un po' meno

215 L1 le piccole mie?

Doc è

L1 no loro non parlano tanto no

Doc uhn uhn

L1 più è la più vecchia

220 Doc [ah va bene

L1 [capisce tutto

Doc e lei ha detto che ha un figlio che parla un po' di italiano

L1 sì mio figlio più vecchio

Doc parla perché ha studiato 
$225 \mathrm{~L} 1$ no/no/no/no por causa de/de/de ... lei le piace leggere ... ci ha contatto con le italiani da Italia con i cugini di Livio

Doc uhn uhn tá ma italiano propriamente detto la lingua italiana

L1 no/no/no

Doc voi parlate quando incontrate amici

$230 \quad$ L1 $\quad$ sìsì/sì

Doc con la RAl come è?

L1 no/no noi parliamo quando si incontriamo così come con voi altri ... intende? quand/ma non parlo proprio ... diretto l'italiano come si deve neh

235 Doc ahn ahn ma ... lei parla ancora bene ((risos))

molto bene tutto questo è quello che si ricorda del periodo che ha studiato

L1 è/è

240 Doc ma quando:

L1 e tanto convivenza con gli italiani neh ... che io con Livio abbiamo sempre avuto ... con/convivenza con gli italiani ... io con Livio abbiamo sempre parlato ... ricordato le/le nostre cose là na Italia ... e così ... siamo sempre stati con le famiglie italiane

245 Doc tá ... due anni ... l'ultima volta che voi siete andati in Italia ... due anni fa

L1 sì due anni fa

Doc a: bene adesso non c'è un'altra

L1 no siamo pronti per andare un'altra volta ... aspettiamo ( ) perché $250 \quad$ Livio non può viaggiare subito neh

Doc hum hum adesso c'è un periodo neh

L1 sì sì ( ) intenzione di andare ( ) settembre ... vediamo

Doc ahn ahn ... va a prendere un mese di vacanza

L1 eh che Livio ci ha/ci ha dei negozi co/con il fratello che aveva là ... 255 quel fratello che aveva là è: vi/ ha vissuto qui trent'anni qui in Brasile ci ha negozio insieme con Livio

Doc ma in Italia?

L1 in $\underline{\text { no }}$ qui in Brasile

Doc in Brasile 
260 L1 e deve disbrigare le robe neh ... allora la cognata questa che è stata vedova ... assieme con Livio vediamo cosa che possiamo fare neh

Doc ah e Livio è che/che

[fa le cose qui

L1 [è Livio ... è Livio

265 Doc è molta cosa no

L1 no:ssa

Doc molto bene uhn ... adesso mi/mi parla un po' ... lei ha conosciuto Livio qui e come era in quel periodo per avere un rapporto ... come funzionava come era con il papà

270 L1 ah era bem: mio papà adorava Livio ... adorava Livio ... mio papà conosceva Livio ... da Italia ... ma sempre con aquele ... i giorni festivi per il namoro

Doc orario

((risos))

275 L1 orario

Doc orario di uscire e principalmente di arrivare

L1 ecco

Doc ahn

L1 andavo alla messa delle nove ... dei italiani che qui c'era la messa 280 delle nove per incontrarmi con lui ((risos)) poi lui mi menava a casa ((risos))

Doc va bene ... lei ha lavorato: quanto tempo dopo il matrimonio [ha lavorato dopo il matrimonio o no

L1 [no/no/no/no non ho più lavorato

285 Doc ahn

L1 io lavoravo só di sortera non ho più lavorato

Doc tá bene si è sposata

L1 sì mi sono sposata

Doc [fermato il lavoro

290 L1 [sì/sì/sì/sì

sono sempre stato dietro a mia famiglia mio marito i miei figli

Doc quanto tempo già di matrimonio

L1 quarantaquattro

Doc a: che bellezza 
295 L1 quarantaquattro anni ho fatto venerdì

Doc ahn

L1 quarantaquattro anni

Doc non c'è stata la messa niente?

L1 no quarantaquattro anni non ... si fa niente

300 Doc ah no la prossima messa italiana noi dobbiamo ... anche dire questo va bene XX tá la ringrazio dell'attenzione se avrò bisogno di più qualcosa

L1 va bene Sonia

Doc le chiedo tá

305 L1 va bene

Doc grazie grazie

\section{Análise das interferências:}

\subsection{Empréstimos totais:}

71 - sempre all'interior

82-83 - ognuna che veniva pra São Paulo che erano tutte nell'interiore 86 - e quando veniva su de/dell'interior/

179-180 - è stata meglio che nel/su/sulla fazenda nell'interiore

O vocábulo interior pode ser classificado como empréstimo total para substituir o equivalente em italiano all'interno, enquanto interiore, embora dicionarizado, é impróprio para o que quis dizer a entrevistada: veniva pra (fazendas di) São Paulo che erano tutte nell'interno.

95 - ho lavorato sulla fabbrica di/di mo/moveis: em italiano, mobili.

99 - lavorava su a fiação ... sul/sul filo: usa o vocábulo português, mas imediatamente se corrige: sul filo, ainda que o mais adequado seja o uso do vocábulo filatura.

120 - bom era qui na alameda Gloria 179 - è: la prima impressione bom ... è stata meglio che nel/su/sulla fazenda: usa bom não como adjetivo, mas sim como um marcador em vez de bene, em italiano.

192 - ... là/là tutti ci davano da mangiare con la caderneta : em italiano, con la tessera. 
270 - ah era bem: mio papà adorava Livio ...: usa o vocábulo como um marcador. Em italiano, bene.

272 - giorni di festa per il namoro: vocábulo não existente na língua italiana.

286 - io lavoravo só di sortera: do português, solteira, em italiano, nubile.

\subsection{Empréstimos parciais: $-\varnothing$}

\subsection{Comutações: $-\varnothing$}

\subsection{Mudanças de Significado:}

254 - ci ha dei negozi co/con il fratello che aveva là ...

256 - ci ha negozio insieme con Livio.

Em ambas as frases a entrevistada usa o vocábulo negozio do português negócio ${ }^{8}$, em vez do vocábulo italiano affari. Poderia ser classificado também como decalque, caso a entrevistada tivesse partido do modelo português negócio. Em italiano o vocábulo é dicionarizado, mas nenhum dos significados correspondente ao que a entrevistada queria dizer.

\subsection{Decalques:}

23 - lui/lui lavorava le mucche per il patrone: do português, patrão. Em italiano, padrone.

104 - mio papà faceva: faceva: ... non era proprio il guardia: do português, o guarda. Em italiano o vocábulo é feminino: ... non era proprio la guardia.

105 - limpava scritori ... faceva così: do modelo português, escritórios. Em italiano, puliva gli uffici.

112-113 - e papà piantava la salata tante: ...: do modelo português, salada, em italiano, insalata.

113 - tante:... verdure come una piccola orta

121 - in quel período c'era lo spazio per fare un'orta ...

${ }^{8}$ Assunto de interesse empresarial e financeiro, segundo o Dicionário Houaiss de Língua Portuguesa. 
em ambos os casos, do português, horta, em italiano, vocábulo masculino orto.

139 - settantacinque ... novanta otto ...: do português, noventa e oito, em italiano, novantotto

189 - figli di italiani ... neti di ital/

202 - sì ... anche con i miei neti: netos em português, em italiano, nipoti.

\subsection{Verbos:}

23 - lui/lui lavorava le mucche: uso indevido do verbo. Deveria ter usado allevava le mucche.

83-84 - ogni una che vinha pra São Paulo chiamava l'altra: a entrevistada apresenta um lapso quanto ao uso do verbo, pois na linha anterior já o havia usado em modo correto: ognuna che veniva pra São Paulo.

105 - limpava scritori ... faceva così: o verbo em italiano é puliva.

159-160-161 - e si abbiamo conosciuti ... lui frequentava anche la mia casa por causa di miei fratelli neh ... si abbiamo conosciuti così: uso do auxiliar avere, em vez do auxiliar essere: ci siamo conosciuti.

232-233 - no/no noi parliamo quando si incontriamo così come con voi altri ... intende?: do português entender, com a pronúncia habitual dos brasileiros. Em italiano, capisci?

\section{Preposições:}

82 - e queste sei famiglie ognuna che veniva pra São Paulo

83-84 - ogni una che vinha pra São Paulo chiamava l'altra. Em ambos os casos, contração da preposição portuguesa para, em vez da preposição italiana per, se bem que, com o verbo venire, nos contextos das duas frases a preposição seria a : ognuna che veniva a São Paulo.

86 - abbiamo lavorato in: ... no Matarazzo: preposição portuguesa em com o artigo definido masculino $\underline{\mathbf{o}}$, no entanto por tratar-se de Indústria Matarazzo, a preposição adequada é nella Matarazzo.

95 - io la prima: fabbrica ho lavorato sulla fabbrica di/di mo/moveis: a entrevistada se confunde, a preposição adequada é nella fabbrica.

99 - lavorava su a fiação ... sul/sul filo: em italiano, nella filatura. 
120 - bom era qui na alameda Gloria: nell'alameda Gloria.

152-153 - Livio era amico tanto di miei fratelli là na Italia ma io non mi ricordo di Livio là na Italia ...: uso indevido da preposição $\underline{\mathbf{d i}}$, pois quando antecede os possessivos no plural deve vir articulada: dei e pelo hábito de usar a preposição portuguesa na, não percebe que a usa duas vezes, em vez da preposição italiana in: Livio era amico tanto dei miei fratelli là in Italia ma io non mi ricordo di Livio là in Italia ...

225-226 - ci ha contato con le italiani da Italia con i cugini di Livio : neste caso usa, também, a preposição da habitual no português, quando deveria usar dell'Italia.

243 - ricordato le/le nostre cose là na Italia ... : em italiano, in Italia.

258 - in/no qui in Brasile ... : parece que iria dizer no Brasile, mas percebe e autocorrige-se in Brasile.

271 - papà conosceva Livio ... $\underline{\text { da }}$ Italia : usa a preposição da como em português. Em italiano, deve ser articulada dall': papà conosceva Livio ... dall' Italia.

279-280 - andavo alla messa delle nove ... dei italiani che qui c'era la messa delle nove per incontrarmi con lui. Articula indevidamente a preposição de seguida de um vocábulo italiano iniciado por vogal: degli italiani.

\section{Artigos:}

17 - miei zii lavoravano in campagna. No português é correto usar os pronomes possessivos sem a presença do artigo definido. Já na língua italiana, os mesmos devem ser usados, salvo em alguns casos no singular: i miei zii.

130-131 - ci ho un zio ancora a Torino ... ci ho un zio ci ho parenti 133 - Adria c'ho un zio. Em todos os casos, o morfema zio necessita do artigo indefinido uno zio.

184 - miei fratelli hanno cominciato a studiare ... : Neste caso, como na linha 17, a entrevistada se confunde e não usa 0 artigo definido para 0 plural de parentes: i miei fratelli.

\section{Pronomes:}


126 - no no eu non abitavo lontano no : usa o pronome em português, em vez do italiano ío.

232-233 - no/no noi parliamo quando si incontriamo così come con voi

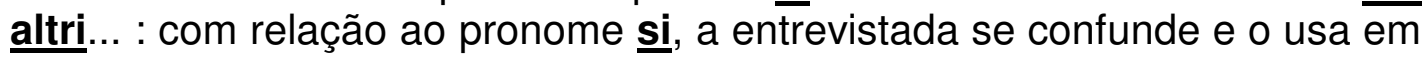
$\overline{v e z}$ do pronome ci que indica a primeira pessoa do plural. Já voi altri, acreditamos seja um dialeto.

271 - ... ma sempre con aquele ... : usa o pronome demonstrativo em português, em vez do italiano quello.

\section{Advérbios:}

139-140 - ... e due anni indietro che è morto il fratello di Livio : Faz uso do dialeto e usa um advérbio quando em língua italiana: ... e due anni fa è morto il fratello di Livio, ou: è da due anni che è morto il fratello di Livio.

146 - era acolá era ... bellissimo : usa um advérbio português, quando poderia ter usado là era ... bellissimo ou quel posto era ... bellissimo.

286 - io lavoravo só di sortera : em italiano, soltanto.

\section{Conjunções:}

79-80 - porque su/sul nostro paese ... : em italiano, perché.

\section{Citações:}

68-69 - quelli della fazenda ${ }^{9}$... e siamo andati tutti in fazenda a lavorare il caffè

179-180 - è stata meglio che nel/su/sulla fazenda nell'interiore.

\section{Comentários:}

1 - O uso de expressões com um empréstimo total ou parcial do português, também é interessante mencionar:

192 - no:ssa ... là/là tutti ci davano da mangiare con la caderneta

\footnotetext{
9 Encontramos como palavra portuguesa já dicionarizada com o significado de azienda agricola
} brasiliana. 
266 - no:ssa: interjeição portuguesa cuja forma completa é Minha Nossa Senhora! ou Minha Nossa! ou ainda Nossa Senhora! que finalmente no discurso popular se reduz a uma só palavra Nossa! É a correspondente em italiano de Madonna mia! ou Madonna santa! ou simplesmente, Madonna!

160-161 - lui frequentava anche la mia casa por causa di miei fratelli neh 225 - no/no/no/no por causa de/de/de ... lei le piace leggere.

Em ambos os casos deveria usar per causa di ou a causa di, sendo que, no primeiro caso, a preposição deve ser articulada: lui frequentava anche la mia casa per causa dei ou a causa dei miei fratelli.

2 - A entrevistada, no início do registro, estava um pouco inibida e controlada; no entanto, no decorrer da entrevista, sentindo-se mais à vontade, manteve um bom ritmo no seu discurso, não se preocupando com o tipo de vocabulário a ser usado.

Tabela no 1 - Empréstimos Totais

\begin{tabular}{|l|l|}
\hline \multicolumn{1}{|c|}{ Português } & \\
\hline interior/interiore (quatro vezes) & all'interno \\
\hline móveis & mobili \\
\hline fio/fiação & filatura \\
\hline bom (duas vezes) & bene \\
\hline caderneta & tessera \\
\hline bem & bene \\
\hline namoro & legame \\
\hline sortera & nubile \\
\hline
\end{tabular}

Tabela no 2 -Mudanças de Significado

\begin{tabular}{|l|l|l|}
\hline \multicolumn{1}{|c|}{ Forma apresentada } & \multicolumn{1}{c|}{ Português correto } & Italiano correto \\
\hline negozi/negozio & negócios/negócio & affare/affari \\
\hline
\end{tabular}

Tabela no 3 - Decalques

\begin{tabular}{|l|l|l|}
\hline \multicolumn{1}{|c|}{ Forma apresentada } & \multicolumn{1}{c|}{ Português correto } & \multicolumn{1}{c|}{ Italiano correto } \\
\hline patrone & patrão & padrone \\
\hline il guardia & o guarda & la guardia \\
\hline scritori & escritórios & uffici \\
\hline salata & salada & insalata \\
\hline orta (duas vezes) & horta & orto \\
\hline
\end{tabular}




\begin{tabular}{|l|l|l|}
\hline \multicolumn{1}{|c|}{ Forma apresentada } & \multicolumn{1}{c|}{ Português correto } & \multicolumn{1}{c|}{ Italiano correto } \\
\hline novanta otto & noventa e oito & novantotto \\
\hline neti (duas vezes) & netos & nipoti \\
\hline
\end{tabular}

Tabela no 4 - Verbos

\begin{tabular}{|l|l|l|}
\hline \multicolumn{1}{|c|}{ Forma apresentada } & \multicolumn{1}{c|}{ Português correto } & \multicolumn{1}{c|}{ Italiano correto } \\
\hline lavorava & tratava/cuidava & allevava \\
\hline vinha & vinha & veniva \\
\hline limpava & limpava & puliva \\
\hline $\begin{array}{l}\text { si abbiamo conosciuti (duas } \\
\text { vezes) }\end{array}$ & nos conhecemos & ci siamo conosciuti \\
\hline intende & entendes & capisci \\
\hline
\end{tabular}

Gráfico das Principais Interferências (I-4)

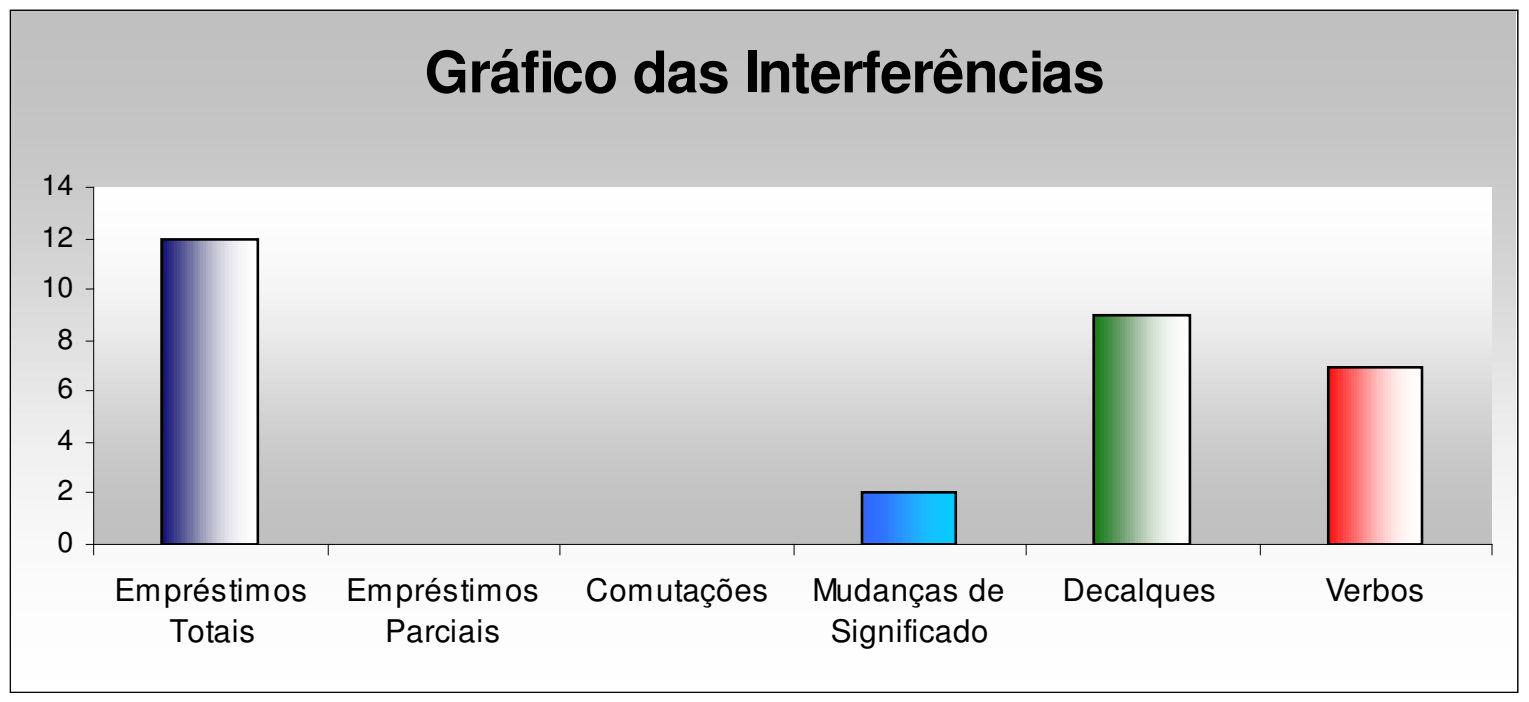




\section{INQUÉRITO № 5 (I-5)}

Sexo: feminino

Data de nascimento: 13/10/1924

Idade: 82 anos

Cidade: Alice Castello

Província: Aosta/Torino

Região de Proveniência: Piemonte

Profissão: casalinga

Data da entrevista: abril/2007

1 Doc il suo nome e cognome

L1 XX XX/eh solo mio o di sposata anche?

Doc no ... può essere di sposata

L1 tutto XX XXX XX

5 Doc età?

L1 età: ... ottantadue fatti ... vuol dire sono nata il dieci ... di ottobre no/no un momento ... tredici di ottobre millenovecentoventiquattro ... perciò c'ho ottantadue anni ... manca poco per ottantatré ottobre è lì ... è vicino

10 Doc eh: professione

L1 ah professione guardi io in Italia facevo la: sarta ... poi ho fatto un corso di modello:... far modelli di/di carta ... per la: per la: i vestiti neh ... e qui ho lavorato nella Moda Berta facendo modelli ... modelli só di carta neh ... perché poi andava: quello è mio/è la mia

15 professione vuol dire sarta va sarta è la miglior cosa neh così

Doc certo dopo parleremo un po' [più su questo

L1 [sì

Doc regione e città di provenienza

20 L1 io sono nata ad Azeglio ... quando io sono nata era provincia ... di Aosta ... adesso è provincia di Torino ... ma sono vissuta ad Alice Castello ... perché è la città dei miei genitori neh ... ad Alice Castello molti anni sono arrivata dal/da Azeglio e / siamo andati ad Alice Castello io avevo/otto anni/nove anni così ... e io son vissuta lì 
25 fino a che son venuta in Brasile ... Alice Castello è provincia di Vercelli ... Piemonte ... neh

Doc come: lei ricorda il suo paese la sua

[città?

L1 [ah sì

30 Doc come era era di campagna?

L1 mio paese dove

[sono vissuta

Doc [parla un po'

35

L1 più è di campagna ... è un paese di agricoltura ... neh un paesetto piccolo ... in mezzo praticamente alle montagne ... è giù ... è basso e poi c'è la montagna ... della Val d'Aosta e: la Valle di ... noi siamo vicino al Santuario di Europa Biella ... tutte quelle città lì ... provincia di Vercelli ma al lato destro ... abbiamo tutte 'ste montagne ... che è meraviglioso ... è una parte meravigliosa ... la mia città è

40 bellissima ... piccolina ... antica ... tutta non si può più toccare le case ... possono riformarle dentro ma fuori no ...che son tombade come dicono qua ... sono: come si chiama in italiano? eh: insomma non lasciano più to/toccare fuori eh ... deve essere: patrimonio antico ... è molto carina la mia città/città di agricoltura neh

$45 \quad$... così

Doc e: qual era il tipo di agricoltura lei si ricorda?

L1 là sì: c'è molto grano... trigo ... grano ... melica ... poi uva piantagione di/di vite le uv/la uva neh ... poi ci sono cosa/adesso fanno molto: piantagione di: fragole ... pesche ... molte pesche ... e: sparagi ...

$50 \quad$ adesso ultimamente ... ci son quelle: colture lì ... che quando son andata in Italia adesso son per sei anni che non ci vado dovuto al mio ... mal di schiena ... allora non mi ( ) non mi riusciva più camminare molto negli aeroporti ... e non voglio andar sulla sedia a rotelle neh ... e allora così: son sei anni che non vado giù in Italia ...

55 ma ci andavo molto cada due anni una volta all'anno ... ero sempre giù neh ... e passavo due/tre mesi là ... perciò: la coltura è quella ... c'è agricoltura un po' di tutto ... MA ADESSO NON SO SEMBRA CHE IL GOVERNO: ... non aiuta più non so cosa che/anzi preferisce che non coltivino ... certi articoli certe cose ... che/non so

60 perché quello ... io vedo che al mio paese alle viti le hanno arrancate via ... ne lasciano qualcuna ... per avere l'uva per la famiglia fare il vino ... se non tirano fuori non so più perché l'italiano è diventato così molto: ... non si preoccupa più con coll'agricoltura come ai miei tempi neh come quando io ero giovane

65 Doc ma perché oggi è diventato un posto di turismo?

L1 non so non è neanche turismo mia città non è una città di turismo ... c'è ancora agricoltura ce n'è ma poca ... è vi/di fronte a quello che 
c'era ai miei tempi no: ... nem non c'è nem la metà di quello che c'era ...lasciano andare così a: lì i pezz/c'è dei pezzetoni grandi di terra ... tutto al gerbido ... e cresce l'erbaccia e non si incomodano/non si preoccupano più ... non so perché quello ... mi sembra che al governo c'è qualcosa/per impor/per importare di fuori ... poter esportare forse ... altra merce italiana ... ha tagliato un pochino in quel modo lì

75 Doc possiamo parlare un po' della guerra?

L1 ah beh quella ce n'è tanto da parlare

Doc parliamo un po' ... cosa lei si ricorda?

L1 di tutto ... io l'ho passata cinque anni di guerra ... nella mia città ... non c'era molto pericolo per i bombardamenti ... perché passavano 80 sopra ... spi//:lo credi che:/che: il sole diventava scuro ... di tanti avion che passavano per andare a Torino Milano e via dicendo ... noi non abbiamo avuto 'sto lavoro dei bombardamenti perché ... non c'era niente di molto importante ... però a due chilometri e mezzo noi abbiamo una polveriera ... che è un deposito di munizioni di 85 guerra neh ... e lì era molto cercata ... ma siccome è stata molto ben mimetizzata ... perché era tutto sotterraneo ... e erano piante era un grande come fosse un grande sítio pieno di alberi ... non l'hanno mai trovata perché se la trovavano ... andavamo per l'aria tutti ... neanche il mio paese ... due chilometri e mezzo lì

90 vicino ... l'han cercata molto ma non l'han mai trovata ... PERÒ abbiamo avuto un disturbo grandissimo per ... eh: fascismo poi c'eran ... le brigate nere ... poi venivano i tedeschi ... generalmente di notte arrivavano i partigiani ... nella: e allora il mio papà aveva la panetteria e di notte con la mitraglia PAN PAN 95 nelle porte ... bisognava aprire ... venivano a comprare il pane quello che avevano bisogno per mangiare ... alla fine di giorno c'erano le brigate nere che cercavano mio papà ... e lui nascosto ... e io fuori di casa ... abbiamo passato una vita da cane/da cane proprio ... arrivavano e erano i padroni la brigata nera erano ... terribili in 100 quell'epoca neh ... in casa mia son venuti praticamente ad abitare ... son arrivati un giorno un: maresciallo: chiam/chiamavano $\mathrm{La} / \mathrm{La}$ Manetta ... che ci mancava una mano ... o la mano storta qualcosa così era della brigata nera ... e entrato in casa mio papà aveva pit/fatto pitturare la casa era tutto pulito ... dice Sì QUESTA VA 105 BENE PER NOI ... e.: sono arrivati quattro cinque ... e si sono ista/ installati là si son messi là ... e si facevano da mangiare andavano nei: cortile dei vicini ammazzavano le galline e se le portavano a casa ... e se le facevano cuocere ((risos)) e io e mio papà mangiavamo ... CAVOLI ... PATATE ... E ... RA/ E ... NABO ... 110 perché è quello che c'era in quell'epoca neh perché carne la vedevamo una volta alla settimana ... che davano ... avevamo un ... un librettino di/di seligni allora cosa si faceva andava a/per andar 
tutti i giorni erano cento grammi di carne e non dava per nessuno ... allora mia mamma aspettava fine settimana andava a tirare i selini là prendeva un chilo ... e faceva il mangiare della domenica ... era quello ... abbiam passato dei brutti tempi ... la sera non si poteva uscir di casa ... c'era coprifuoco ... le/le/le finestre tutte foderate ... con carta blu scuro perché non si vedesse la luce di fuori ... che lì era bombardamenti no/di certo ... insomma :abbiamo avuto una vita da cane proprio ... solo si viveva di giorno ... arrivavano le sei di sera d'inverno bisognava chiudere tutto ... e cercar di spegnere le luci più possibile e:: vivere così ... e poi avere quegli assalti perché di notte si sentiva i bombardamenti passar gli avion ... bombardamenti a Torino ... e:: lì sì ve/cinquanta chilometri dalla mia città Torino

125 Doc [si sentiva tutto

L1 [si sentiva

e si vedeva/si vedevano le fiamme ... terribile foi terrib/è stato terribile ... io ho perso un fratello in guerra ... mio fratello: maggiore era del millenovecentodiciotto ... mio fratello è nato in Nord America ... che i

130 miei genitori hanno vissuto là parecchi anni ahn ... e:: sta: quando poi/poi l'hanno portato in Italia perché son venuti dopo là: ... nel millenovecentoventidue mio papà è tornato dal Nord America ... e si è stabilito lì ... non voleva più tornare indietro poi è stato ammalato è dovuto tornar/al paese per ristabilirsi/ristabilire la/la/la/la la salute ... e

135 allora mio fratello quando ha avuto diciotto anni ... perché non/mio papà ha avuto paura che lo chiedessero per la guerra del millenovecentotrentacinque ... della guerra dell'Africa ... I'ha mandato in America un'altra volta che eravamo molti parenti là ... le sorelle di mia mamma ... è stato là ... andato/andato via nel 140 trentacinque nel quaranta ... nel quarantuno mi sembra che è tor/che è venuto in Italia in guerra ... ha fatto lo sbarco di Anzio ... in bassa Italia ... è venuto su con le truppe americane quando è stato a Monte Marzanello vicino a Montecassino è morto ... e noi non l'abbiamo saputo só due anni dopo quando è finita la guerra ... che speravamo 145 di ricevere letter/perché è morta la mia mamma in quell'epoca nel millenovecentoquarantatré la mia mamma è morta ... di cancro: all'utero ... e noi abbiamo fatto tramite la croce rossa un telegramma l'abbiamo mandato negli Stati Uniti perché non sapevamo che il mio fratello era in guerra pensavamo ... che fosse ... tranquillo là ... 150 abbiamo mandato un telegramma con risposta pagata ... immagini dopo due anni è arrivata la risposta ... nostra quella risposta pagata ... davanti c'era la morte di mia mamma dietro era la morte di mio fratello ... e poi lì logico terminando la guer/ahn tranquillizzando un pochino la situazione ... lì c'erano gli americani di stanza neh che

$155 \quad$... mantenevano ... i posti là ancora ... son venuti in casa un colonello a man di portare la notizia ufficiale ... e mio fratello è morto abbiamo la bandiera americana abbiamo la/la: medaglia d'oro medaglia di 
valor militare ma lui non c'è più ... avrebbe oggi ... quanto ottanta: del diciotto: avrebbe ottantasei no:

160 Doc ottantanove

L1 è: ottantanove anni ... e così la guerra m'ha lasciato tutte 'ste belle cose lì

Doc e quanti: fratelli e sorelle:

L1 no c'ho/c'ho solo ancora un fratello che abita in São Paulo

165 Doc eravate in tre

L1 in tre ... due maschi e io neh ... quello lì era del diciotto ... poi sono io del ventiquattro e mio fratello in São Paulo è del trentadue

Doc hum hum

L1 è il più giovane ... anche lui italiano parla italiano

170 Doc molto bene

L1 ma molto loro/i due marito e moglie sono italiani e loro ... parlano ... solo italiano in casa

Doc hanno dei figli?

L1 c'hanno tre figli ... tre figli uomini

175 Doc e parlano con loro

L1 tutti maschi i figli tutti parlano italiano ma non so perché sono separa/sposati già ... e geralmente son sposati con: persone brasiliane ... sarà difficile che loro frequentino molto l'italiano ... ma con il papà sì ... con il papà come i miei ... i miei figli con me

180 parlano l'italiano ... ma non sempre perché Armando ... più del: parla portoghese qui

Doc quanti figli lei ha?

L1 tre

Doc tre tutti

185 Doc [maschi

L1 [no due donn/

L1 un maschio solo e due femmine ... Ornella che abita a Joinville ... c'ho Mara Margaret ... che abita qui a San Bernardo ... è sposata con un brasiliano ... è così ...e/e Armando

190 Doc va bene ... quando lei è venuta: in Brasile?

L1 io son venuta nel millenovecentocinquanta ... era il mese di gennaio ... del millenovecentocinquanta

Doc ahn perché? 
L1 ah perché in Italia io c'avevo un fratello questo fratello che abita a San Paolo non/non trovava più lavoro ... che dopo la guerra è stato un periodo ... molto triste in Italia non c'era ... lavoro ... non c'era non c'era niente ... non c'era più una speranza ... allora chi poteva uscire se ne andava ... e dopo invece dopo di vari/quattro cinque anni l'Italia si è rimessa e tanto è vero che quelli che son stati là son tutti ricchi

Doc sì

L1 non dico ricchi: ma stanno bene ... hanno lavorato ... hanno progredito insomma poi ci han tutti la pensione ... e se la cavano benino in Italia adesso neh ... ma

205 Doc lei/lei è venuta sposata o no?

L1 io son venuta sposata

Doc con il suo papà o no?

L1 no io guar/sì con il mio papà mio papà è venuto un poco dopo ma è venuto subito dopo noi ... perché io son sposata co/primo matrimonio con Aldo Ravetti ... italiano pure ... ma dopo ho fatto il divorzio ... sono stata in Paraguai e non:: è una vita un po':: ... sa sempre c'è qualche problema neh quando não dá certo ... e allora poi son venuta in Brasile ... con questo mio ma/primo marito ... e dopo/come ho fatto il divorzio ... qui mi sono sposata con Arturo Zara

215 Doc [ma del primo matrimonio

L1 [italiano

Doc lei non ha: avuto figli

L1 sì la prima figlia

Doc ahn ahn

220 L1 la più vecchia la Mara ... Margaret

Doc certo

L1 è la mia figlia del primo matrimonio ... e dopo son sposata con Arturo Zara ... ci siamo sposati ... e ho avuto i due figli

Doc anche lui italiano

225 L1 italiano

Doc di quale regione?

L1 di Vigevano ... Vigevano è vicino a Pavia neh ... Vigevano ... è sempre: Vigevano è Piemonte ancora neh? no aspetta un momento Vigevano:... acho che è provincia di Pavia già di Pavia ... sì che è la 230 città che fanno le scarpe ... una città molto rinomata per le scarpe ... ecco lui è nato lì a Vigevano ... e: è stato: è venuto in Italia/è venuto 
in Brasile già ha portato macchine ... perché lui era un ingegnere neh ... ha portato macchine: industriali già che aveva già una piccola officina là formata ... è venuto qui si è portato su anche la macchina/anche l'automobile un Topolino ... si ricorda il Topolino?

Doc hum hum

L1 lei lo ha visto

[qualche volta neh

Doc [sì sì

240 L1 ecco primo carro/primo automobile di mio marito era un Topolino ... e poi

Doc questo già a San Bernardo

L1 sì

Doc ahn

245 L1 no primei/prima in San Paolo neh ... in San Paolo ha montato l'officina in San Paolo nella:.... là no Tatuapé Tatuapé adesso non mi ricordo più il nome della strada ... rua Cantagalo mi sembra rua Cantagalo Tatuapé ... e dopo siam venuti a San Bernardo ... siam venuti a stare qui ... che lui voleva montare la fabbrica c'ha avu/dei soci anche ma non dava certo ... quei soci lei sa com'è neh?

Doc sì lo so ... in che anno siete venuti a San Bernardo?

L1 siam venuti sì aspetti un momento deix/ver son venuta in San Bernardo ... devo fare il calcolo perché non mi ricordo ... io son stata a San Paolo ... dodici anni ... poi son venuta a stare a Parque 255 Anchieta dove c'ho la casa ... lì son rimasta dieci anni son ventidue ... e dopo son venuta qui sono ventisette anni quanti anni mamma mia ... trenta e: quasi quaranta anni neh

Doc è sì

L1 che siamo usciti da San Paolo... più o meno quello

260 Doc ahn ahn

L1 è

Doc ahn bene ahn ...siete partiti di Italia in che mese:

L1 io son partita in gennaio ... dall'Italia

Doc di che anno?

265 L1 del millenovecentocinquanta abbiamo preso la nave Conte Grande

L1 [a Genova

Doc [ah Conte Grande

L1 è son venuta col Conte Grande ... da Genova ... e siamo arrivati a Santos 
270 Doc quanto tempo di viaggio?

L1 undici giorni

Doc ah già era più veloce

L1 sì?sì già si andava bene

Doc e quali sono i ricordi di questo viaggio?

275 L1 ah: il viaggio ha avuto/eh: guardi il viaggio è stato bello non è stato brutto ... io non soffro la nave sto bene ... non c'ho mal di testa non c'ho niente ... e ci siamo anche divertiti che la gente non pensava ... che andava a emigrare in un paese che non conosceva ... e i primi tempi è stato terribile sa ... che non PARLI la lingua ... non c'hai una casa ... c'hai una vita ... è stato difficile ma ... il viaggio è stato bello ... è stato bello ci siamo anche divertiti proprio ... ci siam/fermati:: è dove ... in:... ahn come si chiama in Africa? ... hum: ... adesso non mi viene in mente ... il nome di quella città ... Dacar ... Dacar non è ben Africa mi pare che appartiene alla Francia qualc/è una colonia francese ... lì guardi siamo scesi dalla nave e mi viene da ridere ancora oggi ... avevo con me una signora di Milano che era una farmascista ... una: aveva il marito in Patagonia lei veniva per andare a raggiungere il marito ... siamo scese a Dacar ... e: lei sapeva tutto quella parlava francese parl/lei diceva neh ... no state tranquilli io vi porto io adesso andiamo a divertirsi ... siamo arrivati in un posto che c'era un: eunuco ... quei alti che c'han quella cosa in testa qui ... che falava Alá: entrate entrate siamo entrati in un posto ... per bere qualcosa di rinfresco ... e ((risos)) era u/come si chiama era un:.... dove vanno far l'amore ... com'è che si chiama quella: quelle case lì ... una casa di/di tolleranza no un ambiente simile ... siamo entrati dentro abbiamo visto tutte/col è: tutte cortine/tende di velutto rosso ... intorno e dicevamo cos'è qua nessuno viene a veder cosa vogliamo niente ... quando è venuto a vedere ha portato le fotografie ... di uomini $e$ donne alti in/in/in corpo in/NATURALE per scegliere

300 Doc ahn

L1 le donne potevano scegliere l'uomo l'uomo poteva scegliere le donne ((risos)) quando abbiam visto quelli ((risos)) siamo fuggiti come dei ladri ... fuggiti di là dentro perché abbiamo avuto paura de/ma cosa come/dove siamo andati a finire ma: ... io credevo che era un 305 ristorante era ... un: un ambiente che si poteva andar a prendere qualcosa rinfresco ... ma guarda abbiamo riso tanto che è stato anche un di/è stato anche un diversivo buono perché ha tirato un un pochino la paura del/del viaggio della neh che venivamo

Doc e è un ricordo

310 L1 è un ricordo/ricordo ... poi siamo arrivati a Mont/ è: Buenos Aires ... no Buenos Aires no prima Montevideo ...si è fermata a Montevideo la 
nave ...siamo scesi tutti ... dodici ore di libertà ... lì abbiamo comprato dei piatti di paste ... pasta una pasticceria finissima ... ba/barata ... poco/poca/poca spesa abbiamo portato via tanti di quel dolci ... insomma abbiam trovato degli spagnoli giù ... che erano nella nave lì ci siamo riuniti tutti ... beh insomma abbiamo fatto una pass/una/un viaggio buono buon da vero ... arrivati a Buenos Aires lì no lì ho avuto dei problemi piuttosto gravi ... perché mio fratello av/ha viaggiato con me ... Giuseppe quello che abita a San Paolo ... e lui 320 aveva diciott'anni e in Italia ... siam partiti ... mancava un: timbro: ... argentino ... nei documenti io non lo sapevo ... nessuno m'ha detto che ci mancasse quella cosa lì ... non lo han lasciato scendere dalla nave ... noi siamo scesi lui è rimasto sulla nave per fortuna che è venuta la bassa marea ... la nave si è piegata di un lato ... ha dovuto fermarsi un tempo ... in questo frattempo 10 ho dovuto affrontare Buenos Aires ne/nella ... nella:: come si chiama la sotterranea ... ahn $\mathrm{METRO} / \mathrm{metro}$ sotterraneo per andar a trovare dove mi facevano 'sto carimbo se no non potevo tirar mio fratello ... dalla nave ... invece così son riuscito ho fatto le cose ... e son arrivata due ore prima che 330 la nave partisse per tirar mio fratello

Doc e senza parlare la lingua

L1 senza parlare la lingua ... e mi arranggiavo come potevo neh ... certo e mi son fatta aiutare un poco della polizia perché avevo paura di ... attaccarmi a altra gente non neh detto non si sa mai come sarà

$335 \quad$... la polizia è stata gentile con me m'han indicato insomma me la son cavata ... ma ho avuto subito una/un'entrata nel Sud America che le dico sinceramente ... poi abbiamo preso un battello ... che abbiamo fatto il rio ... rio Paraguai ... siam venuti per il rio e siam arrivati in Assuncion ... Paraguai

340 Doc perché Paraguai?

L1 non lo so perché/il console paraguayo era della mia città ... e lui è stato un po':: delinquente perché ... ha raccontato storie del Paraguai meraviglia ... questo e quello invece non c'era niente di tutto quello ... abbiamo tribolato ... abbiamo tribolato molto e: il

345 primo anno è stato ... TRISTE è stato difficile

Doc che cosa facevate in

[Paraguai

L1 [io io mi

L1 son messa a lavorare da sarta ho messo l'annuncio sul giornale ... avevo tutti/tutti gli impiegati del consolato italiano ... son venuti anche la Signora Rottini ... quell'epoca c'era il Ministro Rottini ... che era il console ... anche la signora molto gentile una creatura buonissima ... è venuta: io ci facevo la roba gliela portavo là andavo per/ misurargliela ... io su/subito mi sono messa a posto ... per il mio 
355 lavoro ... e gli altri han fatto: mio marito in quell'epoca: ... lui ha lavorato:... in una: ... dove fanno lo zucchero ... zuccherificio ... neh e è stato anche fortunato perché guadagnava bene ma dopo ha cominciato

360 Doc [a bere

L1 e lì è lì che è cominciato il nostro: fine neh ... perché abbiamo fatto il divorzio per quel motivo ... che ha cominciato a bere ... e con la bevanda col/col :whisky si dava le cose buone ... e li mangiava fuori i soldi m'ha fatto dei debiti ho but/ho tribolato molto ... tribulato ma 365 dopo mi son messa a posto e io ho avuto dei bravi/delle amicizie molto buone là ... e finché poi siam tornat/siamo venuti in Brasile e qui mi son separata ... qui ho fatto il divorzio ... è tutto

Doc e lei ha studiato: fino a che in Italia?

L1 io no io ho fatto le elementari: e poi ho preparato/ho fatto il ginnasio 370 perché volevo ... in casa l'ho fatto particolare neh ... che mi venivano le:: come si chiama le:: ... mi mandavano dal collegio mi mandavano:

L1 [come si chiama?

Doc [libretti

L1 librettini ... studiavo per. conto. mio ... perché volevo far l'ostetrica ... 375 volevo andar alla/Torino ... alle Molinette a fare ... fare l'ostetrica neh ... e dovevo prepararmi per affrontare quell'esame per entrare nel/nella faculdade di/di/di medicina di/di ostetricia

Doc [praticamente ha

L1 [ci sarebbe

380 Doc Imparato da sola

L1 partera neh ... e ho imparato per conto mio ... e mio papà non mi lasciava andar/che dovevo andar in un'univers/no in un collegio a Ivrea ... dove chiudermi là dentro ... ma il mio papà non aveva i soldi per pagarmi un collegio ... aveva la panetteria ma in quei tempi là in

385 Italia non si stava molto bene neh ... e poi la mia mamma si è ammalata ... è morta ... e un millione di difficoltà ... così mi son preparata per conto mio e guardi ... ero pronta per fare per entrare entra/sarei entrata a Biella nell'ospedale di Biella... ma alla fine è morta la mia mamma e ho dovuto desistere ... stare in casa a aiutare

$390 \quad$ mio padre ... per la panetteria

Doc e/e quando voi siete venuti dal Paraguai ... a San Paolo ... dopo quanto tempo lei si è divorziata?

L1 io mi son divorziata dopo un anno e mezzo

Doc e quando ha conosciuto il suo secondo marito

395 L1 guarda io lavoravo per la Moda Berta ... Moda Berta era nella: ... rua Augusta ... e: ... no chi ha chi ha portato il mio marito in casa è stato il mio ex marito 


\begin{abstract}
Doc hum
L1 che loro si son conosciuti ... i due ... e l'ha portato in casa per far la

400 bagna cauda ... torinese da presso la bag/ha sentito quella sera là che io parlavo della bagna cauda ... e allora ci ha detto oh vieni in casa che mia moglie fa la bagna cauda molto buona e quello là ... e lui è venuto e ci siamo conosciuti ... beh io già stavo separata per/non dormivo più con mio marito già ero separata ... CARnalmente diremo 405 neh perché non lo sopportavo più ... e allora lui è venuto lì ci siam conosciuti ... meu Arturo si è innamorato della mia bambina della Mara ... più che de/più che della madre ((risos)) gliela aveva sempre in braccio ... e lì ha cominciato il nostro: idillio nostro neh ... ci trovavano andando a lavorare e veniva a prendermi al lavoro mi 410 portava a casa già aveva ... quella macchinetta là quel Topolino ... e: così ha cominciato il nostro romanzo ... ma io ero già separata praticamente lì ho fatto il divorzio ... ho fatto la separazione legale prima ... poi sono andata in Italia perché qui non c'era ancora il divorzio
\end{abstract}

Doc no

415 L1 sono andata in Italia per divorziare là ... ho speso soldi ... ho messo l'avvocato tutto ... alla fine prima di divorziare ... lui prima di divorziare in Italia è venuto il divorzio qua in Brasile ... allora ho visto che andava più in fretta ... abbiam messo l'avvocato qua ... e ha sistemato le cose quando son riuscita a divorziare ... lo sa chi ha 420 firmato il mio divorzio ... un giudice perché lui era morto ... e io non lo sapevo perché lui era già separato da me si è messo con una/un'altra donna e ... sono andati in Uruguai ... è è in Uruguai io non lo sapevo ... vuol dire che quando ... il: I/dovevo fare il div/doveva firmare questo divorzio ... è stato annunciato nel giornale l'hanno 425 cercato non l'hanno trovato non si sapeva ... perché era andato fuori del paese ... allora il giudice mi ha dato il divorzio ... perché ... oramai era .../poteva fare quello

Doc e lei era già vedova

L1 ero già vedova e mi sono sposata come divorziata perché non lo 430 sapevo neh che lui era morto ... quando già ero sposata con Arturo ... che noi abbiamo fatto ... allora è venuta la notizia ... dall'avvocato d'Italia ... quello che avevo messo per il divorzio lui m'ha scritto ... e m'ha detto guardi signora che suo marito è morto tal giorno e così così ... in Uruguai a Montevideo

435 Doc hum hum

L1 e così ... praticamente mi son sposata di vedova non di ... senza saperlo ( ) un romanzo la mia vita ... io sempre l'ho de/ma guarda la mia FIGLIA sempre mi diceva mamma perché non mi spieghi tutta la tua vita che io ti faccio un libro ... ((risos)) un romanzo 
440 Doc [sì è un'opportunità

L1 [ ( (risos))

L1 adesso stiamo facendo quello

Doc metà è registrata mancano i dettagli

Doc dopo:: di San Paolo siete venuti:

445 Doc [subito a San Bernardo

L1 [in San Bernardo

Doc nessun'altra città

L1 no no

Doc no

450 L1 San Paolo San Bernardo

Doc San Paolo a San Bernardo

L1 son venuta a stare a Parque Anchieta siam stati lì undi/dieci anni

Doc e lei ancora faceva la sarta

Doc [ a San Bernardo?

455 L1 [ no no no no

L1 avevo già/no perché mio marito poi ... stava meglio con la fabbrica ha cominciato neh ... migliorare: gli affari ... allora ha detto lascia st/lascia stare non lavori più stai a casa a guardare i tuoi figli

Doc è sempre qui la fabbrica

460 L1 no/no ... prima l'abbiamo/l'ha avuta là na Cantagalo in San Paolo ... dopo quando siam tornati là ... c'è un galpone grande lì e di società ... con un minero e con un giapponese ... è stato cinque anni lì e poi si è stufato dice la società non VAl son stufo ... allora ha comprato abbiamo comprato 'sto sítio non è sítio è una chácara neh era una 465 chácara questa qua ... chácara che crea/allevavano le galline ... giapponese ... l'abbiamo comperata cinquemila metri ... e mio marito ha subito costruito 'sta fabbrica lì con il galpone lì ... e ha cominciato qua ... chi ha cominciato perché poi mio marito è morto ... ha cominciato ha comprato ha fatto gal/galpone qui ... e:: è morto

470 l'ho trovato morto lì fuori nel giardino ... che lui mex/a:aveva sempre la/la/l'hobby delle orchidee ... andava anche alle esposizioni e tutto aveva molte orchidee ... lì dietro aveva fatto un capannone per le orchidee ... e alla sera veniva dal lavoro ... andava giù mex/far le sue orchidee ... e un giorno: non lo vedevo tornare dico dove sarà? 475 chiamo lì dal terrazzo e lui era seduto lì dietro casa morto il cuore ... ha avuto un: attacco fulminante di cuore e guardi che ha mai sentito niente ... non aveva mai niente

Doc in che anno questo? 
480 L1 nel millenovecentottantuno... nell'ottantuno ... tredici di maggio era un giorno freddo era ... e l'ho trovato lì morto io sola in casa alla sera scuro ... ho avuto un trauma molto grande ... e son stata male nove mesi ... poi mio medico m'ha detto vai fate un viaggio vai in Italia stai là un poco vedrai che ti passa tutto ... io non dormivo neh non 485 potevo più dormir la notte ... e infatti sono andata in Italia e son tornata meglio stavo bene ... son stata quattro mesi in Italia.

Doc lei ha dei parenti?

L1 quell'epoca avevo ancora mia suocera viva ... e:: c'è mio cognato a:: fino oggi è vivo il fratello ... unico fratello di mio marito ... lui e la 490 moglie e i nipoti neh ... i nipoti ... un è medico c'è un'altra professoressa di/di religione ... e tutti molto bene sistemati ... in Italia ... e così ogni tanto vado neh ANDAVO perché adesso son sei anni che non vado in Italia

Doc ma ci andrà

495 L1 ma c'ho una voglia matta a: maggio ... se sto bene completamente come penso ... vado senz'altro

Doc e fuori i figli ... lei ha opportunità di parlare l'italiano? con chi? quando?

L1 qui c'è solo un'amica ... ma c'ho un'amica/c'ho un'amica o due qua ... 500 una signora italiana che vado da lei parlo italiano ... e c'è un'altra signora pure che parla è di: di/di Pav/no/no di Pisa ... anche parla parlano italiano lei e il marito ... ogni tanto ci troviamo e è l'unico posto che riesco a parlare l'italiano per quello mi piace andare alle feste italiane ... che c'è l'opportunità di parlare con qualcuno ve/e 505 mio fratello ... neh se vado da mio fratello s/io con lui parlo solo italiano

Doc ma lo vede spesso?

L1 è ogni tanto è stato operato a poco tempo anche lui ha fatto un'operazione come me ... qui nella schiena ... e: sono stata all'ospedale a visitarlo tutto ci vediamo somente sim

Doc lei ha la RAl

L1 [ce l'ho

Doc [legge libri

L1 ce l'ho la RAI l'assisto di domenica ... perché gli altri giorni co 'ste

novelle... oramai mi sono attaccata alle novelle ... assisto anche quella del morro/morro/morro torto là quella novella lì è terribile eh: quello che succede là a Rio de Janeiro ... ma sono curiosa di vedere

Doc ma: la programmazione della RAI ... è terribile durante la settimana non è? 
520 L1 io non so perché non l'assisto l'assisto di domenica ... sabato e domenica

Doc loro fanno programmi di auditorio sempre questo tipo di cosa non c'è quasi niente culturale che sarebbe interessante perchè se è una RAI Internazionale

525 L1 no ma di domenica ci fanno vedere l'Italia ... fanno vedere ... quando è stato poco tempo fa hanno fatto vedere tutta l'isola:... l'isola:.... com'è che si chiama l'isola là l'isola ... di/di ai meu Deus

Doc Elba Capri

L1 Elba ecco l'isola d'Elba ... Isola d'Elba ... l'hanno fatta vedere ... e 530 fanno veder/fanno: mostrano quel che si mangia come si vestono ... come è antigamente le case antiche ... di domenica mi piace per quel motivo lì ... poi ... assisto alle volte tardi ... di sera ... c'è stato: un quindici giorni fa ... l'orchestra dei carabinieri italiani è stato uno spettacolo ... ha un La Turandot ... la/la/la/le pezze di opera 535 meravigliose han suonato che alí $\mathrm{mi} / \mathrm{mi} / \mathrm{mi} / \mathrm{mi} / \mathrm{vien}$ la pelle d'oca poi piango un pochino ... perché dopo alla fine toca/suonano l'Inno Nazionale di Mameli e la dona XX c'ha il fazzoletto in mano e mia figlia mi telefona ... mamma hai pianto? dico sì ((risos))

Doc ha pianto e molto ahn no?

540 L1 ah io sento l'Inno Nazionale ... ma mi commuove l'I/anche quello brasiliano mi commuove ... eh io sono sentimentale non c'è niente da fare ... quello non passa

Doc lei si ricorda di quante volte è tornata in Italia?

L1 guardi in Italia son tornata dunque nell'ottantadue ... poi nell'ottantaquattro

Doc la prima volta che lei

Doc [è stata come è stato

L1 [nell'ottantadue

L1 no nell'ottantadue sono tornata prima di mio marito morire ... son 550 andata nel settan/totto/settantotto/settantanove

Doc da sola o insieme a lui

L1 da sola da so/lui non vole/sempre m'ha detto no dicembre andiamo tutta la famiglia poi ... comprava la macchina nuova ... poi faceva un'altra cosa per la fabbrica ... e non si avanzava mai il tempo di 555 portarmi in Italia ... ho detto ... GUARDA HO DECISO ... O VIENI O VADO ... combiniamo la storia ... no/no vengo anch'io poi ora di partire non poteva perché non si aveva qualche cosa ... dico allora arranggiati perché io ci vado ... e ho finito di andar s/io sono andata in Italia la prima volta quando ancora si pagava ... dodici:.: cruzeiro 
dodici mila cruzeiro/no/cruzeiro di quella ... era una:: cosa che si pagava ... si riceveva só dopo di tanto tempo qui in Brasile ... oltre il viaggio neh ... era una:: come dire ... una cosa fissa che tutti dovevano pagare per il governo ... e dopo ci restituivano dopo tanto tempo ... io ho pagato quello ... siamo arrivati all'aeroporto di

565 Doc lei è andata con chi

L1 io sola ... sola ah: io VADO signora io non me ne importo ... c'è l'aereo che va ... io vado ... in Italia poi che parlo l'italiano io non mi preoccupo neanche un poco/neh io ho viaggiato già molto ... ben sono andata in Italia e siamo arrivati e partivo dall'aeroporto di $570 \quad$ Viracopos... in Campinas ...siamo arrivati là ...ho dimenticato il papel che avevo pagato 'sti dodici mila ((risos)) non volevano imbarcarmi mantenuta ... nel/nello l'ufficio della polizia fino all'ultimo momento ... che non ho potuto salutar nessuno ... quando è il momento di imbarcare perché mio marito ha telefonato qui di qui hanno telefonato 575 là dicendo ... che era stato pagato e che l'avevo dimenticato ma era pagato ... allora m'han dato ordine che potevo imbarcare sono andata sulla nave ... ho fatto ciao a tutti da lontano ... e via son stata via quattro mesi ... son stata ... mia suocera lì ... ci abbiamo obbligato mio marito a venire ... mia suocera mi diceva così $X X$ tu non vai più 580 in Brasile ... se tuo marito non viene a prenderti ... allora ci telefoniamo ... e ci diciamo Arturo non vengo in Brasile se non vieni a prendermi ... e l'abbiamo obbligato a venire così dodici giorni prima che terminava il mio: ... il mio tempo perché c'è un tempo fixo ... lui è arrivato è stato dodici giorni ... è l'unica volta che ancora ha 585 visto la mamma perché dopo poco tempo ... lui è morto ... bah è morto nell'ottantuno ... era nel settantotto settantanove

Doc è morto prima di lei

L1 prima della mamma ... sì ... e abbiamo passato son stata là quattro mesi ... ho viaggiato molto ... con mio cognato 'ste una bravissima 590 persona ... mi portava un po' dappertutto i miei cugini i miei parenti ... ho fatto un viaggio meraviglioso

Doc abitano ancora in

L1 [sì

Doc [Piemonte

595 L1 quei che sono vivi sì ... la maggior parte son già morti neh perché eran tutti più vecchi di me ... mio cognato è vivo ancora ... c'ha ottantacinque ottantasei anni ma è vivo sta bene ancora c'ha la moglie che è ammalata c'ha quel ... zaimer là quel/cosa ... che perdono memoria

600 Doc hum hum e dopo che lui è morto lei è ritornata

L1 io son tornata ... sì in Ita/dopo mio marito è morto nell'ottantuno io sono andata ... nove mesi dopo in Italia ... penso che era 
nell'ottantadue perché è morto a maggio è nell'ottantadue sono andata in Italia

605 Doc e è restata quanto tempo

L1 è sempre resto un due mesi

Doc hum hum

L1 due mesi ... e poi sono andata nell:.:'ottantadue ... sono andata ... nell'ottantaquattro ... e s/nell'ottantacinque anche sono andata

610 un'altra volta ottantacinque ... è nell'ottantacinque dopo sono stata due anni ogni due anni ci andavo in Italia praticamente neh ... e un anno sono andata con la mia figlia ... con la Mara la più vecchia ... son andate siamo state a Parigi ... abbiamo girato un pochino neh ... ecco ... e dopo m'ho fatto qualche altro viaggio di qua perché ho 615 preso un viaggio di nave ... con la nave Eugenio Costa ho fatto trentadue giorni di mare ... meraviglioso ... il viaggio più bello che ho fatto io è stato quello ... siam partiti da Santos Rio de Janeiro poi :Salvador ... dopo in mare aperto ... e siamo andati a San Tomas ... a Arruda San Tomas ... a:: hum come si chama Cancun ... è:: 620 Cosomiel quel posto del Messico ... poi siamo stati in Nova New Orleans ... quella città che è stata rovinata adesso a poco tempo ... di New Orleans siamo stati a Orlando ... di Orlando Miami ... e dopo abbiamo fatto l'altro giro dall'altra parte delle isole ... e siam tornati a Brasil/nel Brasile

625 Doc trenta giorni

L1 trentadue giorni meravigliosi ... meravigliosi ... adesso una cosa che mi ha impressionato è arrivar a Rio de Janeiro ... in un'ora de/che incomincia il sole a andar giù cominciano a accendere le luci ... che spettacolo Rio de Janeiro ... QUELLO dovrebbe essere una delle 630 sette meraviglie del mondo ... perché è bella Rio de Janeiro ... a parte adesso perché c'è molto: disastro là ... ma arrivare di/dal mare ... è uno spettacolo ... è una cosa meraviglios/quello mi è rimasta

Doc si è sentita ( )

L1 mi è rimasta impressionata ... proprio eh

635 Doc va bene tornando un po' indietro ... quando lei è arrivata in Brasile ... è: che cosa le è piaciuto di più: ... che cosa le ha disturbato ... com'è stato ... sebbene che lei già veniva: dal Paraguai

L1 è

640

Doc ma già aveva passato un po' di tempo fuori di Italia ... ma arrivata in Brasile cosa ha sentito cosa le mancava ... cosa le è piaciuto ... cosa le è dispiaciuto 
L1 guardi io non: so perché ho subito trovato lavoro ... non nella Moda Berta perché prima di andare alla Moda Berta ho lavorato ... in una fabbrica che facevano maiô ... costume da bagno ... in quella nella:

645 rua Santo Antonio ... lì nel/Bexiga neh si chama lì/si chiama ecco m'han voluto molto bene ho bisticciato per uscire perché dovevo venir via che avevo trovato l'altro posto che era più addatto a me ... non volevano darmi i documenti che lavora/io sempre sono stata ... una lavoratrice competente e... le mie ore le facevo ... BENE non 650 ero di quelle che fa passare il tempo per andare a ricevere lo stipendio no ... allora dappertutto dove sono andata a pochi posti ... due posti ma m'han voluto molto bene ... e:: non lo so mi son trovata bene

Doc [il clima il cibo qualcosa diverso

655 L1 [anche qui in Bra/

L1 sì il cibo è qualcosa che dal momento che noi/mi facevo da mangiare ... trovavo quello che avevo bisogno ... quello che mi faceva specie in quell'epoca ... non era:: ... era vedere i bambini andar a scuola con le ... i piedi scalzi ... quell'epoca là era così ... malandati mal vestiti ...

660 vedere tutta quell'imondizie di riso e fagioli jogado ... nelle strade ... perché quando io sono arrivata ... son rimasta ... vedevo i negozi pieni perché i negozi erano quel/montagne di latte di olio che quello non si vede in Italia ... in Italia se c'è... dozzina di latte di olio lì poi c'è là nel magazzino ... ma in vista c'è poca roba ... qui no eran quelle

665 pile di cosa vedevo quell'abbondanza quello dicevo mamma mia ma in che paese sto andando ... qui deve essere una fartura come dicono i brasiliani ... meravigliosi neh ... poi vedevo nelle strade ... quelle lata di lixo pieno ... quel riso che cadeva da tutte le parti ... faggioli bistecche così ... di carne ... buttata via quello m'ha lasciato

670 un/un negozio che dicevo mio Dio ma come si spreca 'sto paese come si butta via: davvero quello m'ha lasciato proprio è stato una cosa ... che lo dico fino a oggi ... non l'ho dimenticata 'sta roba lì ... in città in São Paolo neh ... dove sono andata a vivere lì si vedeva quelle cose in in tremende ... una: una fartura di u:/un'abbondanza di

675 di cosa che era una cosa fantastica ... adesso già diminuisce un poco neh la cosa ... quello m'ha lasciato una certa/poi sono arrivata qui che era per/era vicino alla festa di San Paolo ... mese di agosto ... e mi son trovata bene mi portavano i vicini là $\mathrm{d} / \mathrm{ho}$ trovato due o tre signore molto gentili ... mi portavano in piazza a vedere ... le feste i

680 fuochi quelle cose lì non so ... sono stata bene ho trovato subito delle buone ... a/non dico amicizie ma dei buoni vicini ... che m'han/m'han voluto bene ... insomma e ho lavorato ho trovato lavoro che mi piaceva ... e son stata bene ... non/non ho avuto delle difficoltà maggiori no

685 Doc da quando lei è venuta a San Bernardo ... già ha abitato nel Parque Anchieta 
L1 sì sono stata dodici/dieci anni al Parque Anchieta

Doc [ma i

L1 [sì era mia casa

690 Doc ragazzi sono nati lì

L1 no ... i miei figli son nati a San Paolo ... tutti i d/una è nata in Paraguai e due sono nati in San Paolo na Mooca ... perché abitavo na rua Itaqueri ... nella: Belenzinho

Doc hum hum

695 L1 neh e son stata là ... dodici anni ... e poi son venuta al Parque Anchieta già erano tutti ragazzotti i miei figli

Doc ma è stato un bel posto per loro perché lì è una parte buona

L1 ah il Parque Anchieta è meraviglioso

Doc [sì io penso che

700 L1 [nostra casa

Doc è il meglio posto che c'è a San Bernardo

L1 ah sì anche il Parque Anchieta è un dei miglior bairri che ci sono neh ...noi abbiamo comprato una casa vecchia ...l'abbiamo rimessa a posto ... e ha un bel giardino c'è la casa in mezzo con il giardino tutto

705 intorno ... millecinquecento metri di giardino bella ... e adesso è affittata ... c'è una famiglia ... un avvocato dentro con la moglie e due o tre bambini

Doc hum hum

L1 piccolini

710 Doc in questa casa quanto tempo lei vive?

L1 qui son ventisette anni ... che abito qui ... ventisette anni ... certo quando son venuta qua non era così la casa neh ... era già mio marito aveva già riformata rimessa ... a posto ... ma era differente il cortile era ... tutto: molto disorganizzato ... molto in:/molt/perché qui 715 dentro ... chi abitavano erano giapponesi ... e avevano un allevamento di galline ... facevano/vendevano le uova quelle cose lì ... il cortile aveva tutte quelle gaiole di ferro ... loro non le volevano più ... le schiacciavano e le lasciavano lì ... allora il vento viene il vento viene la pioggia ... eran tutte coperte quando noi abbiamo 720 messo lì ... una: mio marito ha pres/preso una zappa è ( ) fuori tutte queste gabbie di ferro abbiam dovuto prendere un trattore ... mettere a posto ... lì abbiamo fatto un giardino meraviglioso ... abbiam fatto la piscina là per i bambini ... insomma abbiamo messo in ordine la casa ... che passava gente li guardavano dal dentro si 
725 fermavano per guardare ... che è pieno di gramado ... pieno di fiori ... no era bella la mi/adesso hanno fatto il galpone m'han tirato via tutto neh

Doc ma è anche molto grande

L1 sì è ancora grande ... e per lavorare ce n'è ancora del lavoro lì $730 \quad$... c'è sempre una persona che lavora lì

Doc ma lei ha una persona che l'aiuta no?

L1 qui in casa

Doc sì

L1 ce l'ho domani ... ma viene solo un giorno alla settimana

735 Doc solo

L1 è

Doc e lei si arranggia bene

L1 :ah io me la tengo io la ca/... non mi piacciono le serve a casa ... io ho avuto la serva tutti i giorni ... m'è durata vent'anni ... perché avevo 740 bambini giovani sa dan lavoro neh ma dopo è morto mio marito ... dico io sono sola non c'ho neanche più ... sì faccio il pranzo perché c'è mio figlio ... cosa sto ad avere una donna tra i piedi tutto il giorno mi scocciano neh quelle cose lì ... allora mi veniva due volte alla settimana ... e adesso dovrebbe venir due volte ... ma 'sta 745 settimana è venu/viene solo domani ... perché ha avuto qualche problema con i bambini neh ... e due volte alla settimana ... per me basta ... mi mantiene la pulizia grossa ... e il resto io me lo faccio

Doc ma lei esce per passeggiare ... lei non resta sempre qui dentro

L1 hum no io vado a fare le mie spese ... in banca ... vado in chiesa

$750 \quad$ ogni tanto ... al pomeriggio e faccio le mie cose ... ce l'ho l'automobile lì fuori me ne vado ... e la pittura anche ... adesso ho smesso un pochino ... dopo ti faccio vedere i miei quadri

Doc ahn ahn

L1 ma: ho fatto cinque anni ho pitturato con: andavo a scuola di pittura ...

755 ho fatto una montagna di quadri i miei figli ( ) la casa piena di quadri

Doc va bene donna XX ... la ringrazio molto dell'attenzione

L1 era solo quello

Doc sì sì se avrei bisogno di

L1 sembra che è andato bene la cosa

760 Doc sì buonissimo se avrò bisogno di più qualcosa

L1 sì venga 

Doc io le dirò
L1 venga venga quando vuole
Doc va bene grazie
765 L1 lei va alla messa degli italiani c'è la messa it/

\section{Análise das interferências:}

\subsection{Empréstimos totais:}

47 - c'è molto grano ... trigo ... grano ... melica : a entrevistada usa primeiramente grano, em seguida trigo e posteriormente repete grano, provavelmente preocupada com o entendimento do entrevistador.

87 - era un grande come fosse un grande sítio ${ }^{10}$ pieno di alberi ... 464-465 - abbiamo comprato 'sto sítio non è un sítio è una chácara neh era una chácara questa qua ... chácara che crea/allevavano le galline ... : indecisa quanto ao termo a ser usado, sítio ou chácara, pois em ambos os casos é difícil especificar a diferença entre os vocábulos, pois não há um correspondente exato em língua italiana.

Acreditamos que o vocábulo italiano que mais se aproxima seja podere.

108-109 - e io e mio papà mangiavamo ... CAVOLI ... PATATE ... E ... RA/E ... NABO ... : a entrevistada estava para dizer rapa, mas se confunde e usa o correspondente em português, nabo.

240 - ecco primo carro/primo automobile di mio marito : usa em um primeiro momento o vocábulo português, carro e, imediatamente se autocorrige, usando o correspondente italiano automobile, porém no masculino.

245 - no primei/prima in San Paolo neh ... : começa com o vocábulo em português, primeiro, mas imediatamente se autocorrige: prima.

312-313-314 - lì abbiamo comprato dei piatti di paste ... pasta una pasticceria finissima $\ldots$ ba/barata $\ldots$ poca/poca/poca spesa : não encontrando, em italiano, um vocábulo único para se expressar, usa o vocábulo português, mas com a pausa encontra uma correspondência em

${ }^{10}$ Segundo o Dicionário Houaiss, dentre as definições, encontramos as que mais se adaptam ao contexto:

sítio: estabelecimento agrícola de pequena lavoura; fazendola, quinta.

chácara: propriedade rural voltada para a avicultura, a pequena criação de animais, o plantio de frutas, legumes, etc. 
italiano: poca spesa, por não se recordar das expressões: prezzo economico, a buon prezzo, a buon mercato.

324-325 - ha dovuto fermarsi un tempo ..., em italiano per poco tempo, ou un certo tempo.

327-328 - per andar a trovare dove mi facevano 'sto carimbo se no non potevo tirar mio fratello ... : em italiano, timbro.

376-377 - ... e dovevo prepararmi per affrontare quell'esame per entrare $\mathrm{nel} /$ nella faculdade di/di/di medicina di/di ostetricia : em italiano, facoltà.

381 - partera neh ... : do português parteira, em italiano, levatrice, figura feminina que praticava o parto em domicílio, ou ostetrica.

461-462 - e di società ... con un minero e con un giapponese : do português mineiro, sem correspondente em italiano.

559-560 - quando ancora si pagava ... dodici::: cruzeiro dodici mila cruzeiro/no/cruzeiro: unidade monetária brasileira de um tempo, sem correspondente em língua italiana.

570-571 - ... ho dimenticato il papel che avevo pagato : usa o vocábulo português papel como sinônimo de documento, com grafia e significado análogos em ambas as línguas.

583 - prima che terminava il mio: il mio tempo perché c'è un tempo fixo : em italiano, fisso ou determinato.

643-644 - ho lavorato ... in una fabbrica che facevano maiô ... costume da bagno ... : vocábulo português de origem francesa não usado em língua italiana. A entrevistada imediatamente após o uso se autocorrige e diz costume da bagni.

666 - qui deve essere una fartura

674-675 - una fartura di u:un'abbondanza di di cose che era una cosa fantastica: vocábulo português com 0 correspondente em italiano un'abbondanza, lembrado pela entrevistada e usado na segunda oportunidade como uma autocorreção.

725 - ... che è pieno di gramado ... pieno di fiori : em italiano, prato.

\subsection{Empréstimos parciais:}

235 - anche l'automobile un Topolino ... si ricorda il Topolino? 240 - ecco primo carro/primo automobile di mio marito era un Topolino 410 - ... quella macchinetta là quel Topolino. 
Topolino um modelo de carro, masculino em português, no entanto feminino invariável em italiano, logo, o artigo indefinido, a preposição, o numeral e o pronome deveriam ser usados no feminino: una Topolino, la Topolino, prima automobile e quella automobile.

668 - quelle lata di lixo pieno ... : em italiano, pattumiera.

\subsection{Comutações:}

514-515-516 - ... perché gli altri giorni co 'ste novelle ... oramai mi sono attaccata alle novelle ... assisto anche quella del morro/morro/morro torto là quella novella lì è terribile. A entrevistada usa indevidamente novelle/novella ${ }^{11}$, partindo do português novelas/novela. Em italiano, telenovelle/telenovella.

morro/morro/morro torto provavelmente é o nome do programa televisivo sem correspondente em língua italiana.

\subsection{Mudanças de significado:}

59 - preferisce che non coltivino ... certi articoli certe cose ... : uso indevido do vocábulo. Poderia ter dito: certe colture.

82-83 - noi non abbiamo avuto 'sto lavoro dei bombardamenti : usa indevidamente o vocábulo. Provavelmente queria dizer: 'sto problema coi bombardamenti ou: 'sta preoccupazione coi bombardamenti.

122-123 - ... e poi avere quegli assalti perché di notte si sentiva $i$ bombardamenti : confunde-se e usa o vocábulo indevidamente, em vez de soprassalti.

337-338-339 - poi abbiamo preso un battello ... che abbiamo fatto il rio ... rio Paraguai ... siam venuti per il rio e siam arrivati in Assuncion ... Paraguai. Acreditamos que tenha feito uso do vocábulo rio, baseando-se na língua portuguesa, pois em italiano o vocábulo significa piccolo corso d'acqua, o que não é o caso do rio Paraguai. Em italiano, fiume Paraguai.

369-370 - ho fatto il ginnasio perché volevo ... in casa l'ho fatto particolare neh ... : parece-nos ter-se referido à escola italiana. Pensando entretanto em português, usa o vocábulo indevidamente. Caso tenha usado um empréstimo do português, este foi pronunciado em italiano, como se pode observar pela dupla consoante ' $n$ '.

${ }^{11}$ Dicionarizado como vocábulo português com desinência italiana, significando teleromanzo in moltissime puntate, a carattere popolare, di origine latino-americana. 
411 - così ha cominciato il nostro romanzo ... : vocábulo normalmente usado para especificar um tipo de narrativa literária. $O$ termo adequado para o que quis dizer é rapporto ou storia d'amore.

534 - ha un La Turandot ... la/la/la/le pezze di opera, do português peças ou trechos, em italiano, brani, arie d'opera.

669-670 - quello m'ha lasciato un/un negozio che dicevo mio Dio ma come si spreca 'sto paese : provavelmente do português negócio, quando da ausência do vocábulo correto para expressar um sentimento. Em italiano, poderia ter dito: un sentimento, una sensazione, un'impressione.

\subsection{Decalques}

41-42 - che son tombade come dicono qua : do português tombadas, ou seja, conservadas e protegidas pelo Governo. Em italiano, protette dalle Belle Arti.

\subsection{Verbos:}

60-61 - io vedo che al mio paese alle vite le hanno arrancate via ... : do português arrancar, com o significado italiano de estirpare, sradicare, strappare, togliere.

62-63 - se non tirano fuori non so più perché l'italiano è diventato così : do português tirar, retirar, arrancar, em italiano, estirpare, sradicare, strappare, togliere.

70-71 - e cresce l'erbaccia e non si incomodano/ non si preoccupano più ... : usa indevidamente o verbo incomodarsi, substituindo-o imediatamente pelo preoccuparsi.

113 - tutti i giorni erano cento grammi di carne e non dava per nessuno ... : do português dar, ser suficiente, em italiano: non era sufficiente/non bastava per nessuno ...

127 - terribile foi terrib/è stato terribile : inicia com o verbo em português, autocorrigindo-se imediatamente: è stato, fu.

197-198 - allora chi poteva uscire se ne andava ... : uso inadequado do verbo, poderia ter dito partire.

229 - acho che è provincia di Pavia già di Pavia ... : uso do verbo em português, quando o correspondente em italiano é penso ou credo. 
249 - ... che lui voleva montare la fabbrica : do português montar, em italiano, metter su una fabbrica, aprire/allestire una fabbrica.

252 -253 - sì aspetti un momento deix/ver son venuta in San Bernardo ... : do português deixe-me ver, com o correspondente em italiano lasciami pensare, lasciami vedere ou como diz anteriormente, aspetti un momento.

291-292 - ... quei alti che c'han quella cosa in testa qui ... che falava Alá: entrate entrate siamo entrati in un posto ... : em italiano, parlava.

307-308 - è stato anche un diversivo perché ha tirato un pochino la paura, usa indevidamente o verbo. Para este caso poderia ter usado ha tolto, ha eliminato.

328 - se no non potevo tirar mio fratello ... dalla nave ...

329-330 - ... e son arrivata due ore prima che la nave partisse per tirar mio fratello. Em todos os casos, usa o verbo português tirar com o sentido de remover, afastar, em italiano, far scendere, togliere.

333-334 - perché avevo paura di ... attaccarmi a altra gente : uso indevido do verbo. Poderia ter dito mantenere contatto con altra gente, ou contattare altra gente.

465 - chácara che crea/allevavano le galline ... : começa com o verbo do português criavam, mas autocorrige-se: allevavano.

470-471 - ... che lui mex/a:avev/sempre la/la/l'hobby delle orchidee ... 473-474 - ... andava giù mex/ far le sue orchidee ...

Em ambos os casos parte do verbo português mexer, não encontrando o correspondente italiano, coltivare.

536-537 - alla fine toca/suonano I'Inno Nazionale di Mameli : parte do português tocar, e autocorrige-se imediatamente: suonano.

645 - ... lì ne/Bexiga neh si chama lì/si chiama ecco : confunde-se e usa o verbo em português, em vez do correspondente italiano, si chiama. Vale ressaltar que existe em vários dialetos o verbo ciamar, porém optamos pela interferência do português.

660 - tutta quell'imondizie di riso e fagioli jogado ... nelle strade ... : em italiano, buttati ou buttati via.

726-727 - m'han tirato via tutto neh : do português tirar. Neste caso, em italiano, 0 verbo correspondente é estirpare/togliere: m'han estirpato/tolto via tutto neh. 


\section{Impropriedades:}

$41-\ldots$ possono riformarle dentro ma fuori no ... : uso impróprio do verbo, o uso correto è ristrutturare.

233-234 - che aveva già una piccola officina là formata ... : do português formada, ou o particípio passado do verbo italiano formare. De qualquer forma, em ambas as línguas o uso deste verbo seria impróprio nesta situação. Normalmente em italiano se diz un'officina già pronta ou già montata.

438-439 - mamma perché non mi spieghi tutta la tua vita che io ti faccio un libro ... : uso impróprio do verbo. Poderia ter dito: perché non mi racconti tutta la tua vita...

712-713 - mio marito aveva già riformata rimessa ... a posto : uso impróprio do verbo, melhor seria, ristrutturata.

\section{Preposições:}

246 - nella::... là no Tatuapé : usa a preposição articulada em português. Em italiano: nel Tatuapé.

303 - fuggiti di là dentro perché abbiamo avuto paura de/ma cosa: preposição em português. Em italiano: $\underline{\mathbf{d i}}$.

436 - ... praticamente mi son sposata di vedova non di ... engana-se e usa duplamente a preposição $\underline{\text { di, }}$ em vez de $\underline{\text { da. }}$.

460 - ... prima l'abbiamo/l'ha avuta là na Cantagalo in São Paulo ... : usa a preposição portuguesa em vez da italiana, nella.

627-628 - ... in un'ora de/che incomincia il sole a andar giù : em italiano, di.

692-693 - e due sono nati in San Paolo na Mooca ... perché abitavo na rua Itaqueri ... : usa duplamente a preposição portuguesa em vez da italiana, nella.

\section{Pronomes:}

55 - ci andavo molto cada due anni una ... volta all'anno ... : em italiano, ogni due anno.

406 - meu Arturo si è innamorato della mia bambina, em italiano, il mio. 


\section{Advérbios:}

13-14 - ... modelli só di carta neh ...

143-144 - e noi non l'abbiamo saputo só due anni dopo quando è finita la guerra : em italiano, soltanto.

509-510 - sono stata all'ospedale a visitarlo tutto ci vediamo somente sim : os dois advérbios foram usados em português. Em italiano, soltanto sì.

531 - come è antigamente le case antiche ... : em italiano, anticamente.

535 - han suonato che alí $\mathrm{mi} / \mathrm{mi} / \mathrm{mi} / \mathrm{mi} /$ vien la pelle d'oca ; em italiano, lì ou là.

561 - ... si riceveva só dopo di tanto tempo qui in Brasile : em italiano, soltanto.

\section{Conjunções:}

62-63 - se non tirano fuori non so più perché l'italiano è diventato così : do português senão. Em italiano, altrimenti.

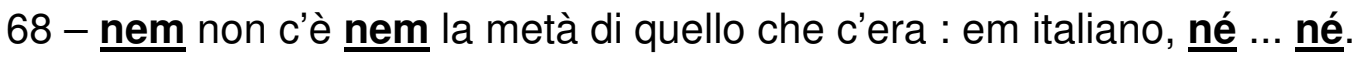

\section{Observações:}

$1-69-\ldots$ lasciano andare così a: lì i pezz/c'è dei pezzetoni grandi di terra, non encontra o correspondente em italiano para especificar uma grande faixa de terra, em italiano, un'area, una grande area.

2 - $\quad 112$ - ... un librettino di/di seligni allora cosa si faceva andava a/ 114-115 - allora mia mamma aspettava fine settimana andava a tirare i selini là prendeva un chilo ... : em duas ocasiões procura o correspondente em italiano, tagliandini, sendo que no segundo caso usa um vocábulo mais próximo do português, selo, com a desinência do diminutivo em italiano, -ini.

3 - $\quad 174$ - c'hanno tre figli ... tre figli uomini : em português é normal dizer filhos homens, o que não acontece em italiano. Acreditamos que tenha usado o vocábulo por esquecimento ou o hábito do uso em potuguês, mas recorda-se e usa corretamente na linha:

176 - tutti maschi i figli tutti parlano italiano

4 - $\quad 212-$ c'è qualche problema neh quando não dá certo ... 249-250 - c'ha avu/dei soci anche non dava certo ... 
Em ambos os casos usa a expressão em português, ainda que na vez sucessiva use a negação em italiano. O que a entrevistada quis dizer é que non va bene, non andava bene.

5 - $\quad 262$ - siete partiti di Italia in che mese:

263 - io son partita in gennaio ... dall'Italia. Neste caso, a entrevistadora formula a pergunta com a preposição indevida e a entrevistada a corrige, com muita sutileza, na resposta.

6 - $\quad 361$ - e lì è lì che ha cominciato il nostro: fine neh ... : usa o masculino do português o nosso fim, correspondente em italiano, la nostra fine

7 - 363 - si dava le cose buone - si dava alle cose buone

\section{Empréstimos italianizados:}

80-81 - il sole diventava scuro ... di tanti avion che passavano per andare a Torino Milano 123 - si sentiva i bombardamenti passar gli avion ... : do português avião, em italiano, aereo.

461 - ... c'è un galpone grande lì

467 - ha subito costruito 'sta fabbrica lì con il galpone lì ...

469 - ha comprato ha fatto gal/galpone qui ...

726 - adesso m'hanno fatto il galpone

Do português galpão, em italiano, capannone.

702 - il Parque Anchieta è un dei miglior bairri che ci sono : do português bairros, em italiano, rioni ou quartieri.

717 - il cortile aveva tutte quelle gaiole di ferro : do português gaiolas, em italiano, gabbie.

\section{Citações estrangeiras:}

338-339 - e siam arrivati in Assunción ... : Assunzione.

341 - il console paraguayo era della mia città ... : paraguaiano ou paraguayano.

598 - che è ammalata c'ha quel ... zaimer là quel/cosa : Alzheimer

\section{Comentários:}


1 - 527 - ai meu Deus. Expressão portuguesa correspondente à italiana Oh Dio Mio.

2 - Durante todo o registro do inquérito, a entrevistada se sentiu muito à vontade. Não tivemos em nenhum momento que motivá-la a falar, pois com muita simpatia nos contou os fatos tanto de sua vida na Itália, quanto no Paraguai e no Brasil. Com a mesma naturalidade se entregou a momentos de emoções quando se lembrou de seu irmão morto na guerra e do falecimento de seu segundo marido. Comunica-se bem em língua italiana e acreditamos que este fato se deva às diversas viagens que ela fez e faz com uma certa regularidade à Itália.

\section{Tabela no 1 - Empréstimos Totais}

\begin{tabular}{|l|l|}
\hline \multicolumn{1}{|c|}{ Português } & \multicolumn{1}{c|}{ Italiano } \\
\hline trigo & grano \\
\hline sítio (três vezes) & fazendola \\
\hline chácara (três vezes) & podere \\
\hline nabo & rapa \\
\hline carro & automobile \\
\hline primei/ & prima \\
\hline barata & a buon mercato \\
\hline un tempo & per poco tempo/un certo tempo \\
\hline carimbo & timbro \\
\hline faculdade & facoltà \\
\hline partera & levatrice \\
\hline minero & sem correspondente \\
\hline cruzeiro (três vezes) & cruzeiro \\
\hline papel & documento \\
\hline fixo & fisso/determinato \\
\hline maiô & costume da bagni \\
\hline fartura (duas vezes) & abbondanza \\
\hline gramado & prato \\
\hline
\end{tabular}


Tabela no 2 - Empréstimos Parciais

\begin{tabular}{|l|l|l|}
\hline \multicolumn{1}{|c|}{ Forma apresentada } & \multicolumn{1}{c|}{ Português correto } & \multicolumn{1}{c|}{ Italiano correto } \\
\hline lata de lixo & lata de lixo/lixeira & pattumiera \\
\hline un Topolino (duas vezes) & um Topolino & una Topolino \\
\hline il Topolino & o Topolino & la Topolino \\
\hline quel Topolino & aquele Topolino & quella Topolino \\
\hline primo automobile & primeiro automóvel & prima automobile \\
\hline
\end{tabular}

Tabela no 3 - Comutações

\begin{tabular}{|c|c|c|}
\hline Forma apresentada & Português correto & Italiano correto \\
\hline novella/novelle (três vezes) & novela/novelas & telenovella/telenovelle \\
\hline
\end{tabular}

Tabela no 4 - Mudanças de significado

\begin{tabular}{|l|l|l|}
\hline \multicolumn{1}{|c|}{ Forma apresentada } & \multicolumn{1}{c|}{ Português correto } & \multicolumn{1}{c|}{ Italiano correto } \\
\hline articoli & artigos/produtos & colture \\
\hline lavoro & problema & preoccupazione \\
\hline assalti & sobressaltos & soprassalti \\
\hline rio (três vezes) & rio & fiume \\
\hline ginnasio & ginásio & corso di avviamento \\
\hline romanzo & romance/relacionamento & rapporto \\
\hline pezze & peças/trechos & brani/arie d'opera \\
\hline negozio & sentimento & sensazione/impressione \\
\hline
\end{tabular}

Tabela no 5 - Decalques

\begin{tabular}{|l|l|c|}
\hline \multicolumn{1}{|c|}{ Forma apresentada } & \multicolumn{1}{|c|}{ Português correto } & Italiano correto \\
\hline tombate & tombadas & protette dalle Belle Arti \\
\hline
\end{tabular}

Tabela no 6 - Verbos

\begin{tabular}{|l|l|l|}
\hline \multicolumn{1}{|c|}{ Forma apresentada } & \multicolumn{1}{c|}{ Português correto } & \multicolumn{1}{c|}{ Italiano correto } \\
\hline hanno arrancate & arrancaram & hanno strappato/tolto \\
\hline tirano & arrancam & strappano/tolgono \\
\hline si incomodano & se preocupam & si preoccupano \\
\hline non dava & não dava/não era suficiente & non bastava/non era sufficiente \\
\hline foi & foi & è stato \\
\hline uscire & sair/partir & partire \\
\hline
\end{tabular}




\begin{tabular}{|l|l|l|}
\hline \multicolumn{1}{|c|}{ Forma apresentada } & \multicolumn{1}{c|}{ Português correto } & \multicolumn{1}{c|}{ Italiano correto } \\
\hline acho & acho & penso/credo \\
\hline montare & montar/abrir & metter su/aprire/allestire \\
\hline deix/ver & deixa-me ver & lasciami vedere \\
\hline falava & falava & parlava \\
\hline ha tirato & tirou/retirou & ha tolto/ha eliminato \\
\hline tirar (duas vezes) & tirar & far scendere/togliere \\
\hline attacarmi & contactar & contattare \\
\hline crea/ & criavam & allevavano \\
\hline mex/ (duas vezes) & cuidava/mexia & coltivava \\
\hline toca/ & tocam & suonano \\
\hline si chama & se chama & si chiama \\
\hline jogado & jogados & buttati \\
\hline han tirato & tiraram & hanno stirpato/hanno tolto \\
\hline
\end{tabular}

\section{Gráfico das Principais Interferências (I-5)}

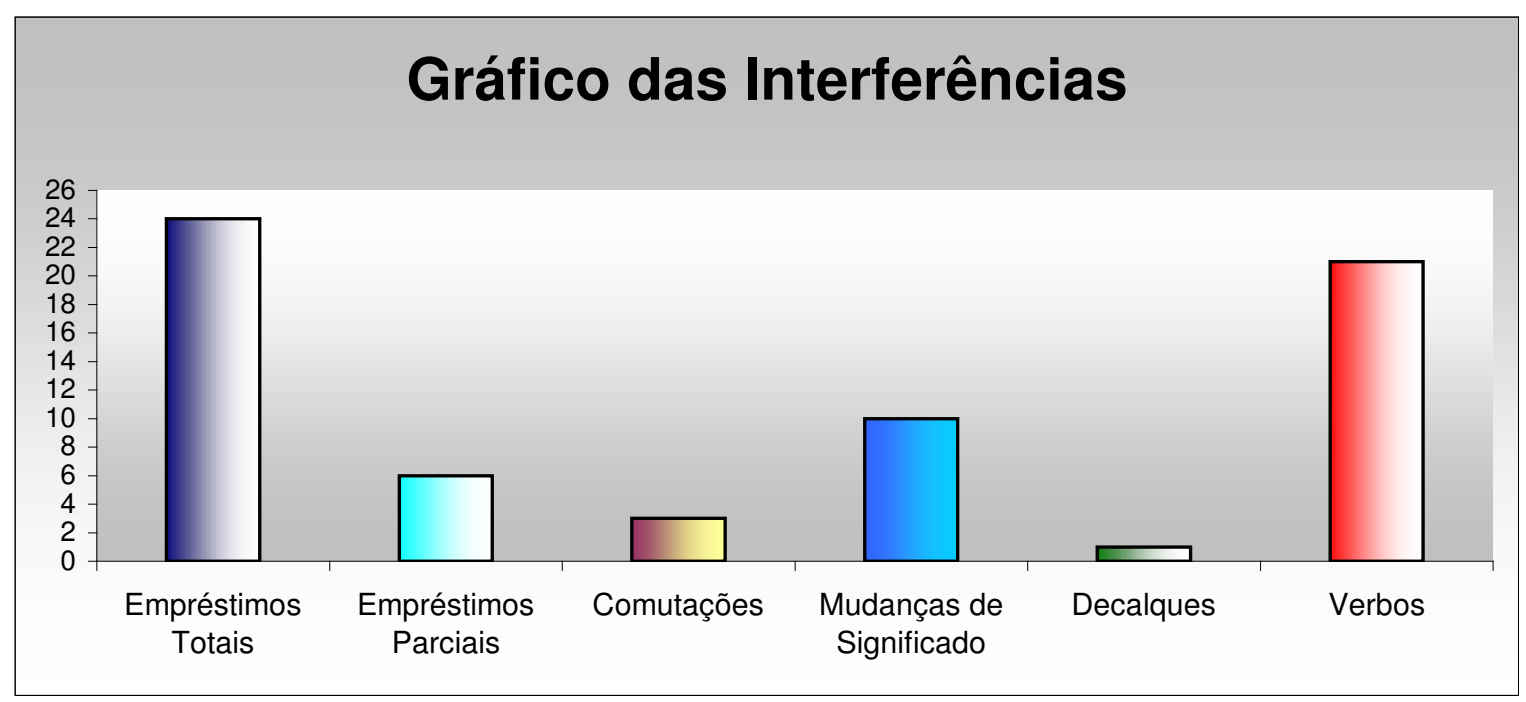




\section{INQUÉRITO № 6 (I-6)}

Sexo: Masculino

Data de nascimento: 28/03/1934

Idade: 73 anos

Cidade: La Spezia

Província: La Spezia

Região de Proveniência: Liguria

Profissão: aposentado

Data da entrevista: maio/2007

$\begin{array}{lll}1 & \text { Doc } & \text { nome e cognome } \\ \text { L1 } & \text { XXX XXX } \\ \text { Doc } & \text { età } \\ \text { L1 } & \text { sessan/settantatré anni }\end{array}$

5 Doc settantatré anni?

L1 settantatré

Doc professione?

L1 professione adesso sono ... sono stato ... giubilato ... ossia sono in pensione ... ma io ho fatto diversi lavori tra i quali ... io ero stato

10 capo di officina della Mercedes Benz ... sob/sobre gli attrezzi di ferramentaria ... perciò ho fatto diversi lavori entre i quali ... ho lavorato in diverse compagnie qui in Brasile ... in Italia però avevo studiato e ... di là ho potuto averne ... profitto dei miei studi

15 L1 su questo

Doc regione e città di provenienza

L1 La Spezia provincia neh ... e:: avevo ... avevamo noi una posse/possessione là in la Spezia ... ahn dove avevamo nostro appartamento ... però mio padre aveva anche in campagna a Biazza

$20 \quad \ldots$ u:una proprietà ... colla quale noi si viveva a quei tempi ... perché era/noi si viveva di agricoltura ... e avevamo una cantina anche nelle Cinque Terre... e: per cui mio padre... eh/ lo chiamava come Tramonti ... era chiamato Tramonti ... si andava a piedi non c'era/a quei tempi non c'erano strade ... che portassero là perciò era una bella

25 camminata neh 
Doc :era una città di campagna che lei ha detto dove voi avete piantagione

L1 sen/senza dubbio ... era di/di cui noi si viveva ... perché mio padre ... inoltre a quello ... era portalettere perciò erano i pochi che avevano stipendio ... e a quei tempi i nostri ... diciamo i nostri compaesani ... tutti vivevano di agricoltura ... non si aveva soldi ... era l'Italia era molto povera a quei tempi ... e allora per esempio per fare un esempio ... si piantava il grano ... e quando si doveva macinare al molino ... si dava dieci per cento ... e per quello e per non pagarlo si dava dieci per cento ... e quando si andava al frantoio per/per le olive era la stessa cosa ... perciò era una una cosa ... e noi vivevamo giustamente di questo ... e in una di queste occasioni che andava a aiutare mio padre ... nei lavori della vi/della vite ... che se noi avevamo le viti ci facevamo il nostro vino dipendendo da... 40 dall'annata ... noi facevamo millecinquecento duemila litri ... che si bevevano tutti noi noi avevamo noi/i nos/i nostri componenti della nostra famiglia ... eravamo in otto ... perciò mio padre: fino a da piccolo io bevevo anch'io il vino e la mamma tutti insomma ... era una cosa familiare perciò per quello che volevo: dire ... che una delle ragioni ... che io posteriormente sono venuto qua in Brasile ... uno di questi giorni che io aiutavo mio padre nei lavori ... lui $\mathrm{mi} /$ sedutosi per fare uno spuntino ... mi ha detto ... XXX sono molto preoccupato con la nostra famiglia ... e io gli ho risposto pa/babbo ma di che della guerra? sì anche della guerra però ... la guerra ... finirà ... invece il problema che io sto pensando è più grave ... e gli ho detto perché papà? perché: vedi noi siamo ... in sei/siete in sei figli ... se noi ... possiamo vivere ... con quello che che noi/noi ri/riusciamo a ri/ricevere della terra ... però se io devo distribuire a sei persone questo ... come farete voi a vivere ... perché anche voi avrete la 55 vostra moglie i vostri figli ... e non ci avete bisogno di/di con questo poco che ... noi non possiamo ... allora penso che a qualcuno di voi dovrà sacrificare ... e andare fuori dall'Italia per cercare: altri posti ... e quello mi è rimasto nella/nella mente ... e.: posteriormente ... è successo che uno dei nostri parenti lontani qui del Brasile ... è venuto a trovarci in Italia ... già qualche anno dopo ... e io sono stato ... ahn: diciamo così ... messo a disposizione di questo parente per fargli conoscere la città ... ho fatto il cicerone per lui gli ho fatto conoscere ... i musei ... gli ho fatto conoscere le chiese ... gli ho fatto conoscere i bei/bei monumenti ... insomma ... ho fatto per lui un cicerone è lui si/si è molto invaghito $\mathrm{di} \mathrm{mi} / \mathrm{mi}$ è rimasto gli sono rimasto simpatico ... e mi ha chiesto se io ... volessi venire in Brasile ... io gli ho detto sì mi piacerebbe perché io non conosco ma ... lui mi ha detto che avevo molti parenti qua in Brasile ... e allora io gli ho detto sì ma mio padre è l'unico che lavora e noi non abbiamo ... possibilità ... che qualcuno faccia questo per noi ... perciò io non $\mathrm{mi} /$ non penso di andare in Brasile ... comunque ... e lui ha detto ma 
bene volevo sapere solo se ti piacerebbe ... e quando sono stato a accompagnarlo alla stazione ... lui che parlava un italiano ... discreto così ... lui/ho detto beh allora addio ... piacere d'averlo conoscere lui m'ha detto ... addio no ... arrivederci ... beh io sono rimasto così pensativo perché dicevo ... arrivederci è che ci rivediamo presto perciò ... ahn: ma lui ha detto/io ho detto guarda che è addio ... no/no ha detto arrivederci a presto ... perciò sono rimasto così mezzo confuso $\mathrm{ma}$... mi è passato dalla mente ... passato quasi/circa tre 0 80 quattro mesi ... mi arriva una lettera dal Brasile dicendo ... che lui aveva parlato con i miei zii ... con i miei cugini che avevo qua in Brasile ... e loro avrebbero ... mi avrebbero ... pagato il viaggio e inoltre ... avrei già ... una casa per abitare assieme a una famiglia ... dei miei cugini ... e in questa casa c'erano três/tre figlie ... e: due 85 figli ... perciò io ho fatto il terzo figlio ... siamo/sono arrivato qua in San Bernardo ... e questa famiglia di José Lazzuri ... mi ha ospitato assieme alla a::.: queste ... tre sorelle che ave/tre sorelle ... che io le ho considerate anche adesso che sono vive ... sono le mie sorelle qua ... son maggiore do che/di che me ... e c'erano gli altri due

90 fratelli che infelicemente già sono ... sono decessi ... e io perciò mi son trovato qua in Brasile senza saperlo ... e e avendo fatto la volontà di mio padre che tempo addietro mi aveva detto ... e io posteriormente ho portato altri due fratelli qua in Brasile

$\begin{array}{lll}95 & \begin{array}{l}\text { Doc } \\ \text { L1 }\end{array} & \begin{array}{l}\text { ma prima solo lei } \\ \text { prima solo io }\end{array} \\ & \text { Doc } & \text { in che anno lei è venuto? } \\ \text { L1 } & \text { nel millenovecentocinquantadue } \\ & \text { Doc } & \begin{array}{l}\text { cinquantadue } \\ \text { [dopo la guerra } \\ \text { [febbraio } \\ \text { sono arrivato qui il venti febbraio del cinquantadue }\end{array}\end{array}$

Doc dopo il suo arrivo noi parleremo un pochettino ... adesso lei si ricorda della guerra? che cosa lei si ricorda e può raccontarmi

L1 guardi ... la guerra per me ... è stata una cosa terribile ... in primo 105 caso noi quando abitavamo ancora a:: alla Spezia ... nell'appartamento perché mio padre come le avevo detto anche se aveva un'altra abitazione là a Biazza dove ... si poteva coltivare ... lui ha portato la famiglia ... in città ... perché voleva che noi studiassimo come di fatto stavo studiando già a scuola là ... e allora ... la guerra è scoppiata ... è cominciato i primi ... i primi: segni quando sono arrivati ... eh in Italia le/le truppe alleate che: sono sbarcate in Sicilia... e una delle cose che mi ricordo bene ... come le/le saline italiane sono tutte in Sicilia ... una delle prime cose che hacominciato a mancare per noi era il sale ... il sale 'sta era una cosa molto 
importante per uno mangiare/mangiare le:.:. diciamo così ... qualsiasi pietanza ... senza sale è:: terribile ... noi che abitavamo vicino al mare ci/con l'acqua salata ci si arrangiava ... ma le altre persone che abitavano un po' più lontane ... allora noi facevamo bollire molta acqua di mare ... per fare che/che dopo che asciugasse ... rimanesse un fondo di sale ... e si poteva così ... fare un: abbiamo fatto un: venti trenta chili di sale ... per poter cambiare con farina ... con altre cose che le persone ... che abitavano più lontano dal mare loro avevano la farina avevano le altre cose ... ma non avevano il sale ... perciò ... per diciamo due chili di sale si cambiava con un sacco di 125 farina ... era una cosa così ... então sono state le prime cose che mi ricordo ... però diciamo così ... quello che più $\mathrm{mi} \mathrm{ha/mi} \mathrm{ha} \mathrm{marcato}$ è stato nell'epoca che ... già si sentivano i rimbombi dei cannoni ... che stava arrivando gli alleati per ... giustamente ... liberare l'Italia dai tedeschi ... i tedeschi ci opprimivano là ... noi avevamo certi/non potevamo fare niente che c'erano sempre i tedeschi ... ahn era una cosa terribile ... e cominciarono i bombardamenti de/degli alleati per giustamente noi/come la Spezia ... è un porto militare ... è:.:. è un golfo ... in cui ... c'è un'entrata solamente di trecento metri ... e tutto ... e tutto intorno ... sono le montagne ... e su queste montagne 135 c'erano cinquantatré batterie antiaeree ... per giustamente salvaguardare la la flotta italiana che era sediata là ... tutte le navi ... tutti i sommergibili stavano ... là in la Spezia ... perciò noi eravamo molto:: bombardati ... perché loro volevano arrivare sulle ... sulle navi però ... come c'erano le/le batterie antiaeree che proteggevano ... loro 140 dovevano lanciare le bombe di molto alto ... e perciò no/non riuscivano a colpire ... le navi anziché ... le nostre abitazioni hanno sempre ... più ce/allora noi/quando si è cominciato i primi bombardamenti ... noi abitavamo in una regione che vicino avevamo un tunnel del treno ... una galleria ... perciò la prima cosa che ci è 145 venuto in mente quando suonava la sirena d'allarme ... a quei tempi loro ... pochi minuti prima che arrivassero gli aerei avevano ... quella indumentaria ... radar dell'epoca che erano molto grezzi ma ... infatti ( ) un po' allora suonava la sirena ... noi tutti camminavamo per andare a rifugiarsi sotto la galleria de treno ... là eravamo sicuri ... e 150 di fatti quan/quante volte... si andava a dormire ... già vestiti ... ognuno con la sua valigetta dalla parte ... perché quando suonasse la sirena tutti dovevano scappare e andare a rifugiarsi ... allora ... una di queste eh queste sirene che suonavano mi ricordo ... e:: mio fratello era più piccolo ... allora mia/mio padre ha detto ... io prendo Carlo ... 155 l'altro la mamma ha detto io vado con Giuliano io ero già un po' più grande e ho detto io vado da solo... cercherò di arrivare prima di voi ... io ero svelto a quei tempi ... e allora sì tutti quanti scappavano giovani e vecchi no: era/era una una cosa di persone camminando verso la galleria ... e/e cominciato in/quei a quell'ora già gli/gli aerei 160 stavano ... sopra noi ... e le batterie hanno cominciato a sparare allora sembrava un pandemonio perché c'era ... i riflettori che per 
vedere se perlustravano in cielo se vedevano gli aerei ... e allora cominciato i bombardamenti e io mi sono spaventato ho cominciato a correre ... ali una scheggia ... di un proiettile ... mi ha/mi ha preso qui e io sono caduto ... sulla canaletta che c'è è:: dove sono i binari del treno ci sono le canalette ... e è una canaletta un po' profonda più di un metro neh ... e sono caduto e devo aver perso i sensi perché sono svenuto ... quando mi sono risvegliato ... è::.:.: vedevo che le persone già erano tutte si sentivan le/lo scoppiar delle bombe tutto ... e il 170 bombardamento già era pieno movimento ... allora i marinai che venivano da lontano anche loro per proteggersi andavano a correre ... mi hanno ... visto ah c'è un bambino ferito lì ... allora mi ricordo che uno dei marinai mi ha preso sotto il braccio ... l'altro dall'altra parte ... e mi hanno detto ... metti i piedi sulla rotaia ... che così mi trascinavano ... e io non ero tanto pesante ma insomma ... per loro poter correre per andar ... mi ricordo e allora quando siamo entrati nella galleria ... tutto buio ognuno qualche d'uno ci aveva ...ah qualche/qualche diciamo farolete a pila neh diciamo ... e allora ... dicevano per me dove è XXX mia madre mi cercava ... e allora ... ha 180 detto guarda c'è un bambino ferito ... e non si sa chi è perché è pieno di sangue perché come ... la scheggia mi aveva battuto vicino alla tempia qua che si avesse battuto qui ... non sarei più per raccontare qui... allora ero/avevo una maglione bianco che mia madre stessa aveva ... fatto per me ... e ero pieno di sangue ... ma non ave/non 185 era una ferita dopo è stato trovato che $\mathrm{n} / \ldots$ ho fatto solo due punti e ... va bene ma come ... il/il/il momento di io stare svenuto e di passare alcuni minuti ... mi ero riempito di sangue allora ... sembrava una cosa e allora ... mia madre voglio vedere chi è voglio vedere chi è ... e quando $\mathrm{mi}$ ha visto che ero io perché mi ha riconosciuto per causa della maglia di lana ... :è svenuta anche lei ... abbiamo avuto invece/dopo c'era un medico là che era ... mi ha ripulito la ferita ... guarda non c'è niente di/di grave ... dopo che finito il bombardamento andiamo là nel mio consultorio ... facciamo una/curativo e pronto ... e vuol dire ma ... è stato una tremenda di 195 una ... di una cosa... posteriormente appunto per quello che è successo quello ... mio padre è:/ha detto non possiamo stare più qui alla Spezia ... cosa facciamo? allora a:/andiamo a sfollare ... per la Toscana ... siamo andati in Garfagnana che mio/mio nonno è di là ... mia madre pure è nata là in/a Chiosa proprio neh ... e allora noi 200 siamo andati là a Castelnuovo Garfagnana ... c'era una casa che abbiamo affittato ... e siam rimasti là per un tempo allora mio padre ... veniva tutti i venerdì ... dopo tornava alla Spezia per fare il suo mestiere di portalettere ... e noi abbiamo abitato là per un po' di tempo ... fino a quando abbiamo saputo che giustamente quando 205 arrivavano gli alleati ... andrebbero a passare giustamente per Castelnuovo Garfagnana ... allora siamo dovuti partire ... e questa volta invece di rimanere alla Spezia siamo andati ... nelle Cinque 
Terre là na cantina perché là non c'era pericolo di bombardamenti perché ... era dall'altra parte del/de/ là dove bombardavano la Spezia ... perciò vedi quante cose che abbiamo fatto in:: qualsiasi tempo ... io ho fatto la ter/la quarta la quinta elementare in Italia ... in tre o quattro scuole diverse ... imagína se io posso esser/ave/ aver imparato qualcosa ... ci passavano: facevano promuo/promuovere di a/di anno anche se non ... perché dicevano ... po/poveretti cosa 215 ha/hanno fatto di male ... non son potuti venire a scuola ... un giorno c'era un bombardamento ... un giorno c'era di quà di là ... e allora è una cosa brutta

Doc quanti anni lei aveva in questo periodo?

L1 in questo periodo ... io avevo ... dodici anni ... dodici anni tredici anni 220 così ... più o meno

Doc va bene e:: in che anno $e$ in che mese lei è venuto in Brasile e si ricorda con quale nave?

L1 sì sì mi son arrivato con una nave argentina ... perché ... io: quando siamo ... partiti là da Genova ... eh: mia mia sorella ... mio padre non 225 è potuto venire:: e allora mia sorella maggiore è venuta per accompagnarmi fino a: alla nave ... e il capitano mi ha detto come ero minorenne ... a quei tempi ci avevo diciassette anni ... mi ha detto lui resterà in mia consegna io lo ... lo farò ... conoscere a un'altra famiglia ... e di fatti lui $\mathrm{mi} h \mathrm{ha} / \mathrm{mi}$ ha portato in una cabina ... c'era $\underline{\mathbf{o}}$ 230 padre ... e altri due figli ... e lui ha detto guarda ... questo ragazzo qua ... farà parte della tua famiglia ... provvisoriamente per questo viaggio ... se lui fa qualche cosa di sbagliato me lo ... me lo dici subito che io lo ... non lo faccio ... non lo faccio ( ) io no invece sono stato sempre un/una persona da quei tempi sempre molto ubbidiente non 235 ho avuto problemi ... perciò tutti i giorni mi chiamava il passajero señor $X X X$ si apresenta a la cabina del comandante ... perché era argentino neh ... e lui mi diceva se: se ero ben trattato se avevo bisogno di qualche cosa ... perciò ... fino all'ultimo giorno che lui mi ha detto adesso oggi ... vieni qua in cabina ... siamo arrivati a Santos $240 \quad \ldots$ te di qua ... mi fai vedere dove sta tuo zio ... che lui sarà chiamato a bordo ... e io ti consegnerò ... se tuo zio non è venuto ... te ritorni in Italia con me ... perché io non posso ... lasciarti scendere ... perciò appena che siamo arrivati là che io non lo conoscevo ... lo conoscevo di fotografia mio zio qua ... perché: allora: l'ho visto ho detto eccolo là mandato il marinaio a prenderlo ... e io son potuto così sbarcare ... e sono arrivato qui a: San Bernardo ... dove ho trovato una nuova famiglia non mi son ... trovato mai ... come quello che ... passa/hanno passato i miei antepassati ... che han t/han trovato di andare a lavorare nel/nel/nei/nei cafezal nelle altre cose no ... ho 250 io ho trovato qui un'altra famiglia ... $\mathrm{mi}$ son trovato subito da/primo/primo giorno ... come se fossi nato qui in Brasile ... perciò io c'ho un grande amore per questa terra ... anche se sono italiano ... e 
io c'ho mio figlio ... ci sono i miei nipoti ... sono tutti brasiliani ... anche loro hanno u/la doppia cittada/cittadania ... e hanno/hanno approfittato di questo io per esempio ... io vorrei essere anch'io doppia cit/doppia cittadino non posso ... o scelgo essere brasiliano ... o italiano ... ma io come ho una piccola pensione là in Italia ... io pretendo continuare italiano

Doc e in che anno lei è arrivato?

260 L1 nel millenovecentocinquantadue ... in febbraio ... venti di febbraio

Doc come si chiamava na nave?

L1 Corrientes

Doc Corrientes

L1 è il capitano si chiamava ... Pablo Neruda ... che era nome di un

265 L1 [poeta famoso

Doc [sì sì sì

L1 ero ... non lo ... sapevo ma Neruda era cileno neh

Doc sì

L1 invece lui era argentino

270 Doc sì

Doc va bene allora appena arrivato ... come ha cominciato la sua vita è andato subito al lavoro ha potuto studiare

L1 beh io ... appena che sono arrivato qua in Brasile ... ho riincontrato/ questa persona che si chiama Attilio Miele ... che aveva una fabbrica

275 di mobili in San Bernardo ... dove oggi è c'è la piazza Lauro Gomes ... era là che era là/l'industria sua ... Mobili Miele che era:: ... in ... per: mobili ... per escritorio diciamo così ... e lui mi ha detto se vuoi venire ... puoi venire a lavorare qui con me ... e io ho detto ... va bene io accetto qualsiasi cosa ... por/però ... son stato là qualche tempo ...

280 e allora un mio cugino ... mi ha detto guarda ... perché non vieni a lavorare con/con me ... qui da/la fabbrica di Felicio Pelosini ... è che là impari un mestiere ... è fogliador fa tagliare la foglia ... per i mobili ... e allora per qualche tempo ... sono andato là ... però subito dopo ... le industrie ... Francisco Matarazzo la Fiação Lidia di San 285 Bernardo ... avevano bisogno di un/un cilindra/cilindraio ... e rettificatore ... e io come avevo questa possibilità ... e là avevo la possibilità di guadagnare un po' meno/un po' di più ... ho pensato subito di andarci e allora ho avuto/ho parlato con/con Attilio Miele ... e lui mi ha detto no ... cerca di andare dove puoi guadagnare di più $290 \quad$... perché come te devi aiutare un po' la tua famiglia in Italia se guadagni di più ... io sempre mandavo qualche cosa tutti i mesi di quello che guadagnavo per mio padre neh ... e allora ... ahn sono 
andato a lavorare alla Matarazzo ... ma sono stato là ... diciamo due anni più o meno ... in quei tempi ... sono poi andato a lavorare al Cotonificio São Bernardo ... qui nella Vila Pauliceia ... perché uno dei capi là di/di Matarazzo era stato trasferito ... e lui aveva bisogno di me ... come contramestre a: già avevo ... un posto di alto qui nella/nella rua Piratininga in San Paolo ... sobre fiação e tecelagem ... e allora io già ero in:/in/in grado di esser capo reparto ... e allora avrei guadagnato di più se ... anche lì ho fatto un cambio ... per causa di di questo ... e:: inoltre ... mi avevano dato una casa ... e io come ero fidanzato a quei tempi ho pensato così di poter sposarmi ... e mi sono sposato perché ho avuto in/in/la casa e per me è stato più facile ... e: esser sposato neh ... e a quei tempi dopo/poco dopo ... è cominciato la Mercedes Benz ... quando la Mercedes Benz si è installata sono stato uno dei primi ... a arrivare là ... e loro ... prestamente hanno avuto ... non ho avuto nemmeno fare il test loro hanno detto no abbiamo bisogno di ... mano d'opera specializzata e te servirai e molto per noi ... tanto è vero che dopo di un poco di tempo... io sono stato promosso a/a mestre di sezione là neh ... nella afiação di ferramenta da Mercedes ... e a quei tempi: ... afiação era molto importante perché no/no qui in Brasile ... non existia ... Senai e Sesi per insegnare il mestiere ... perciò non si trovavano afiador di ferramenta ... io dovevo insegnare a questi/ questi per poter avere delle persone ... no/non ho mai avuto la possibilità di avere già de/degli operai che fossero specializzati ... perciò era era difficile a quei tempi ... e allora ho avuto molte ricompense monetarie ... sono rimasto ... molto bene sono rimasto diciotto anni nella Mercedes ... dopo di che ... ho avuto un in/un invito per andare a lavorare in una firma austriaca ... ahn: che era di San Paolo l'Aços Fenix Büller ... che oggi è situata qui in Diadema ... e là o:: ero consolente tecnico sobre la specializzazione di metallo duro ... e ho avuto l'impegno di essere assistente ... e facevo il Brasile ... inoltre l'America del Sud ... per dare la mia contribuzione ... ho lavorato là anche là ... ahn dodici anni

Doc dopo è andato in pensione

L1 sì ... ma comunque che dopo di pensione anche ho lavorato in altri posti ... nella propria Aços Fenix ho lavorato come ... come diciamo come si dice una persona che non è registrata

330 Doc ha lavorato per conto

L1 sì per conto proprio ... e anche ho lavorato come assistente di:/di ve/vereador di Lenildo Madalena ho lavorato nella la Prefettura qui ... ho lavorato durante due anni

Doc va bene e lei è tornato in Italia quante volte quando è stata la prima volta? 
L1 la prima volta che son tornato è stato nel millenovecento: ... ahn sessantasei ... sessantasei ... perciò già faceva qualche anno neh ... e ho trovato l'Italia molto cambiata molto ... e.: insomma io ... ho/ho trovato con un pochino di ... già que/quella volta che sono tornato la prima volta ... che gli italiani avevano perso un po' della sua ... spontaneità ... e erano ... diventati tutti ... anche perché la loro vita era migliorata molto nella part/uno ... per esempio ... il giorno che ci siamo incontrati con i miei amici più intimi ... uno diceva io sono avvocato io sono ingegnere io son quello/quello/quello ... e la cosa che più $\mathrm{mi}$ ha/mi ha toccato che è stata la propria mia sorella ... che all/nell'arrivare il giorno dopo ... io era un bel giorno primaverile mi son messo una camicia sport ... i pantaloni sono andato a prender la colazione con lei ... e dopo ho detto adesso faccio un giretto qui per ... per i dintorni per vedere se ri/incontro qualche amico ... sì sì ... ha detto benissimo ... ti ho già preparato guarda qui ... c'è il tuo: tuo vestito ... i pantaloni la giacca la cravatta tutto ma ... io ho detto ... macché tu stai scherzando ... no non sto scherzando ... te non puoi adesso uscire qui ... che dopo chi paga le pene sono io ... dice ma come la sorella di XXX farlo uscire così ... tutto ... a:: senza stare in ordine ... io c'ho detto ma così di bocca aperta guarda che me ne vado adesso eh ... io sono venuto qui ... per ricordare i vecchi tempi ... non sono mica venuto qui per fare:: la/la/la sfile di moda no/no/ non sono venuto qui ... ha detto guarda ... e si è messa quasi a piangere guarda $X X X \mid / /$ 'Italia è cambiata ... te te non sei più qua ... 360 ma se te fai questo che adesso se ti faccio uscire come vuoi te ... vedrai che la/chi va a pagare dopo sono io ... perciò per favore ... e allora quando sono arrivato là che sono andato dopo ... che era un giorno di/di sabato e ... ho incontrato già sul piazzale vari amici ... e anche loro erano tutti vestiti come me ... e allora ho detto ma ... come 365 mai così oggi non è giorno di festa di niente ... è $\mathrm{mi} / \mathrm{mia}$ sorella ... mio padre mia madre ... mia nonna ... uno trovava sempre qualcuno che era sempre donna che ... allora siete schiavi delle donne ... come io di mia sorella ... capito ... ma quello non era inoltre dopo cominciando a parlare ... loro dicevano e allora mi fai 370 veder/sai XXX te ... sei stato fuori io ho/ho fatto questo studio adesso sono capo reparto ... e quello lì loro volevano far vedere ... quello che erano riusciti a costruire ... molto bene ... è è un piacere di sapere che tutti i miei amici stavano bene ... e.: allora è: io ... dopo di che ... io ho detto guarda ... io avrei piacere di invitarvi voi ... per noi 375 andare a mangiare fuori in un ristorante ... per noi è: ricordare nosso passato ... e allora hanno accettato il mio invito ... di fatti siamo andati là ... hum dopo qualche giorno ... e torn/arrivati là ... tutti in cravatta ((risos))t'ho detto ... per favore ... se noi vogliamo ricordare i nostri tempi qui non ci sono ... nonne mamme e sorelle che ci/ci 380 guardano ... perciò ... se volete stare bene con me ... tiriamoci la cravatta ... la giacca e mettiamo tutti ... a/a raccontarci quando noi andavamo a rubare l'uva ... quando andavamo a ((risos)) prendere 
questo quello ... che si faceva da ragazzo quello che abbiamo passato nella guerra tutto ... raccontarci quello ... e loro ... dopo si sono sentiti bene ... ma anche ho visto che ... lo l'hanno fatto solo per farmi ... farmi piacere a me ... perché loro già erano abituati a quello a quelle cose lì

Doc e quante volte lei è tornato in Italia?

L1 è: ho fatto già un tre o quattro viaggi diciamo così neh ... e: a: quei 390 tempi che lavoravo nell'Aços Fenix Büller c'era là ... in Vienna c'era là la nostra sede ... e andavo sempre per sapere le novità sulle sulle varie ... esperienze ... e così potevo fare un/una scappatina anche in Italia ... quando andavo là

395 L1 no adesso

Doc in Brasile è venuto solo lei?

L1 no/no

Doc ah

L1 posteriormente ... dopo la mia venuta qui ... ancora sapendo che in 400 Italia avevamo dei problemi ... ho mandato a prendere a venure/venire altri due fratelli miei ... prima Giuliano ... e dopo Carlo ... Giuliano sta in Mogi das Cruzes ... lui ha una piccola costru/tora ... fa case di alto livello ... e mio fratello è a ... Campo di Jordão ... ha un piccolo hotel ... e: ha una pizzeria anche là ... insomma lui ... là

405 sta bene là a Campo do Jordão

Doc ta e lei si è sposato quando?

L1 mi sono sposato nel millenovecentocinquantasei ... con una: con la: ragazza brasiliana ... il cui nome è Carmelita ... che adesso abita in San Bernardo nella rua Marechal Deodoro ... e ci siamo separati una ventina di anni dopo

Doc ahum hum avete avuto quanti figli?

L1 uno figli/un figlio solo perché ... ha avuto un parto difficile ... e lei non ha voluto più ... io per il mio ... grande dispiacere perché tutti i miei fratelli hanno avuto tre o quattro figli ... e io avrei voluto anch'io 415 avere una famiglia numerosa ma non posso dire ... che sia stata la:/il problema che lei ha dovuto ... scegliere una cosa che io non/contra piacere/ma non potevo dire a lei ... la vita era sua non mia ... perciò se lei ha scelto di non avere più figli ... è stato una delle cosa che anche ... ha fatto con che noi ci separassimo

420 Doc e lei ha detto che ha quanti nipoti?

L1 nipoti due 


\begin{tabular}{|c|c|c|}
\hline & $\begin{array}{l}\text { Doc } \\
\text { L1 }\end{array}$ & $\begin{array}{l}\text { due } \\
\text { Paula e João }\end{array}$ \\
\hline 425 & $\begin{array}{l}\text { Doc } \\
\text { L1 }\end{array}$ & $\begin{array}{l}\text { quanti anni loro hanno? } \\
\text { João ventuno ... e Paula ... diciassette }\end{array}$ \\
\hline & $\begin{array}{l}\text { Doc } \\
\text { L1 }\end{array}$ & $\begin{array}{l}\text { grandi } \\
\text { è }\end{array}$ \\
\hline & $\begin{array}{l}\text { Doc } \\
\text { L1 }\end{array}$ & $\begin{array}{l}\text { ma ... non sono sposati ancora } \\
\text { no }\end{array}$ \\
\hline
\end{tabular}

430 Doc no

L1 nessuno dei due ... è: João è stato negli Stati Uniti per imparare la lingua ... e si è form/formato là: ha fatto ... un'immersione là negli Stati Uniti ... ha studiato due anni qua in San B/in Santo Andre ... no 435 negli Stati Uniti ... e perciò dopo un anno è tornato ... adesso ... sta facendo: vestibular per entrare ... lui vuol fare anche come mio figlio ... medicina ... mio figlio è medico ... e lavora nella Mercedes Benz

440

Doc lei ha opportunità di parlare italiano qui a San Bernardo con chi? dove? quando?

L1 è io ho avu/qual/qualche amici ... eh: ne avevo più quando ho lavorato in altri locali ... ma sempre anche nella Mercedes Benz ... c'erano: più o meno: una diecina di italiani ... e noi parlavamo sempre in italiano ... e: adesso quando ho lavorato nell'Aços Fenix Büller ...

445 pure là avevo molti amici italiani ... che: perciò io sempre ho cercato ... di mantenere questo e: ... anche con i: ho cercato di parlare con i miei figli ma lui ... ero/ero molto a quei tempi ero molto lontano lavoravo molto ... facevo molte ore extra allora non ho potuto ... e con i miei con miei nipoti ... io parlo un po' di italiano a loro 450 neh ... e per quello anche che mia nipote vorrebbe forse fare un corso neh ... e: perciò io sempre/sempre ho cercato di parlare italiano ... inoltre io faccio ... le parole incrociate la settimana enigmistica ... leggo molti: libri italiani ... cerco di ... eh:: di mantenere mi/adesso che è venuta a/la tevê internacional ... tutti i giorni ascolto l'Italia 455 perciò ... il/il mio italiano che era arcaico ... si è tornato novamente ... accessibile ... che quando sono arrivato là una di quei viaggi che ho fatto che a quei tempi era di nave ... e come ho viaggiato con una famiglia italiana io parla/erano di Bologna ... mia sorella mi ha detto ... non sapevo che in/che in Brasile parla/ 460 parlavate il bolognese ... ha detto perché? è perché te c'hai l'accento di Bologna invece di aver l'accento de La Spezia ... ho detto ho parlato una settimana con i bolognese ho preso l'accento di loro 
Doc ma lei non frequenta associazioni ... eventi italiani ... niente di questo?

465 L1 molto poco no/no/non ho mai frequentato adesso ... che sono entrato nel coral ... coral italiano allora ... cercherò di frequentare di più ... mi sono iscritto nel Brasilitalia sto facendo parte di questo neh ... e ho intenzione di farlo ancora di più ... d'ora in avanti

Doc e va bene ... parliamo un po' di quello che ha studiato quando è arrivato in Brasile

L1 beh ... io in Brasile ... ho fatto solo questo corso na rua Piratininga in São Paulo ... di fiação e tecelagem

Doc e già parlava portoghese?

L1 è ... insomma parlo male anche adesso ma a quei tempi era 475 più/difficile ancora neh ... e tanto è vero che ... perfino per quando si andava: a cercare di ... una ragazza per poter parlare avevo delle difficoltà tremende perché ... non riuscivo a mantenere un dialogo così ... per molto tempo ... ma insomma dopo di un po' di tempo si riesce ...e e perciò io non ho mai studiato niente sulla lingua 480 portoghese io non/non conosco ... quello che so è solo nella pratica ... non ho mai imparato niente

Doc e suo figlio non parla italiano

L1 lui ... lui parla un:.: italiano molto molto ... diciamo così italo ahn spagnolo ((risos)) lui fa una/ma non parla italiano

485 Doc [ma capisce

L1 [capisce tutto sì

lui capisce tutto ... quando va in Italia lui fa capire bene ... non c'è problema

Doc e abita anche qui

[vicino

L1 [sì sì sì

lui abita qui a Rudge Ramos anche lui

Doc va bene

L1 lui è medico inoltre ha una/una piccola impresa ... di ... è come si dice 495 qua? ahn: fanno ... la la parte dell'ergonomia ... e adesso sono in due soci ... e hanno/hanno molto lavoro ... lui pretende qualche tempo dovrà andare in pensione che lavora nella Mercedes ... a più di vent'anni ... e allora lui è capo reparto della medicina ... della medicina del lavoro del trabalho neh ... come dicono qua in Brasile

500 Doc e lei abita da solo?

L1 sì ... io ho ho una ragazza diciamo così una fidanzata ... a molti anni però lei sempre ha abitato in casa sua e io in casa mia ... lei ha avuto 
la/la sfortuna di avere un cancro ... a otto anni e perciò ha avuto un cancro ... va/molto molto difficile ha fatto una chimioterapia ... molto 505 di più di un anno ... e: come donna ... non/non si può più non la posso ... più contare come compagnia perché ... lei si sente sempre male ad/ha sempre dei disturbi la pressione molto alta ... perciò io continuo con lei ... ci vediamo ... prima ci vedevamo molto di più ad/adesso una volta per settimana ... così lei viene a trovarmi là

510 nel mio appartamento ma nemmeno resta per dormire ... la ca/la riporto a casa sua così ... perciò mi dispiace ma ... è: l'unica diciamo che ... no momento ho neh

Doc e chi cucina? lei cucina?

L1 io ogni tanto faccio qualche cosa io lo/faccio il minestrone ... eh: 515 quella quella pimentinha che ho ... vi ho fatto provare là nella festa ... e altre cose una pastasciutta insomma ... mi arrangio bene ... faccio la pasta al pesto ... ahn una cosa così mi/mi diverte neh ... e.: io io praticamente faccio tutto da solo in casa ... solo viene due volte: al mese una ... diciamo così una don/donna della pulizia ... e il resto

520 lo faccio tutto io mi lavo: quello che c'ho da mandare in tintureria l'altro/l'altro lo faccio io ... e: le cose intime così si lavano da sole ... e dopo le stiro e si mette tutto

Doc va bene signore $\mathrm{XXX}$ la ringrazio se avrò bisogno di più qualcosa

L1 [ahn ahn

525 Doc [le dico

Doc grazie

L1 sì sì

Análise das interferências:

\subsection{Empréstimos totais}

10-11 - gli attrezzi di ferramentaria ... : italiano, ferramenta.

75-76 - io sono rimasto così pensativo perché dicevo ... : em italiano, pensieroso.

84 - e in questa casa c'erano três/tre figlie : usa o numeral em português, mas autocorrige-se imediatamente.

146-147 - gli aerei avevano ... quella indumentaria ... : sem correspondente italiano, acreditamos que queria dizer attrezzi ou equipaggi. 
193-194 - andiamo là nel mio consultório ... faciamo una/curativo e pronto ... : em italiano: andiamo là nel mio ambulatorio... facciamo una medicazione e pronto ...

249 - di andare a lavorare nel/nel/nei/nei cafezal nelle altre cose no ... : em italiano, piantagioni di caffè.

277 - mobili ... per escritório diciamo così ... : em italiano, ufficio.

$296-297$ - ... e lui aveva bisogno di me ... come contramestre. Em italiano esta palavra é variável dependendo do tipo de trabalho que se exerce: capomastro, capogruppo, capofficina, caporeparto. Pelo discurso do entrevistado, acreditamos que quis dizer aiuto: lui aveva bisogno di me ... come aiuto.

298-299 - ...sobre fiação e tecelagem ... e allora io già ero in:/in/in grado di esser capo reparto : em italiano, sul (nel) reparto di filatura e tessitura.

311-312 - e a quei tempi: ... afiação era molto importante : em italiano, affilatura.

320 - per andare a lavorare in una firma austriaca ... : em italiano, ditta.

328 - ... nella propria Aços Fenix ho lavorato come ... : em italiano, stessa.

331-332 - ... e anche ho lavorato come assistente di:/di ve/vereador : em língua italiana, assessore comunale.

402 - lui ha una piccola costru/tora ... : em italiano, impresa edile.

435-436 - ... sta facendo: vestibular per entrare ... : sem correspondente em língua italiana. Poderia, também, ser entendido como uma citação.

454 - che è venuta a/la tevê internacional ... : em italiano, la tv internazionale ou la televisione internazionale.

465-466 - sono entrato nel coral ... coral italiano : em italiano, coro.

471-472 - in Brasile ... ho fatto solo questo corso na rua Piratininga in São Paulo ... di fiação e tecelagem : di filatura e tessitura.

515 - quella pimentinha che ho ... vi ho fatto provare là nella festa : o que 0 entrevistado quis dizer é: quel pepe, quel peperoncino che vi ho fatto assaggiare nella festa ... 


\subsection{Empréstimos parciais:}

89 - son maggiore do che/di che me ... : usa a preposição portuguesa, mas autocorrige-se: di che.

201 - ... e siam rimasti là per un tempo, uso impróprio, melhor seria, per un periodo ou per qualche tempo.

248 - hanno passato i miei antepassati ... do português antepassados, em italiano, antenati.

298-299 - già avevo ... un posto di alto qui nella rua Piratininga, do português um cargo alto, em italiano, un posto più qualificato.

310 - io sono stato promosso a/a mestre di sezione là neh : do português chefe de seção, em italiano, caposettore.

311 - nella afiação di ferramenta da Mercedes ... : usando em português afiação e a preposição da, cremos que queria dizer: nel settore affilatura della.

313-314 - ... perciò non si trovavano afiador di ferramenta ... : em italiano, affilatore (di) ferramenta.

403-404-405 - e mio fratello è a ... Campo di Jordão ... insomma lui ... là sta bene là a Campo do Jordão: em ambos os casos suprime o $\mathbf{s}$ de Campos e, na primeira menção, usa a preposição italiana di.

456-457 - ... che quando sono arrivato là una di quei viaggi che ho fatto a quei tempi era di nave ... : confunde o gênero no uso do numeral.

497-498 - che lavora nella Mercedes ... a più di venti anni ... : em italiano, da.

501 - ho una ragazza diciamo così una fidanzata ... a molti anni, do português há muitos anos, em italiano, da molti anni.

503-504 - ... lei ha avuto la/la sfortuna di avere un cancro ... a otto anni, do português há oito anos, em italiano, otto anni fa.

511-512 - ... è: l'unica diciamo che ... no momento ho neh : com preposição em português, poderia ter dito al momento. 


\subsection{Comutações: $-\varnothing$}

\subsection{Mudanças de significado:}

17-18 - avevamo noi una posse/possessione là in La Spezia : vocábulo raramente usado com o sentido de podere ou proprietà, como foi usado na linha:

20 - ...u:una proprietà ... colla quale noi si viveva a quei tempi ...

282 - là impari un mestiere ... è fogliador fa tagliare la foglia ... : foglio sottile di legno preggiato.

332 - ho lavorato nella Prefettura qui ... : usa o vocábulo com o sentido de: nel municipio.

391-392 - per sapere le novità sulle sulle varie ... esperienze ... : sperimentazioni.

441-442 - quando ho lavorato in altri locali ... : in altri posti, in altre ditte.

\subsection{Decalques}

178 - qualche farolete a pila neh diciamo : do português farolete/lanterna, ao invés de torcia.

254 - hanno u/la doppia cittada/cittadania ...

255-256 - io vorrei essere anch'io doppia cit/doppia cittadino non posso ... o entrevistado se confunde usando cittadania, do português cidadania, tenta se corrigir e usa cittadino, não conseguindo recordar o vocábulo correto: cittadinanza.

329 - come si dice una persona che non è registrata, do português trabalhador não registrado, em italiano, lavoratore autonomo.

331 - sì per conto proprio ... : do português, por conta própria, quando em italiano é lavoratore autonomo.

337 - ... perciò già faceva qualche anno neh ... : do português já fazia alguns anos, em italiano, da qualche anno ou da alcuni anni.

520-521 - quello che c'ho da mandare in tintureria l'altro/l'altro lo faccio io ... : do português tinturaria, em italiano, tintoria. 


\subsection{Verbos:}

8-9 - sono stato ... giubilato ... ossia sono in pensione : usa indevidamente o verbo, mas autocorrige-se: sono in pensione.

52-53 - possiamo vivere ... con quello che che noi/noi ri/riusciamo a ri/ricevere della terra : usa indevidamente o verbo; poderia ter dito ricavare.

90 - infelicemente ... già sono decessi, em vez de sono deceduti.

126 - quello che più mi ha/mi ha marcato : em vez de mi ha colpito.

129 - i tedeschi ci opprimivano là ...: em vez de opprimevano.

135-136 - per giustamente salvaguardare la la flotta italiana che era sediata là ... : do português sediar, em italiano, stanziata/ancorata.

212 - imagína se io posso esser/ave/aver imparato : usa o verbo em português, em vez de immagina.

213-214 - ci passavano: facevano promuo/promuovere di a/di anno anche se non ... : pela indecisão do entrevistado, nota-se que não encontra o verbo adequado para se expressar. Neste caso, seguindo o nível do registro lingüístico do entrevistado, seria mais adequado usar passare di anno.

258 - ... io pretendo continuare italiano : do português pretender, em italiano, intendo.

312-313 - qui in Brasile ... non existia ... Senai e Sesi per insegnare il mestiere ... : usa o verbo em português, em vez do italiano c'era.

380-381 - se volete stare bene con me ... tiriamoci la cravatta ... : uso indevido do verbo, correto seria togliamoci.

400-401 - ho mandato a prendere a venure/venire altri due fratelli miei ... parece-nos que por causa do uso indevido da preposição a, confunde-se ao usá-la novamente, erra 0 verbo e autocorrige-se imediatamente. Acreditamos que queria dizer ho mandato prendere ou ho chiesto di venire.

455 - il/il mio italiano che era arcaico ... si è tornato novamente ... accessibile ... : uso correto: è ridiventato.

515 - quella pimentinha che ho ... vi ho fatto provare là nella festa : uso impróprio do verbo, melhor seria assaggiare. 


\section{Impropriedades:}

344-345 - ... e la cosa che più $\mathrm{mi}$ ha/mi ha toccato che è stata la propria mia sorella ... : do português tocado, em italiano, o uso do verbo toccare para este caso é impróprio, poderia ter usado impressionato.

\section{Preposições:}

9-10-11 - io ero stato capo di officina della Mercedes Benz ... sob/sobre gli attrezzi di ferramentaria ... : em italiano, sugli ou negli.

11 - ho fatto diversi lavori entre i quali ... : em italiano, $\underline{\text { tra }}$.

29 - inoltre a quello ... era portalettere : uso correto, oltre.

280-281 - per che non vieni a lavorare con/con me ... qui da/la fabbrica di Felicio Pelosini ... : não sabemos se usa a preposição da em português ou em italiano. De qualquer modo, o correto é nella.

312 - perché no/no qui in Brasile ... : autocorrige-se e usa in Brasile.

323-324 - ... e facevo il Brasile ... inoltre l'America del Sud ... :usa indevidamente o advérbio, quando deveria ter usado a preposição oltre a.

433-434 - ... ha studiato due anni qua in San B/in Santo André ... no Singular ... : nel Singular.

460-461 - è perché te c'hai l'accento di Bologna invece di aver l'accento de La Spezia ... : di.

471 - ho fatto solo questo corso na rua Piratininga : nella.

\section{Artigos:}

229-230 - c'era o padre ... e altri due figli ... : il padre ... $434-\ldots$ e ha fatto o terzo anno là ... : il terzo anno là ...

\section{Pronomes:}

375-376 - per noi è: ricordare nosso passato ... : usa o possessivo português e, como habitualmente nesta língua não se usa o artigo definido, também o omite. Em italiano: il nostro passato ... 


\section{Advérbios:}

$164 \ldots$ alì una scheggia $\ldots$ di un proiettile ... : lì ou là

\section{Conjunções:}

125-126 - então sono state le prime cose che mi ricordo ... : em italiano, allora.

279 - io accetto qualsiasi cosa ... por/però ... son stato là qualche tempo ... estava para usar porque, mas autocorrige-se: però.

\section{Observações:}

1 - 344-345 - ... e la cosa che più $\mathrm{mi} h \mathrm{~h} / \mathrm{mi}$ ha toccato che è stata la propria mia sorella... : usa uma construção indevida da frase, pois queria dizer: è stata la mia propria sorella.

2 - 353 - ... che dopo chi paga le pene sono io ... : expressão correta em italiano: la pena.

3 - 357 - ... non sono mica venuto qui per fare:: la/la/la sfile di moda : do português desfile de moda, em italiano, sfilata di moda.

4 - 419 - ... ha fatto con che noi ci separassimo : correto: ha fatto che ci fossimo separati.

5 - $\quad 441$ - io ho avu/qual/qualche amici ... : impropriedade gramatical, correto: qualche amico ou alcuni amici.

6 - $\quad 499$ - medicina del lavoro del trabalho neh ... come dicono qua in Brasile : cremos que neste caso o entrevistado fez uso do vocábulo em português, preocupado com a compreensão do entrevistador.

\section{Empréstimos italianizados:}

282 - là impari un mestiere ... è fogliador fa tagliare la foglia ... : do português folheador.

431-432 - ... e si è form/formato là: ha fatto ... : do português formado/se formou, em italiano, ha concluso un corso, si è diplomato. 


\section{Comentários:}

O entrevistado, em idade escolar, durante a Segunda Guerra, teve dificuldades em concluir seus estudos na Itália e declarou que conseguiu melhorar o seu falar italiano aqui no Brasil, assistindo a RAI Internacional. Apesar de muito falante, notamos a preocupação do mesmo em expressarse corretamente na língua italiana. Poucas vezes se sentiu inseguro durante o inquérito, ou seja, quase não se autocorrigiu. A maioria das interferências e impropriedades foram cometidas sem que fossem percebidas, tal a naturalidade com que foram inseridas no contexto.

\section{Tabela no 1 - Empréstimos Totais}

\begin{tabular}{|l|l|}
\hline \multicolumn{1}{|c|}{ Português } & \multicolumn{1}{c|}{ Italiano } \\
\hline ferramentaria & ferramenta \\
\hline pensativo & pensieroso \\
\hline três & tre \\
\hline indumentária & attrezzi/equipaggi \\
\hline consultório & ambulatorio \\
\hline curativo & medicazione \\
\hline cafezal & piantagione di caffè \\
\hline escritório & ufficio \\
\hline contramestre & capofficina/sottocapo \\
\hline sobre fiação e tecelagem & sul(nel) reparto di filatura e tessitura \\
\hline afiação & affilatura \\
\hline firma & ditta \\
\hline própria & stessa \\
\hline vereador & assessore comunale \\
\hline costrutora & impresa edile \\
\hline vestibular & sem correspondente \\
\hline tevê internacional & televisione internazionale \\
\hline coral (duas vezes) & coro \\
\hline fiação e tecelagem & filatura e tessitura \\
\hline pimentinha & peperoncino \\
\hline
\end{tabular}


Tabela no 2 - Empréstimos Parciais

\begin{tabular}{|l|l|l|}
\hline \multicolumn{1}{|c|}{ Forma usada } & \multicolumn{1}{c|}{ Português correto } & \multicolumn{1}{c|}{ Italiano correto } \\
\hline maggiore do che & maior que & maggiore di che \\
\hline per un tempo & por um tempo & per qualche tempo \\
\hline antepassati & antepassados & antenati \\
\hline un posto di alto & um posto mais alto & un posto più qualificato \\
\hline mestre di sezione & chefe de seção & caposettore \\
\hline afiação di ferramenta da & afiação de ferramentas da & affilatore ferramenta della \\
\hline afiador di ferramenta & afiador de ferramentas & affilatore ferramenta \\
\hline $\begin{array}{l}\text { Campo di Jordão (duas } \\
\text { vezes) }\end{array}$ & Campos de Jordão & Campos de Jordão \\
\hline una di quei viaggi & uma daquelas viagens & uno di quei viaggi \\
\hline a più di & há mais de & da più di \\
\hline a molti anni & há muitos anos & da molti anni \\
\hline da otto anni & há oito anos & otto anni fa \\
\hline no momento & no momento & al momento \\
\hline
\end{tabular}

Tabela no 3 - Mudanças de Significado

\begin{tabular}{|l|l|l|}
\hline \multicolumn{1}{|c|}{ Forma apresentada } & \multicolumn{1}{c|}{ Português correto } & \multicolumn{1}{c|}{ Italiano correto } \\
\hline possessione & propriedade & proprietà \\
\hline la foglia & a madeira & $\begin{array}{l}\text { foglio sottile di legno } \\
\text { preggiato }\end{array}$ \\
\hline Prefettura & Prefeitura & municipio \\
\hline esperienze & experiências & sperimentazioni \\
\hline locali & lugares & ditte/posti \\
\hline
\end{tabular}

Tabela no 4 - Decalques

\begin{tabular}{|l|l|l|}
\hline \multicolumn{1}{|c|}{ Forma apresentada } & \multicolumn{1}{c|}{ Português correto } & \multicolumn{1}{c|}{ Italiano correto } \\
\hline farolete & lanterna & torcia \\
\hline cittadania & cidadania & cittadinanza \\
\hline cittadino & cidadania & cittadinanza \\
\hline non registrata & não registrada & lavoratore autonomo \\
\hline per conto proprio & por conta própria & lavoratore autonomo \\
\hline già faceva qualche anno & já fazia alguns anos & da alcuni anni \\
\hline tintoreria & tinturaria & tintoria \\
\hline
\end{tabular}


Tabela no 6 - Verbos

\begin{tabular}{|l|l|l|}
\hline \multicolumn{1}{|c|}{ Forma apresentada } & \multicolumn{1}{c|}{ Português correto } & \multicolumn{1}{c|}{ Italiano correto } \\
\hline sono stato giubilato & aposentei & sono andato in pensione \\
\hline ricevere & retirar & ricavare \\
\hline sono decessi & morreram & sono deceduti \\
\hline ha marcato & marcou & ha colpito \\
\hline opprimivano & oprimiam & opprimevano \\
\hline sediata & ancorada & stanziata/ancorata \\
\hline imagína & imagina & immagina \\
\hline promuovere di a/di anno & passar de ano/ser aprovado & passare di anno \\
\hline pretendo & pretendo & intendo \\
\hline existia & existia & c'era \\
\hline tiriamoci & retiremos/tiremos & togliamoci \\
\hline $\begin{array}{l}\text { ho mandato a prendere } \\
\text { a venure/venire }\end{array}$ & mandei vir & $\begin{array}{l}\text { ho mandato prendere/ho } \\
\text { chiesto di venire }\end{array}$ \\
\hline si è tornato & tornou-se & è rediventato \\
\hline provar & provar/experimentar & assaggiare \\
\hline
\end{tabular}

Gráfico das Principais Interferências (I-6)

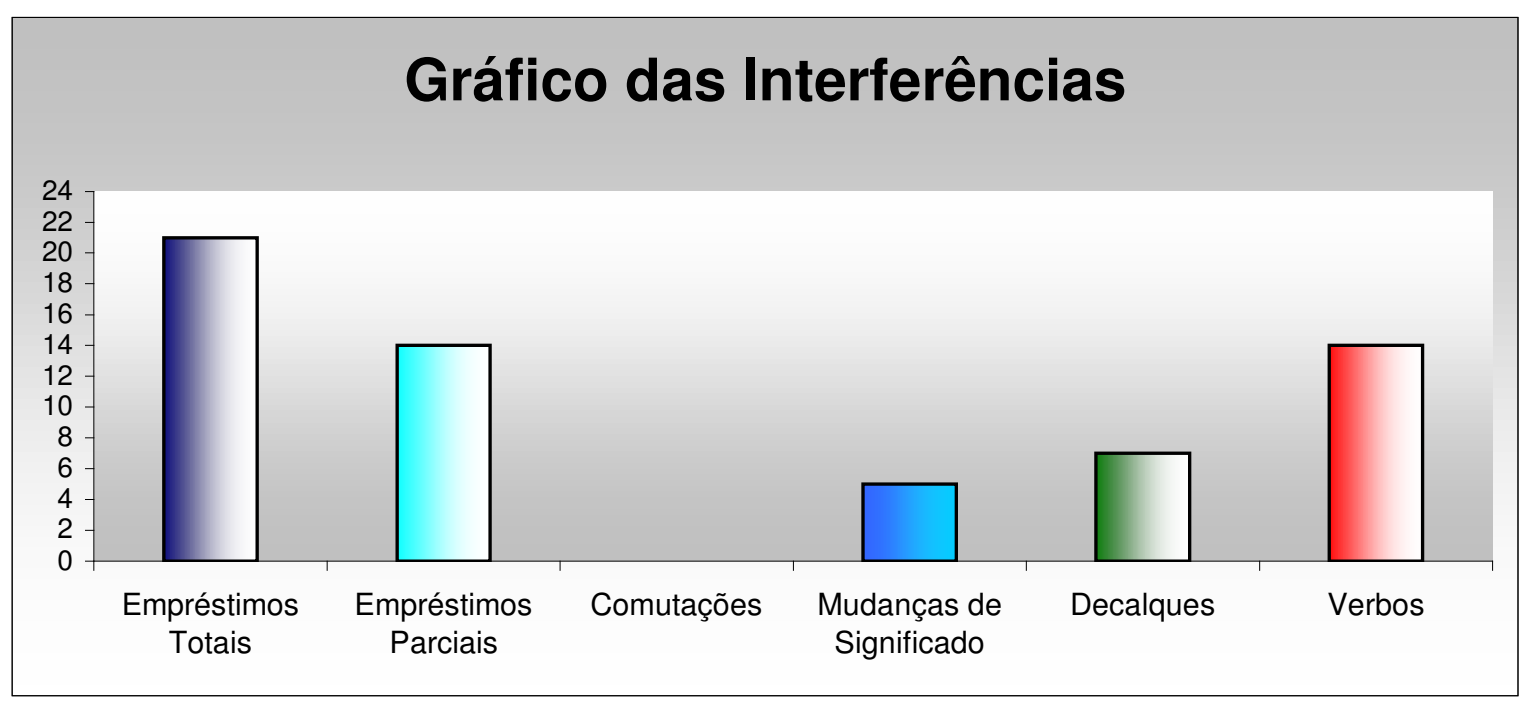




\subsection{Tabelas e Gráficos gerais das principais interferências}

A seguir, serão apresentadas as tabelas gerais, ou seja, um resumo das principais interferências encontradas nas análises feitas de todos os entrevistados, com 0 respectivo número de ocorrências e 0 gráfico correspondente.

Tabela geral no 1 - Empréstimos totais

\begin{tabular}{|l|l|c|}
\hline \multicolumn{1}{|c|}{ Português } & Italiano & Ne ocorrências \\
\hline a gente & a noi & 1 \\
\hline a moça & la ragazza & 1 \\
\hline afiação & affilatura & 1 \\
\hline barata & a buon mercato & 1 \\
\hline bastante & abastanza/numerosi/diversi & 1 \\
\hline bem & bene & 4 \\
\hline bom & bene & 1 \\
\hline caderneta & tessera & 1 \\
\hline cafezal & piantagione di caffè & 1 \\
\hline câncer & cancro & 1 \\
\hline carimbo & timbro & 1 \\
\hline carro & macchine & 1 \\
\hline carro & automobile & 3 \\
\hline chácara & podere & 1 \\
\hline chefe & capo & 1 \\
\hline consultório & ambulatorio & 1 \\
\hline contramestre & capofficina/sottocapo & 2 \\
\hline coral & coro & 1 \\
\hline costrutora & impresa edile & 3 \\
\hline cruzeiro & cruzeiro & 1 \\
\hline curativo & medicazione & 1 \\
\hline de autônomo & lavoratore autonomo & 1 \\
\hline disinvolvimento & sviluppo & 1 \\
\hline disturbio & disturbo & 1 \\
\hline efetivo concursado & di ruolo & 1 \\
\hline escritório & ufficio & 1 \\
\hline faculdade & facoltà & 2 \\
\hline fartura & abbondanza & 1 \\
\hline ferramentaria & ferramenta & \\
\hline & & 1 \\
\hline
\end{tabular}




\begin{tabular}{|c|c|c|}
\hline $\begin{array}{l}\text { Português } \\
\end{array}$ & Italiano & № de ocorrências \\
\hline fiação e tecelagem & filatura e tessitura & 1 \\
\hline fio/fiação & filatura & 2 \\
\hline firma & ditta & 1 \\
\hline fixo & fisso/determinato & 1 \\
\hline ginásio & corso di avviamento & 3 \\
\hline gramado & prato & 1 \\
\hline indumentaria & attrezzi & 1 \\
\hline interior/interiore & all'interno & 4 \\
\hline maiô & costume da bagni & 1 \\
\hline minero & sem correspondente & 1 \\
\hline móveis & mobili & 1 \\
\hline nabo & rapa & 1 \\
\hline namoro & legame/fidanzamento & 2 \\
\hline pai & padre & 1 \\
\hline papel & documento & 1 \\
\hline partera & levatrice & 1 \\
\hline pensativo & pensieroso & 1 \\
\hline pimentinha & peperoncino & 1 \\
\hline poste & $\begin{array}{l}\text { palo per l'elettricità/palo della } \\
\text { luce }\end{array}$ & 2 \\
\hline prédio & edificio & 1 \\
\hline primei// & prima & 1 \\
\hline própria & stessa & 1 \\
\hline sítio & fazendola & 3 \\
\hline sobre fiação e tecelagem & $\begin{array}{l}\text { sul(nel) reparto di filatura e } \\
\text { tessitura }\end{array}$ & 1 \\
\hline sortera & nubile & 1 \\
\hline tevê A & sem correspondente & 2 \\
\hline tevê internacional & televisione internazionale & 1 \\
\hline três & tre & 1 \\
\hline trigo & grano & 1 \\
\hline um tempo & per poco tempo & 1 \\
\hline vereador & assessore comunale & 1 \\
\hline vestibular & sem correspondente & 1 \\
\hline
\end{tabular}




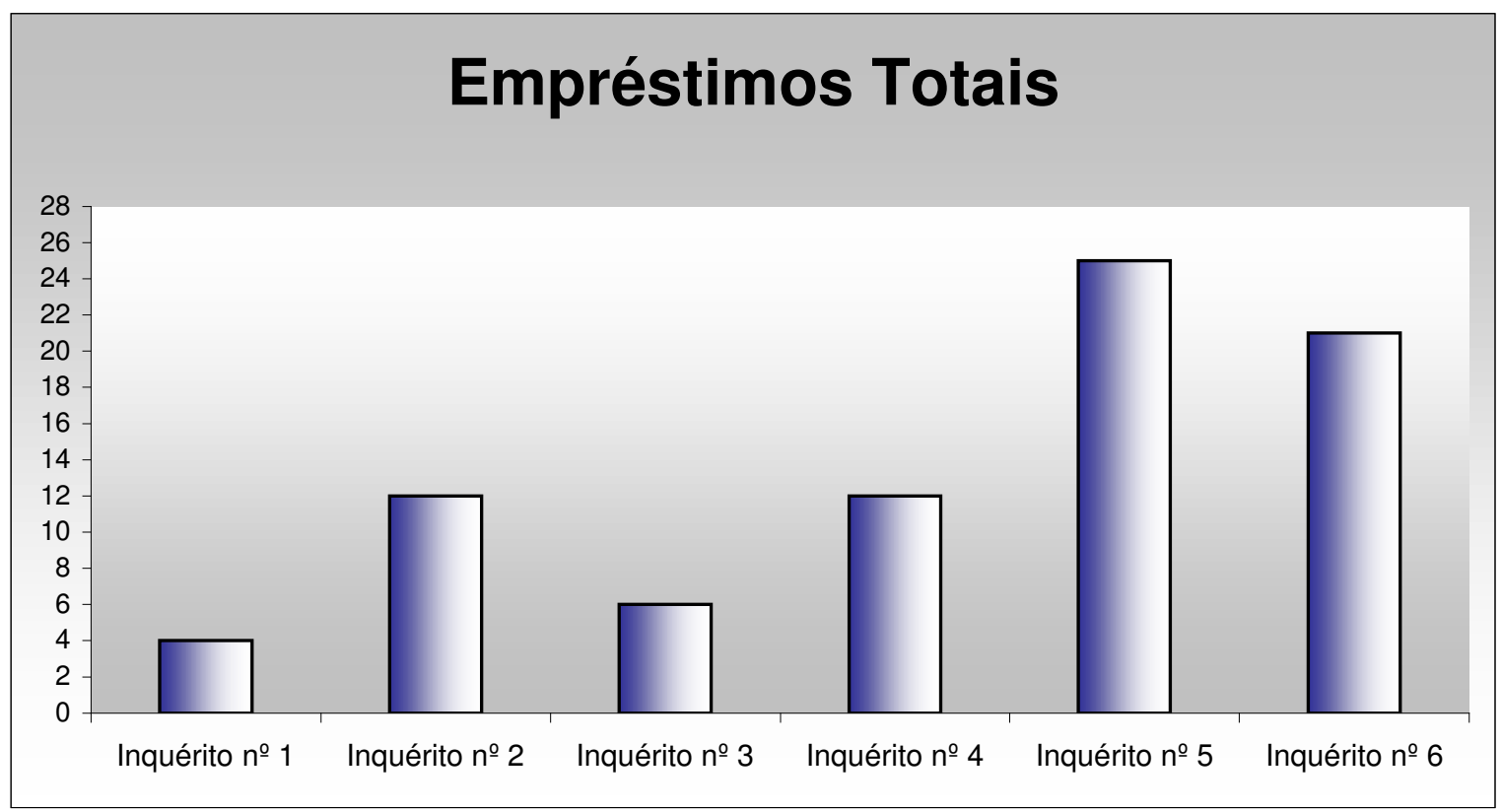

Tabela geral no 2 - Empréstimos parciais

\begin{tabular}{|l|l|l|c|}
\hline \multicolumn{1}{|c|}{$\begin{array}{c}\text { Forma } \\
\text { apresentada }\end{array}$} & Português correto & \multicolumn{1}{|c|}{ Italiano correto } & $\begin{array}{c}\text { No de } \\
\text { ocorrências }\end{array}$ \\
\hline a molti anni & há muitos anos & da molti anni & 1 \\
\hline a più di & há mais de & da più di & 1 \\
\hline $\begin{array}{l}\text { afiação di } \\
\text { ferramenta da }\end{array}$ & $\begin{array}{l}\text { afiação de ferramentas } \\
\text { da }\end{array}$ & settore affilatura della & 1 \\
\hline $\begin{array}{l}\text { afiador di } \\
\text { ferramenta }\end{array}$ & afiador de ferramentas & affilatore ferramenta & 1 \\
\hline antepassati & antepassados & antenati & 1 \\
\hline Campo di Jordão & Campos de Jordão & Campos de Jordão & 2 \\
\hline da otto aani & há oito anos & otto anni fa & 1 \\
\hline $\begin{array}{l}\text { Estado di São } \\
\text { Paulo }\end{array}$ & Estado de São Paulo & Estado de São Paulo & 1 \\
\hline il Topolino & o Topolino & la Topolino & 1 \\
\hline lata di lixo & lata de lixo/lixeira & pattumiera & 1 \\
\hline maggiore do che & maior que & maggiore di che & 1 \\
\hline mestre di sezione & chefe de seção & caposettore & 1 \\
\hline nel quarto ano & no quarto ano & la quarta elementare & 1 \\
\hline no momento & no momento & al momento & 1 \\
\hline per um tempo & por um tempo & per qualche tempo & 1 \\
\hline primo automobile & primeiro automóvel & prima automobile & 1 \\
\hline
\end{tabular}




\begin{tabular}{|l|l|l|c|}
\hline \multicolumn{1}{|c|}{$\begin{array}{c}\text { Forma } \\
\text { apresentada }\end{array}$} & \multicolumn{1}{|c|}{ Português correto } & \multicolumn{1}{|c|}{ Italiano correto } & $\begin{array}{c}\text { No de } \\
\text { ocorrências }\end{array}$ \\
\hline quel Topolino & aquele Topolino & quella Topolino & 1 \\
\hline sul Jeep & no Jeep & sulla Jeep & 1 \\
\hline un Jeep & um Jeep & una Jeep & 2 \\
\hline un posto di alto & um posto mais alto & $\begin{array}{l}\text { un posto più } \\
\text { qualificato }\end{array}$ & 1 \\
\hline un Topolino & um Topolino & una Topolino & 2 \\
\hline una di quei viaggi & $\begin{array}{l}\text { uma daquelas } \\
\text { viagens }\end{array}$ & uno di quei viaggi & 1 \\
\hline
\end{tabular}

\section{Gráfico Geral dos Empréstimos Parciais}

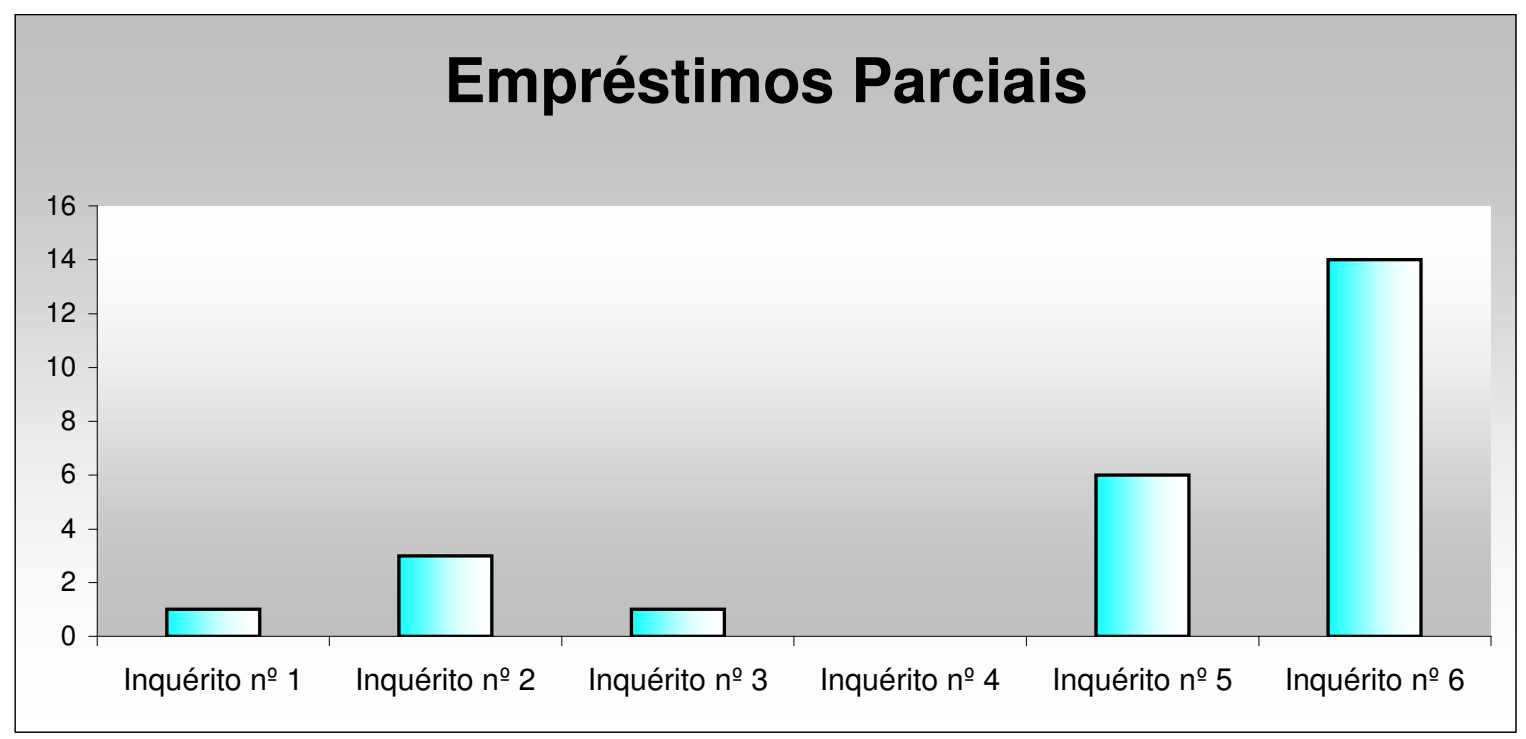

Tabela geral no 3 - Comutações

\begin{tabular}{|l|l|l|c|}
\hline Forma apresentada & Português correto & Italiano correto & $\begin{array}{c}\text { No } \text { de } \\
\text { ocorrências }\end{array}$ \\
\hline cirurgie & cirurgias & operazioni chirurgiche & 1 \\
\hline la viagge & a viagem & il viaggio & 1 \\
\hline novella/novelle & novela/novelas & telenovella/telenovelle & 3 \\
\hline reali & reais & reais & 1 \\
\hline
\end{tabular}




\section{Gráfico Geral das Comutações}

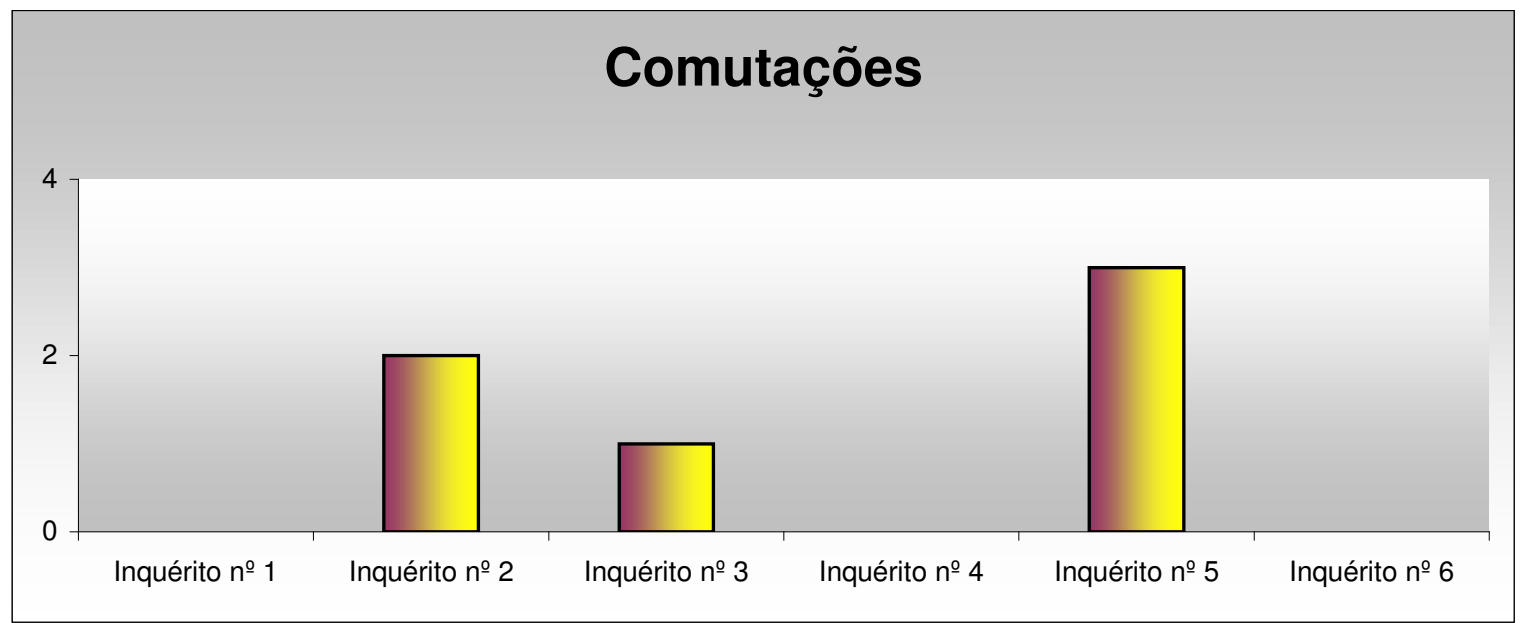

Tabela geral no 4 - Mudanças de significados

\begin{tabular}{|l|l|l|c|}
\hline Forma apresentada & Português correto & \multicolumn{1}{|c|}{ Italiano correto } & $\begin{array}{c}\text { No de } \\
\text { ocorrências }\end{array}$ \\
\hline articoli & artigos/produtos & colture & 1 \\
\hline assalti & sobressaltos & soprassalti & 1 \\
\hline carte & cartas & lettere & 1 \\
\hline esperienze & experiências & sperimentazioni & 1 \\
\hline ginnasio & ginásio & scuola italiana & 1 \\
\hline la foglia & folha de madeira & $\begin{array}{l}\text { foglio sottile di legno } \\
\text { preggiato }\end{array}$ & 1 \\
\hline lavoro & problema & preoccupazione & 1 \\
\hline locali & lugares & ditte/posti & 1 \\
\hline negozi/negozio & negócios/negócio & affari/affare & 2 \\
\hline negozio & sentimento & $\begin{array}{l}\text { sensazione/impressio } \\
\text { ne }\end{array}$ & 1 \\
\hline pezze & peças/trechos & brani/arie d'opera & 1 \\
\hline possessione & propriedade & proprietà & 1 \\
\hline prefettura & prefeitura & municipio & 1 \\
\hline rio & rio & fiume & 3 \\
\hline romanzo & $\begin{array}{l}\text { romance/relaciona- } \\
\text { mento }\end{array}$ & $\begin{array}{l}\text { rapporto sentimentale } \\
\text { /storia d'amore }\end{array}$ & 1 \\
\hline
\end{tabular}




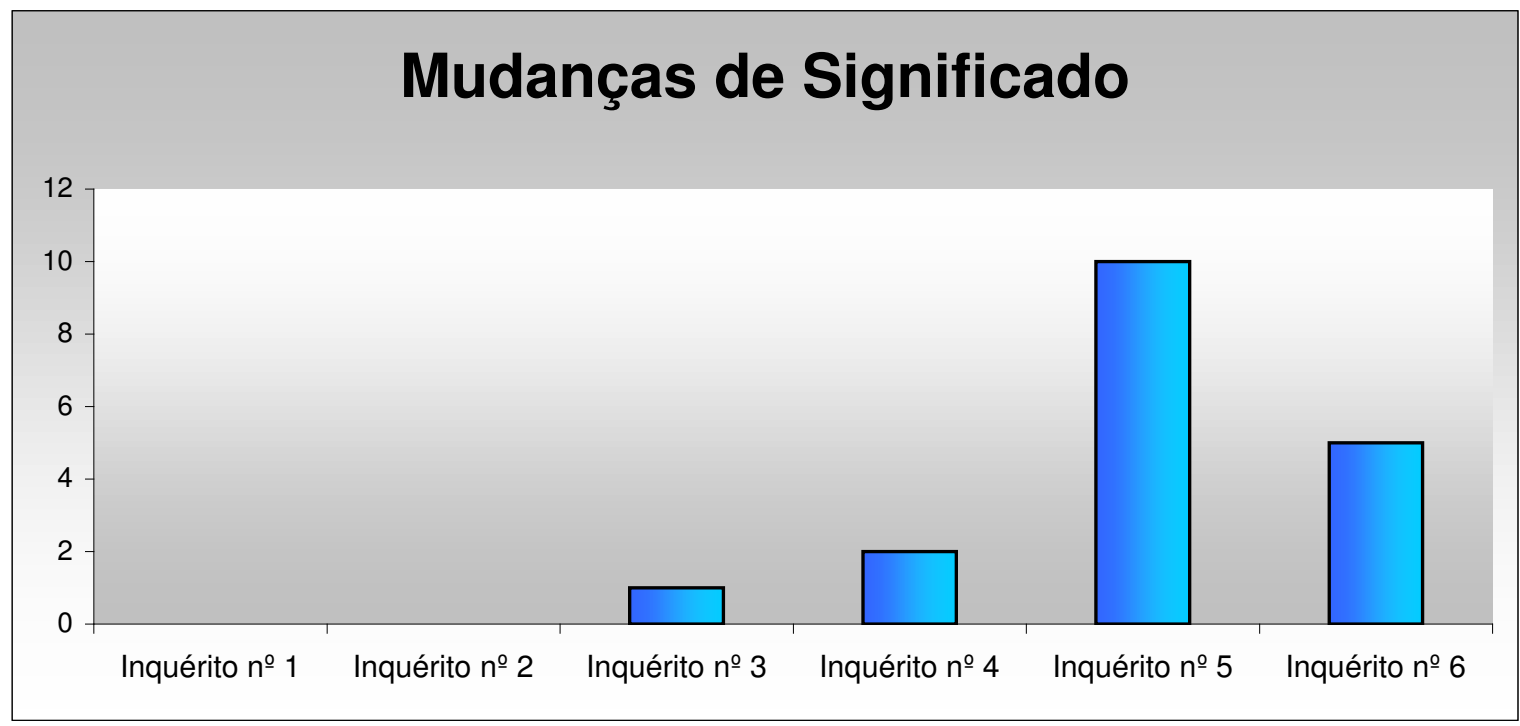

Tabela geral no 6 - Decalques

\begin{tabular}{|l|l|l|c|}
\hline Forma apresentada & Português correto & \multicolumn{1}{|c|}{ Italiano correto } & $\begin{array}{c}\text { № de } \\
\text { ocorrências }\end{array}$ \\
\hline a faccia di tutto & a frente de tudo & $\begin{array}{l}\text { a capo di tutto /attenta } \\
\text { a tutto }\end{array}$ & 1 \\
\hline cittadania & cidadania & cittadinanza & 1 \\
\hline cittadino & cidadão & cittadinanza & 1 \\
\hline col muro & com as paredes & con le mura & 1 \\
\hline dicessete & dezessette & diciassette & 1 \\
\hline duemille e tre & dois mil e três & duemilatré & 1 \\
\hline farolete & lanterna & torcia & 1 \\
\hline $\begin{array}{l}\text { già faceva qualche } \\
\text { anno }\end{array}$ & já fazia alguns anos & da alcuni anni & 1 \\
\hline hanno fatto questione & fizeram questão & hanno preteso & 1 \\
\hline il guardia & o guarda & la guardia & 1 \\
\hline neti & netos & nipoti & 2 \\
\hline non registrata & não registrada & lavoratore autonomo & 1 \\
\hline novanta otto & noventa e oito & novantotto & 1 \\
\hline orta & horta & orto & 2 \\
\hline passarella & passarela & passerella & 1 \\
\hline patrone & patrão & padrone & 1 \\
\hline
\end{tabular}




\begin{tabular}{|l|l|l|c|}
\hline Forma apresentada & Português correto & \multicolumn{1}{|c|}{ Italiano correto } & $\begin{array}{c}\text { No de } \\
\text { ocorrências }\end{array}$ \\
\hline per conto proprio & por conta própria & lavoratore autonomo & 1 \\
\hline salata & salada & insalata & 1 \\
\hline scritori & escritórios & uffici & 1 \\
\hline sobradino & sobradinho & casetta/villetta & 1 \\
\hline stabilimento & estabelecimento & qui all'edificio & 1 \\
\hline tintoreria & tinturaria & tintoria & 1 \\
\hline tombate & tombadas & $\begin{array}{l}\text { protette dalle Belle } \\
\text { Arti }\end{array}$ & 1 \\
\hline venti: un & vinte e um & ventuno & 1 \\
\hline
\end{tabular}

\section{Gráfico Geral dos Decalques}

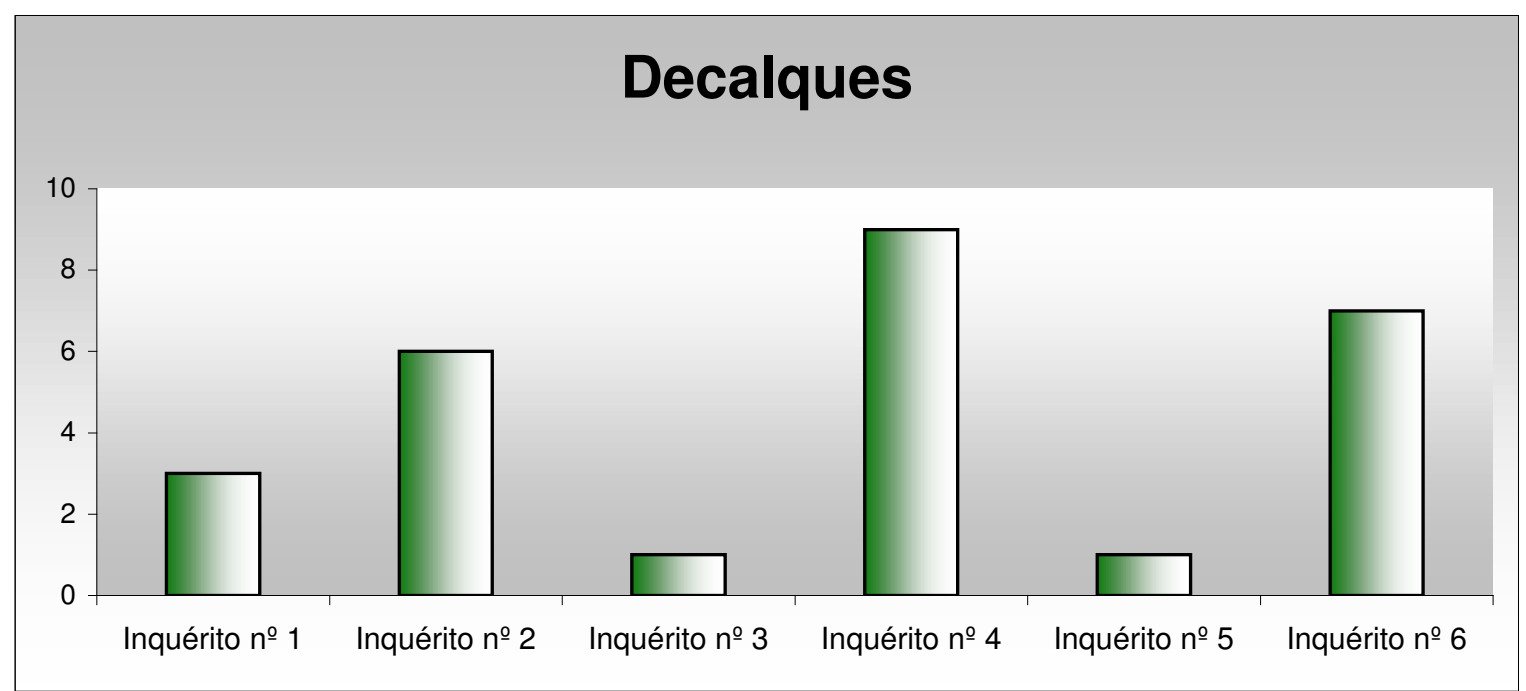

Tabela geral $n \circ 8$ - Verbos

\begin{tabular}{|l|l|l|c|}
\hline Forma apresentada & Português correto & \multicolumn{1}{|c|}{ Italiano correto } & $\begin{array}{c}\text { No de } \\
\text { ocorrências }\end{array}$ \\
\hline abbiamo andato & fomos & siamo andati & 3 \\
\hline abbiamo arrivato & chegamos & siamo arrivati & 1 \\
\hline abbiamo venuto & viemos & siamo venuti & 4 \\
\hline ach/acho & acho & penso che/credo che & 2 \\
\hline
\end{tabular}




\begin{tabular}{|c|c|c|c|}
\hline Forma apresentada & Português correto & Italiano correto & 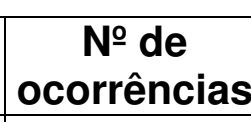 \\
\hline attacarmi & contactar & contattare & 1 \\
\hline crea/ & criavam & allevavano & 1 \\
\hline dá & dá & è sufficiente & 2 \\
\hline deix/ver & deixe-me ver & lasciami vedere & 1 \\
\hline è dovuto a lavorare & tive de trabalhar & $\begin{array}{l}\text { sono dovuto andare a } \\
\text { lavorare }\end{array}$ & 1 \\
\hline è fatto & fez & ha fatto & 1 \\
\hline existia & existia & c'era & 1 \\
\hline falava & falava & parlava & 1 \\
\hline falt/ & falta & manca & 1 \\
\hline fanno & faz & sono & 1 \\
\hline foi & foi & è stato/fu & 1 \\
\hline fondato & instalado/implantado & portato & 1 \\
\hline ha/cha/chiama/chiamò & chamou & ha chiamato & 1 \\
\hline ha marcato & marcou & ha colpito & 1 \\
\hline ha piaciuto & agradou & è piaciuto & 1 \\
\hline ha tirato & tirou/retirou & ha tolto/ha eliminato & 1 \\
\hline han tirato & tiraram & hanno stirpato/tolto & 1 \\
\hline hanno arrancate & arrancaram & hanno strappato/tolto & 1 \\
\hline ho andato & fui & sono andato & 1 \\
\hline $\begin{array}{l}\text { ho mandato a prende- } \\
\text { re a venure /venire }\end{array}$ & mandei vir & $\begin{array}{l}\text { ho mandato prendere/ } \\
\text { ho chiesto di venire }\end{array}$ & 1 \\
\hline ho nato & nasci & sono nato & 1 \\
\hline ho venuto & vim & sono venuto & 1 \\
\hline imagína & imagina & immagina & 1 \\
\hline intende & entendes & capisci & 1 \\
\hline jogado & jogados & buttati & 1 \\
\hline lavorava & tratava/cuidava & allevava/curava & 1 \\
\hline limpava & limpava & puliva & 1 \\
\hline $\operatorname{mex} /$ & cuidava/mexia & coltivava & 2 \\
\hline mi è sposato & casei & mi sono sposato & 1 \\
\hline montare & montar/abrir & metter su/allestire & 1 \\
\hline non dava & $\begin{array}{l}\text { não dava/não era } \\
\text { suficiente }\end{array}$ & $\begin{array}{l}\text { non bastava/non era } \\
\text { sufficiente }\end{array}$ & 1 \\
\hline num dá & não dá/não é possível & non si púò & 1 \\
\hline opprimivano & oprimiam & opprimevano & 1 \\
\hline passano & transmite & trasmette & 1 \\
\hline pretendo & pretendo & intendo & 1 \\
\hline $\begin{array}{l}\text { promuovere di/a di } \\
\text { anno }\end{array}$ & $\begin{array}{l}\text { passar de ano/ser } \\
\text { aprovado }\end{array}$ & passare di anno & 1 \\
\hline
\end{tabular}




\begin{tabular}{|l|l|l|c|}
\hline Forma apresentada & Português correto & \multicolumn{1}{|c|}{ Italiano correto } & $\begin{array}{c}\text { No de } \\
\text { ocorrências }\end{array}$ \\
\hline provar & experimentar/provar & assaggiare & 1 \\
\hline ricevere & retirar & ricavare & 1 \\
\hline sediata & ancorada & stanziata/ancorata & 1 \\
\hline si abbiamo conosciuti & nos conhecemos & ci siamo conosciuti & 2 \\
\hline si chama & se chama & si chiama & 3 \\
\hline si chamava & se chamava & si chiamava & 1 \\
\hline si è morta & morreu & è morta & 1 \\
\hline si è tornato & tornou-se & è ridiventato & 1 \\
\hline si incomodano & se preocupam & si preoccupano & 1 \\
\hline sono decessi & morreram & sono deceduti & 1 \\
\hline sono renovato & renovo & ho rinnovato & 1 \\
\hline sono stato giubilato & aposentei & sono andato in & 1 \\
& pensione & 1 \\
\hline tem & tem & c'è & 1 \\
\hline tirano & arrancam & strappano & 2 \\
\hline tirar & tirar/retirar & far scendere/togliere & 1 \\
\hline tirare & retirar/cancelar & togliere & 1 \\
\hline tiriamoci & retiremos/tiremos & togliamoci & 1 \\
\hline toca/ & tocam & suonano & 1 \\
\hline uscire & sair/partir & partire & 1 \\
\hline vinha & vinha & veniva & 1 \\
\hline vo/ & vou & vado & \\
\hline
\end{tabular}

\section{Gráfico Geral dos Verbos}

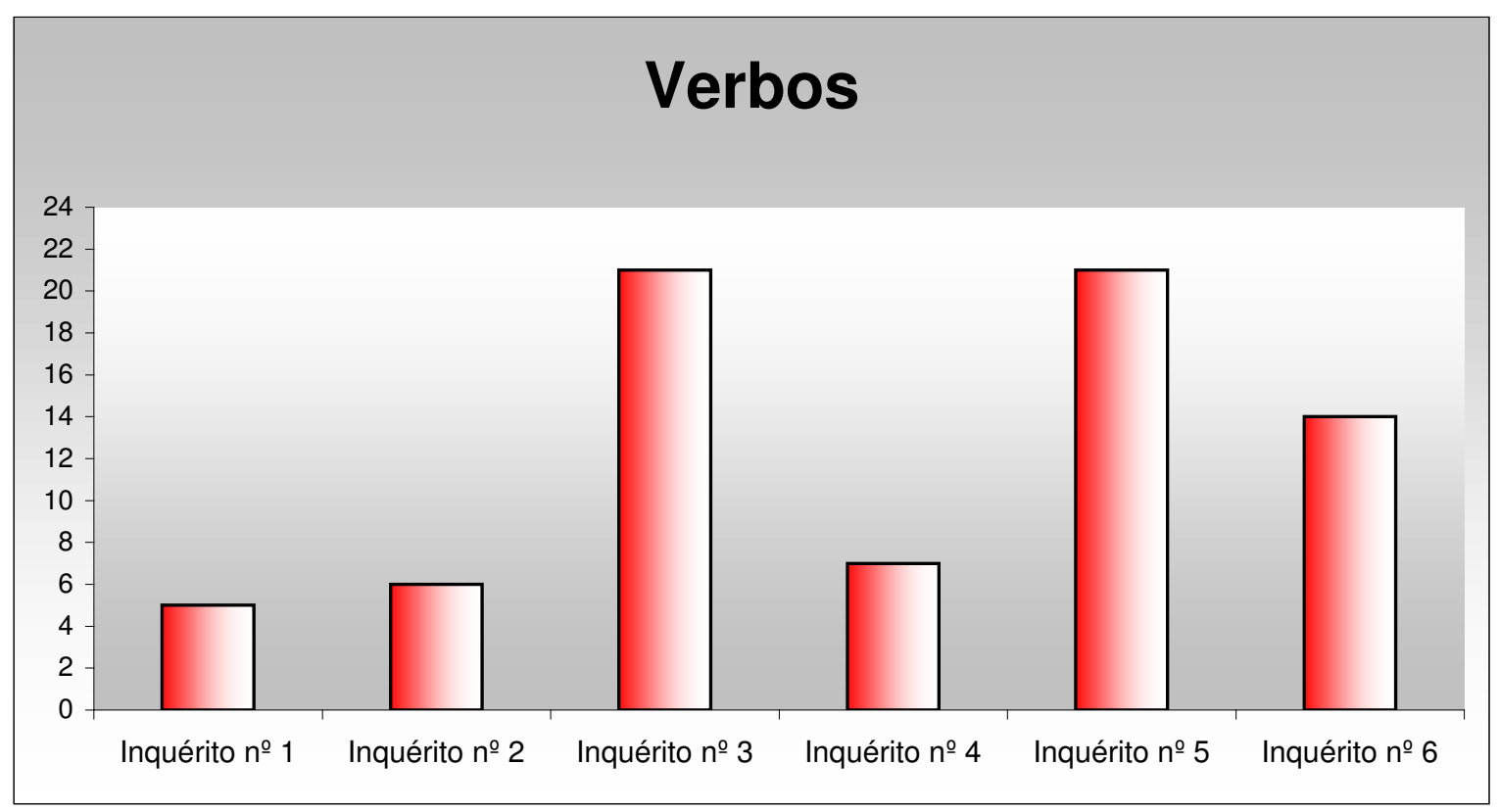


Gráfico Geral das Principais Interferências Apresentadas

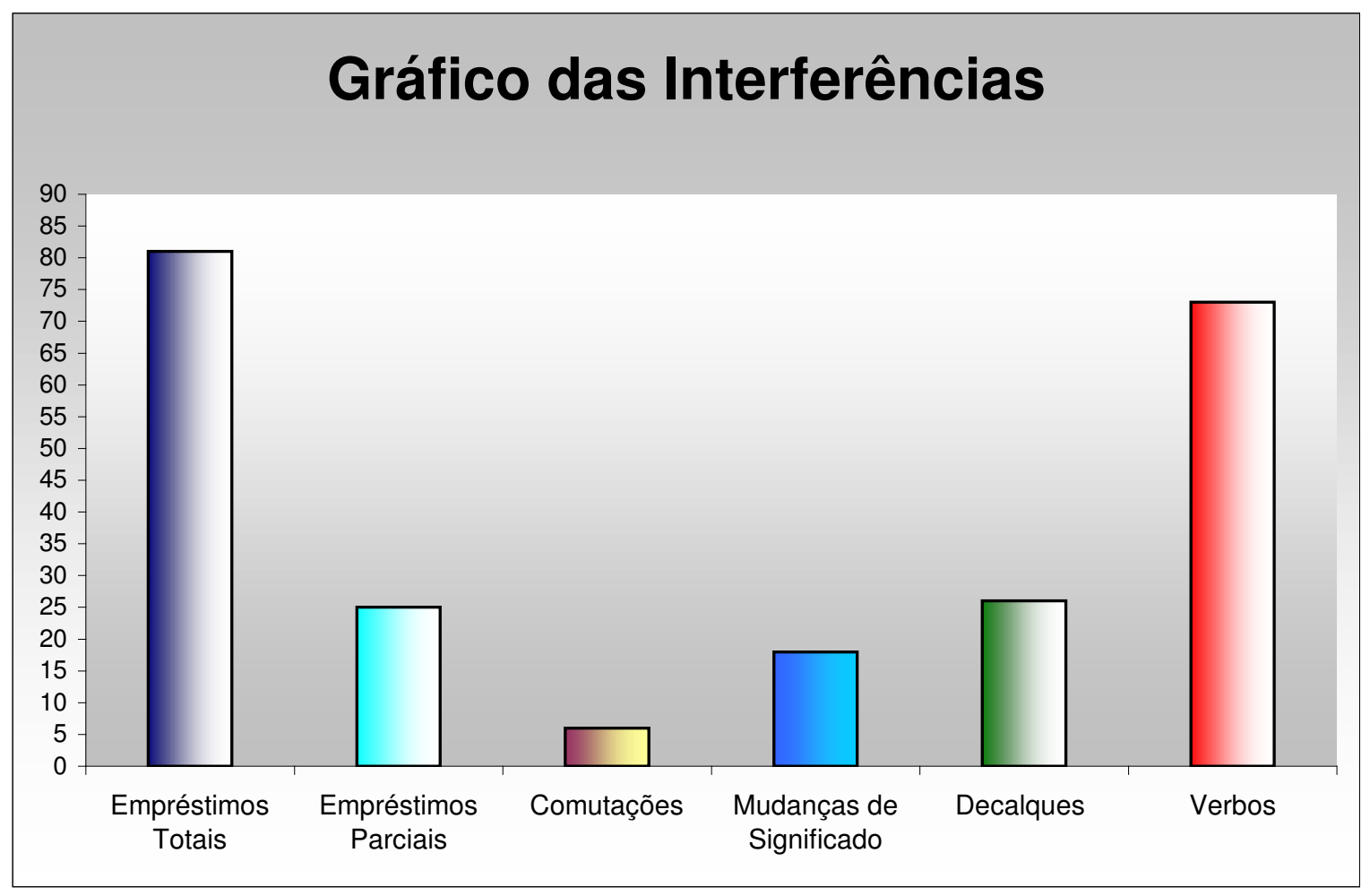




\section{CONSIDERAÇÕES FINAIS}

Composta por imigrados italianos e um grande número de descendentes e de simpatizantes, a comunidade italiana de São Bernardo do Campo tem procurado manter as suas tradições, unindo-se nos diversos eventos organizados pelo poder público Municipal, pelas festas italianas promovidas pelas Associações, pela própria comunidade e pela língua, embora empobrecida e falada aproximadamente. A missa em italiano, que vem sendo realizada há dois anos, constitui o que consideramos o fator principal para a re-união, recuperação e manutenção da língua italiana e para os encontros entre os indivíduos desta comunidade. Muito freqüentada pelos participantes do curso Italiano Comunitario nella Chiesa, os alunos, na grande maioria descendentes de imigrados italianos, vêem a missa como um lugar não só de oração, mas também como uma oportunidade de manter um contato com a língua italiana, que é usada durante toda a celebração. Consciente da importância do evento, o Pe. Giuseppe Bortolato faz a preghiera usando termos de fácil compreensão e em um ritmo mais lento do que aquele que seria usado normalmente em uma comunidade bilíngüe. As leituras são todas feitas pelos alunos dos cursos, o que gera um interesse muito grande quanto à pronúncia e a compreensão das mesmas. O objetivo do evento, que inicialmente era o de reunir a comunidade, além de estar sendo alcançado, mostrou-nos como a Igreja é importante neste processo de resgatar as origens e a cultura italiana, pois os próprios imigrados, têm dado a sua contribuição ajudando e motivando os descendentes e simpatizantes em todos os eventos que têm sido organizados.

Deste modo, a língua italiana que estava sendo pouco utilizada, voltou a fazer parte do cotidiano. Observamos que em encontros entre membros da comunidade e estudantes, têm-se usado a língua italiana, ainda que com muitas dificuldades por ambos os grupos, pois os imigrados tiveram a sua língua de origem empobrecida e os demais não têm, ainda, um vocabulário suficiente para discorrer sobre assuntos diversos. 
Pelo que pudemos observar, através dos depoimentos recolhidos e pela análise que nos propusemos a fazer, o empobrecimento lingüístico e as interferências são relevantes e se devem a diversos fatores, mas principalmente, à necessidade que os imigrados tiveram de se comunicar e se adaptar ao novo ambiente, à segunda Pátria que os acolheu. Como conseqüência, "a adoção do termo estrangeiro pode ser um ato de cultura e gosto, mas é sempre gerada por uma necessidade prática (competência lexical insuficiente)" (Carvalho, 1989: 69).

Com um baixo grau de escolaridade italiana, assim que chegaram, os novos emigrados encontraram muitos imigrados da primeira leva e seus descendentes. Esse grupo de pessoas, não consciente das mudanças lingüísticas ocorridas na Itália, acreditava que a língua usada por eles, em grande parte dialetal, ainda fosse a mesma trazida pelos imigrados do Segundo Pós-Guerra. Por sua vez, esse novo grupo já havia freqüentado, obrigatoriamente, a escola na Itália, mas no cotidiano familiar ainda usava o dialeto do seu paese.

A proximidade da língua portuguesa com a língua italiana, o uso de diversos dialetos, o convívio com os primeiros imigrados e seus descendentes, a baixa escolaridade e a ausência de contatos e viagens para a Itália foram fatores que contribuíram para o empobrecimento da língua italiana, sendo que as características mais marcantes do discurso dos entrevistados, além de diversos tipos de interferências e das impropriedades lexicais, foram:

- Discurso desconexo causado pela falta de algumas conexões gramaticais e a ordem indevida das palavras usadas;

- Confusão quanto ao uso do sujeito;

- O uso incorreto dos auxiliares dos verbos;

- O uso indevido de preposições ou o uso das preposições baseado no modelo português;

- O uso indevido ou a ausência dos artigos qualificativos.

Ainda, assim, pela amostragem apresentada, podemos classificar a comunidade italiana de São Bernardo do Campo como uma comunidade bilíngüe 
e, dentro do esquema de variedades do italiano contemporâneo de Berruto, inserila, naturalmente, com muita cautela, entre os grupos de falantes de um italiano regional popular, simplificado e privado de expressões idiomáticas características.

Nas seis entrevistas transcritas, cinco dos entrevistados tiveram a sua alfabetização feita na Itália e chegaram ao Brasil sem nenhum conhecimento da língua local. O sexto chegou na primeira infância, antes da idade escolar.

Visto o pouco grau de cultura escolar, o dialeto usado por cada grupo regional, o encontro com os imigrados da primeira leva em sua maioria não alfabetizados ou pouco alfabetizados, fez com que o português do Brasil, pouco a pouco se misturasse à $L 1$ até substituí-la, pelo menos em alguns casos.

Em um artigo publicado na Revista de Italianística (2004: 103), Caprara e Mordente nos explicam como acontece a erosão de uma língua:

La lingua, che è l'elemento fondamentale dellidentità di un popolo, se non è coltivata quotidianamente in famiglia e nel convivio sociale o lavorativo, un po' alla volta, nel contatto prolungato col portoghese locale, si semplifica e si riduce fino a limitarsi, nei parlanti isolati e meno istruiti, a un discorso frammentato e mescolato col portoghese, a una specie di interlingua, o, molte volte, finisce col restringersi a frasi e parole stereotipate, ripetute quasi a caso.

Os entrevistados fazem parte de um grupo que não chegou a esse limite. Ainda conseguem se expressar em um italiano reconhecível como tal.

Um fator importante para a redução do uso da língua materna pelos imigrados foi a necessidade de não interferir na alfabetização dos filhos que freqüentaram as escolas brasileiras e que, além de não conhecerem a língua italiana, ainda contribuíram com o ensinamento da língua portuguesa a seus pais. Dessa segunda geração, poucos são os que se interessaram em estudar a língua italiana. No entanto, a terceira geração tem buscado resgatar suas raízes, procurando obter a cidadania italiana junto ao Consulado Italiano e na própria Itália, freqüentando cursos de língua italiana e viajando para a Itália, graças às facilidades encontradas atualmente.

Embora o presente trabalho não trate dessa terceira geração, um outro estudo, futuramente, poderá ser feito com esse grupo. 


\section{BIBLIOGRAFIA}

ALVES, I.M. (2001). Neologismo - criação lexical. São Paulo: Ática.

AUBERT, F.H. (1996). Introdução à metodologia da pesquisa terminológica bilíngüe. São Paulo: Humanitas - FFLCH - USP.

BACCIN, P.G. (1997). Italianismos dicionarizados. Revista de Italianística. São Paulo: FFLCH-Universidade de São Paulo, 2000. n.5. pp. 281-286.

BARBOSA, M.A. (1996). Língua e Discurso. Contribuição aos estudos semânticosintáxicos. São Paulo: Plêiade.

BARBOSA, N.A.M. (1975). $1^{\circ}$ Centenário da imigração italiana no Brasil. São Bernardo do Campo: Bandeirante S.A. Indústria Gráfica.

BECCARIA, G.L. (1988). Italiano antico e nuovo. Milano: Garzanti.

BERRUTTO. G. (1994). Sociolinguistica dellitaliano contemporaneo. Roma: La Nuova Italia Scientifica.

BETTONI, C. (1993). Italiano fuori d'Italia. In: Introduzione all'italiano contemporaneo. La variazione e gli usi. Bari: Laterza. pp. 411-460.

(2001). Imparare un'altra lingua. Roma-Bari: Laterza.

CAPRARA, L. de S. (1998). L'italiano a San Paolo: interferenze lessicali. CAPRARA, L. de S. \& ANTUNES, L.Z. (org.) O italiano falado e escrito. São Paulo: Humanitas. pp. 269-277. 
CAPRARA, L. de S. (2003). L'italiano degli italiani di San Paolo alla fine del XX secolo. DE FINA A. \& BIZZONI, F. Italiano e Italiani fuori d'Italia. Perugia: Guerra. pp. 199-216.

CARVALHO, N. (1989). Empréstimos lingüísticos. São Paulo: Ática.

CENNI, F. (1975). Italianos no Brasil. São Paulo: Martins-EDUSP.

DE FINA, A. e BIZZONI, F. (2003). Italiano e italiani fuori d'Italia. Perugia: Guerra.

DE MAURO, T. (1991). Storia linguistica dell'Italia unita. Bari: Laterza. (1986). Guida all'uso delle parole. Editori Riuniti - VII Ed.

FARACO, C.A. (org.) (2001). Estrangeirismos guerras em torno da língua. São Paulo: Parábola.

GOMES, F.S. (2002). Origem das famílias de São Bernardo do Campo. Famílias tradicionais e ilustres. V.1. São Paulo: Edicon.

JOHNSON, M.D. (1977). Livro do tombo do Mosteiro de São Bento da cidade de São Paulo. São Paulo: Comgraf. pp. 108-111.

KRASHEN, S.D. (1998). Second language acquisition and second language learning. Prentice-Hall International.

LEDDA, F. e PALOTTI, G. (2004). Lo sviluppo dell'italiano come seconda lingua: l'interlingua. In: L. MADDII (a cura di), Insegnamento e apprendimento dell'italiano L2 in età adulta. Atene: Edilingua. 
MAGGIO, G. (1997). Pedrinhas Paulista: comunidade italiana que ainda permanece ligada à língua materna. Revista de Italianística, São Paulo: FFLCH-Universidade de São Paulo, 2000. n.5. pp. 275-280.

MARCUSCHI, L.A. (2006). Análise da conversação. São Paulo: Ática.

MEDICI, A. (2002). Os 100 anos da Savóia ítalo-brasileira - (1990-2000). Santo André: Bartira Gráfica e Editora S.A.

PALLOTTI, G. (1998). La seconda lingua. Milano, Bompiani.

PRETI, D. (org.). (1995). Análise de textos orais. São Paulo, Humanitas FFLCH/USP. . (2006). Estudos de língua falada - variações e confrontos. São Paulo: Humanitas.

RASO, T. (2003). L'italiano parlato a San Paolo da madrelingua colti. Primi sondaggi e ipotesi di lavoro. Revista de Italianística. São Paulo: FFLCHUniversidade de São Paulo, n. 8. pp.9-49.

SANTOS, W. (1992). Antecedentes históricos do ABC paulista: 1550-1892. Prefeitura do Município de São Bernardo do Campo. Secretaria de Educação, Cultura e Esportes. Departamento de Cultura.

TAUNAY, A.de E. (1968). João Ramalho e Santo André da Borda do Campo. São Paulo: Empresa gráfica da revista dos tribunais.

TRENTO, A. (1989). Do outro lado do Atlântico. São Paulo: Nobel. 
(1989). L'emigrante italiano in Brasile nel $2^{\circ}$ dopoguerra (1946-1960).

In: Studi Emigrazioni, Torino: Fondazione Agnelli.

TRIFONE, P. ( a cura di).(2007). Lingua e identità. Una storia sociale dell'italiano. Roma: Carocci.

VEDOVELLI, M. (2002). Guida all'italiano per stranieri. Roma: Carocci.

VILELA, M. (1979). Estruturas léxicas do português. Coimbra: Almedina.

(1994). Estudos de lexicologia do português. Coimbra: Almedina.

WEINREICH, U. (1974). Lingue in contatto. Torino: Boringhieri.

WEINREICH, U., LABOV, W. e HERZOG, M.I. (2006). Fundamentos empíricos para uma teoria da mudança lingüística (trad. Marcos Bagno). São Paulo: Parábola.

\section{Gramáticas e Dicionários:}

HOUAISS, A. (2001). Dicionário Houaiss de língua portuguesa. Rio de Janeiro: Objetiva.

SENSINI, M. (1974). La grammatica della lingua italiana. Milano: Mondadori.

ZINGARELLI, N. (1996). Vocabolario della lingua italiana. Bologna: Zanichelli.

\section{Teses e Dissertações:}


BILIA, M.B. (1998). Análise lexical das interferências da língua portuguesa na língua italiana falada por italianos de nível universitário residentes na cidade de São Paulo. Dissertação de Mestrado. FFLCH-USP.

CASTELLANO TSAI, M. (2006). Palavras da memória: uma análise das interferências da língua portuguesa na língua italiana falada por italianos na cidade de São Paulo. Dissertação de Mestrado - FFLCH-USP.

FERNANDES, L.L. (2006). A fala dos italianos em Pedrinhas Paulista. Algumas considerações sobre alimentação. Dissertação de Mestrado. FFLCH-USP.

MAGGIO, G. (2002). Pedrinhas Paulista: memória e invenção. Tese de Doutorado. FFLCH-USP. 